MÉTODO DOS ELEMENTOS FINITOS GENERALIZADOS APLICADO A PROBLEMAS DE FRATURA ELÁSTICA EM 3D

Karla Fernanda dos Santos 


\title{
"MÉTODO DOS ELEMENTOS FINITOS GENERALIZADOS APLICADO A PROBLEMAS DE FRATURA ELÁSTICA EM 3D"
}

\author{
Karla Fernanda dos Santos
}

Dissertação apresentada ao Programa de PósGraduação em Engenharia de Estruturas da Escola de Engenharia da Universidade Federal de Minas Gerais, como parte dos requisitos necessários à obtenção do título de "Mestre em Engenharia de Estruturas".

Comissão Examinadora:

Prof. Dr. Felício Bruzzi Barros

DEES - UFMG (Orientador)

Prof. Dr. Rodrigo Guerra Peixoto

DEES - UFMG

Prof. Dr. Marcos Arndt

UFPR

Belo Horizonte, 05 de Março de 2018 
S237m Método dos elementos finitos generalizados aplicado a problemas de fratura elástica em 3D [manuscrito] / Karla Fernanda dos Santos. - 2018.

xiii, 107 f., enc.: il.

Orientador: Felício Bruzzi Barros.

Dissertação (mestrado) - Universidade Federal de Minas Gerais, Escola de Engenharia.

Apêndices: f. 96-103.

Bibliografia: f. 104-107.

1. Engenharia de estruturas - Teses. 2. Método dos elementos finitos - Teses. I. Barros, Felício Bruzzi. II. Universidade Federal de Minas Gerais. Escola de Engenharia. III. Título. 
"A ciência nunca resolve um problema sem criar pelo menos outros dez." George Bernard Shaw. 


\section{Índice}

Índice

Lista de Tabelas vii

Lista de Figuras $\quad$ x

Resumo xi

Abstract xii

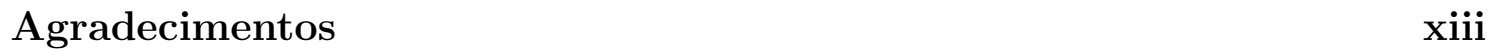

\begin{tabular}{lll}
\hline & Introdução & 1
\end{tabular}

1.1 Contextualização . . . . . . . . . . . . . . . . . . . . . . . . . . . 1

1.2 Justificativa $\ldots \ldots \ldots \ldots$. . . . . . . . . . . . . . . . . . . . . 4

1.3 Objetivos $\ldots \ldots \ldots \ldots \ldots \ldots$

1.3.1 Objetivo Geral . . . . . . . . . . . . . . . . . . . . 4

1.3.2 Objetivos Específicos . . . . . . . . . . . . . . . . . . . . . . . . . . . . . . 5

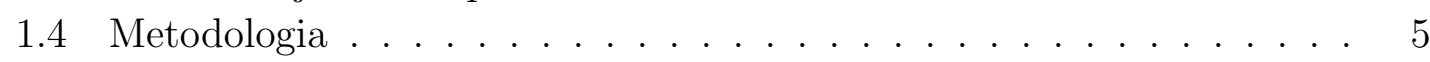

1.5 Organização do Texto . . . . . . . . . . . . . . . . . . 5

2 Método dos Elementos Finitos Generalizados 6

2.1 Conceitos Gerais . . . . . . . . . . . . . . . . . 6

2.2 Formulação do Método dos Elementos Finitos Generalizados . . . . . 7

2.3 Funções de Enriquecimento . . . . . . . . . . . . . . . . . . . . 10

2.3 .1 Funções de Enriquecimento Polinomiais . . . . . . . . . . . . . 10

2.3 .2 Funções de Enriquecimento com Derivadas Singulares . . . . . 10

2.4 Método dos Elementos Finitos Generalizados - Global-Local . . . . . 14

2.5 Formulação da Técnica Global- Local . . . . . . . . . . . . . . . . . . 17

2.5 .1 Problema Global . . . . . . . . . . . . . . . . . . . . . 17

2.5 .2 Problema Local . . . . . . . . . . . . . . . . . . . . . . . . . . 19

2.5 .3 Problema Global Enriquecido . . . . . . . . . . . . . . . . . 21

$\begin{array}{lll}3 & \text { Implementação Computacional } & \mathbf{2 3}\end{array}$

3.1 Principais Aspectos do Sistema INSANE . . . . . . . . . . . . . . . . 23 
$3.2 \quad$ Ampliação do Sistema INSANE $\ldots \ldots \ldots \ldots$

3.2 .1 Visão Geral das Classes a serem Alteradas . . . . . . . . . . . 29

3.2.2 Generalização da Construção das Funções de Forma Enrique-

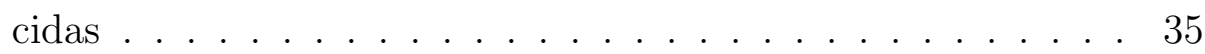

3.2.3 Generalização das Funções Representativas do Comportamento na Vizinhança da Frente de uma Trinca. . . . . . . . . . . . . 36

3.2 .4 MEFG com Técnica Global-Local - Tridimensional . . . . . . 38

4 Análise de Modelos Estruturais via MEFG e Técnica Global-Local 41

4.1 Problemas Abordados . . . . . . . . . . . . . . . . . . 41

4.2 Detalhes da Modelagem dos Problemas Abordados . . . . . . . . . . 43

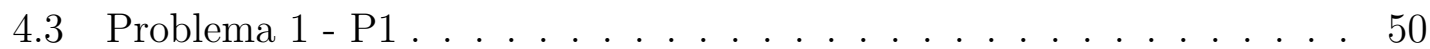

4.3 .1 Enriquecimento com Funções Singulares . . . . . . . . . . 51

4.3 .2 Enriquecimento com Técnica Global-Local - Trinca Coincidente com as Faces dos Elementos Globais . . . . . . . . . . . 56

$4.3 .3 \quad$ Enriquecimento com Técnica Global-Local - Trinca no Interior dos Elementos Globais . . . . . . . . . . . . . . . . 62

4.3 .4 Consolidação dos Resultados do P1 . . . . . . . . . . . . 73

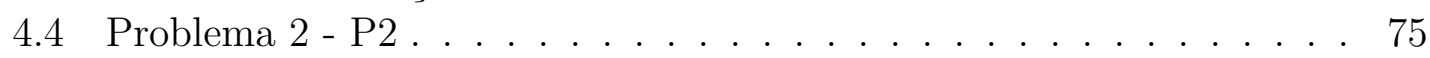

4.4.1 Enriquecimento com Técnica Global-Local - Trinca Coincidente com as Faces dos Elementos Globais . . . . . . . . . . . 77

$4.4 .2 \quad$ Enriquecimento com Técnica Global-Local - Trinca no Interior dos Elementos Globais . . . . . . . . . . . . . . . . . . . . 83

$4.4 .3 \quad$ Consolidação dos Resultados do P2 $\ldots \ldots \ldots \ldots$. . . . . 88

$\begin{array}{lll}5 \text { Conclusões } & 91\end{array}$

$5.1 \quad$ Breve Resumo do que Foi Exposto . . . . . . . . . . . . . . 91

5.2 Conclusões do Trabalho e Sugestões de Trabalhos Futuros . . . . . . 91

Apêndice A Entrada de dados no Sistema INSANE para um modelo tridimensional utilizando MEFG com técnica Global-Local $\quad 96$

A.1 Entrada de Dados do Modelo Global . . . . . . . . . . . . . . . . 96

A.2 Entrada de Dados do Modelo Local . . . . . . . . . . . . . . . . . . 98

Apêndice B Programa Responsável por converter Dados da Malha do $\begin{array}{ll}\text { Software } A N S Y S^{(\mathrm{R})} & \text { para o Sistema INSANE } \\ \end{array}$

\begin{tabular}{ll}
\hline Referências Bibliográficas & 104
\end{tabular} 


\section{Lista de Tabelas}

4.1 P1 contendo nós enriquecidos com funções singulares: Energia de deformação - Tração y- . . . . . . . . . . . . . . . . 53

4.2 P1 contendo nós enriquecidos com funções singulares: Energia de deformação - Cisalhamento x- . . . . . . . . . . . . . 53

4.3 P1 contendo nós enriquecidos com funções singulares: Energia de - deformação - Cisalhamento z- . . . . . . . . . . . . . . 55

4.4 P1 contendo nós enriquecidos com funções singulares: Energia de deformação comparando quantidade de pontos de integração - Cisalhamento $\mathrm{z}^{-}$. . . . . . . . . . . . . . . . . . . 55

4.5 P1 contendo nós enriquecidos via técnica Global-Local em modelos \begin{tabular}{|c|}
\hline de trinca coincidente com as faces dos elementos Globais: Energia de \\
\hline
\end{tabular} deformação - Tração y- . . . . . . . . . . . . . . . 57

$4.6 \quad$ P1 contendo nós enriquecidos via técnica Global-Local em modelos de

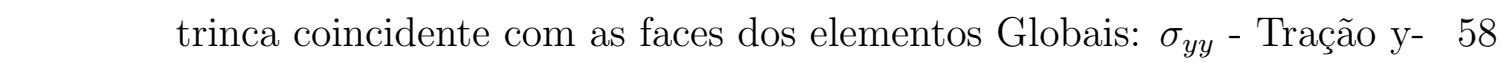

4.7 P1 contendo nós enriquecidos via técnica Global-Local em modelos de trinca coincidente com as faces dos elementos Globais: Abertura - de Trinca - Tração y- . . . . . . . . . . . . . . . . 58

4.8 P1 contendo nós enriquecidos via técnica Global-Local em modelos \begin{tabular}{|c|}
\hline de trinca coincidente com as faces dos elementos Globais: Energia de \\
\hline
\end{tabular} deformação - Cisalhamento x- . . . . . . . . . . . . . . . . 59

4.9 P1 contendo nós enriquecidos via técnica Global-Local em modelos de trinca coincidente com as faces dos elementos Globais: $\sigma_{y y}$ - Cisalhamento $\mathrm{x}-$. . . . . . . . . . . . . . . . 6 60

4.10 P1 contendo nós enriquecidos via técnica Global-Local em modelos de trinca coincidente com as faces dos elementos Globais: Abertura de Trinca - Cisalhamento $\mathrm{x}-$. . . . . . . . . . . . . . . 60 60 
4.11 P1 contendo nós enriquecidos via técnica Global-Local em modelos de trinca coincidente com as faces dos elementos Globais: Energia de deformação - Cisalhamento z- . . . . . . . . . . . . . . . . . . . . 61

4.12 P1 contendo nós enriquecidos via técnica Global-Local em modelos \begin{tabular}{|c|c|}
\hline de trinca coincidente com as faces dos elementos Globais: $\sigma_{y y}$ - Cisa- \\
\hline
\end{tabular}

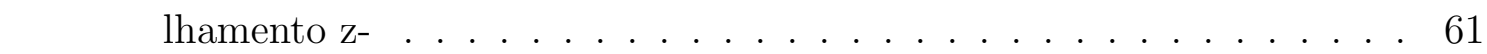

4.13 P1 contendo nós enriquecidos via técnica Global-Local em modelos de trinca coincidente com as faces dos elementos Globais: Abertura de Trinca - Cisalhamento $\mathrm{z}-$. . . . . . . . . . . . . . . . . . . . 62

4.14 P1 contendo nós enriquecidos via técnica Global-Local em modelos de trinca no interior dos elementos Globais: Energia de deformação -

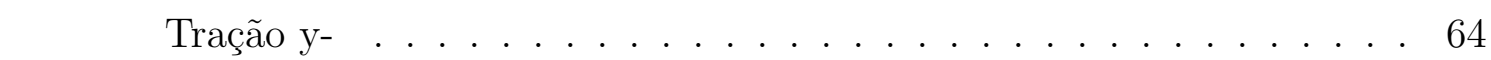

4.15 P1 contendo nós enriquecidos via técnica Global-Local em modelos

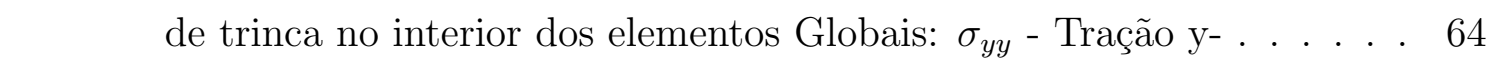

4.16 P1 contendo nós enriquecidos via técnica Global-Local em modelos de trinca no interior dos elementos Globais: Abertura de Trinca - Tração $\mathrm{y}-\ldots \ldots \ldots \ldots \ldots \ldots$

4.17 P1 contendo nós enriquecidos via técnica Global-Local em modelos de trinca no interior dos elementos Globais: Energia de deformação - Cisalhamento $\mathrm{x}-$. . . . . . . . . . . . . . . . . 65

4.18 P1 contendo nós enriquecidos via técnica Global-Local em modelos

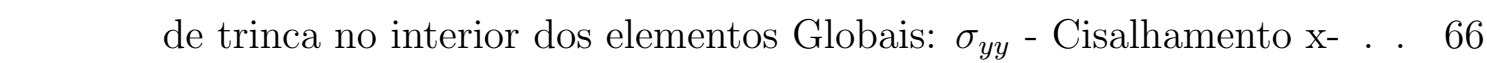

4.19 P1 contendo nós enriquecidos via técnica Global-Local em modelos de trinca no interior dos elementos Globais: Abertura de Trinca Cisalhamento $\mathrm{x}-$. . . . . . . . . . . . . . . . 66

4.20 P1 contendo nós enriquecidos via técnica Global-Local em modelos de trinca no interior dos elementos Globais: Energia de deformação -

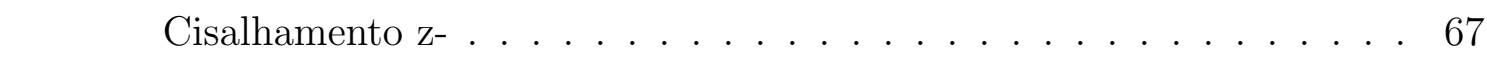

4.21 P1 contendo nós enriquecidos via técnica Global-Local em modelos

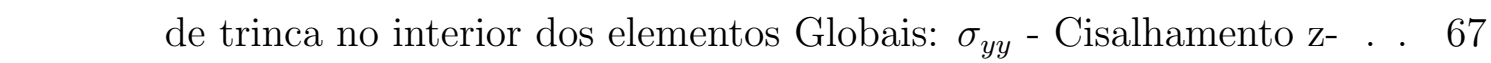

4.22 P1 contendo nós enriquecidos via técnica Global-Local em modelos de trinca no interior dos elementos Globais: Abertura de Trinca Cisalhamento z- . . . . . . . . . . . . . . . . . 67 
4.23 Teste da variação do parâmetro de penalidade para P1: Energia de deformação - Tração y- . . . . . . . . . . . . . . . . . . . . 69

4.24 Teste da variação do parâmetro de penalidade para P1: $\sigma_{y y}$ - Tração y- 69

4.25 Teste da variação do parâmetro de penalidade para P1: Abertura de Trinca - Tração y- . . . . . . . . . . . . . . . . . . 69

4.26 Teste da influência dos ciclos da técnica Global-Local para P1: Energia de deformação - Tração y- . . . . . . . . . . . . . . . . . 70

4.27 Teste da influência dos ciclos da técnica Global-Local para P1: $\sigma_{y y}{ }^{-}$

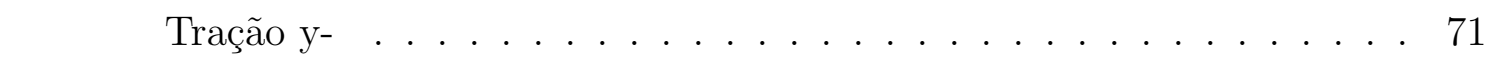

4.28 Teste da influência dos ciclos da técnica Global-Local para P1: Abertura de Trinca - Tração y- . . . . . . . . . . . . . . . . . 71

4.29 Teste do enriquecimento dos nós com funções singulares na malha local para P1: Energia de deformação - Tração y- . . . . . . . . . . 72

4.30 Teste do enriquecimento dos nós com funções singulares na malha local para P1: $\sigma_{y y}-$ Tração y- . . . . . . . . . . . . . 72

4.31 Teste do enriquecimento dos nós com funções singulares na malha local para P1: Abertura de Trinca - Tração y- . . . . . . . . . . . . 72

4.32 P2 contendo nós enriquecidos via técnica Global-Local em modelos de trinca coincidente com as faces dos elementos Globais: Energia de deformação - Tração y- . . . . . . . . . . . . . . . . 78

4.33 P2 contendo nós enriquecidos via técnica Global-Local em modelos de

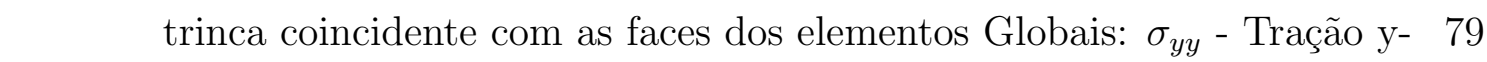

4.34 P2 contendo nós enriquecidos via técnica Global-Local em modelos de trinca coincidente com as faces dos elementos Globais: Abertura de Trinca - Tração y- . . . . . . . . . . . . . . . . . . 79

4.35 P2 contendo nós enriquecidos via técnica Global-Local em modelos de trinca coincidente com as faces dos elementos Globais: Energia de deformação - Cisalhamento $\mathrm{x}-$. . . . . . . . . . . . . . 80

4.36 P2 contendo nós enriquecidos via técnica Global-Local em modelos de trinca coincidente com as faces dos elementos Globais: $\sigma_{y y}$ - Cisa- lhamento $\mathrm{x}-$. . . . . . . . . . . . . . . . 80

4.37 P2 contendo nós enriquecidos via técnica Global-Local em modelos de trinca coincidente com as faces dos elementos Globais: Abertura de Trinca - Cisalhamento $\mathrm{x}-$. . . . . . . . . . . . . . . . . . . 81 
4.38 P2 contendo nós enriquecidos via técnica Global-Local em modelos de trinca coincidente com as faces dos elementos Globais: Energia de deformação - Cisalhamento z- . . . . . . . . . . . . . . . . . . . . . . 82

4.39 P2 contendo nós enriquecidos via técnica Global-Local em modelos \begin{tabular}{|c|c|}
\hline de trinca coincidente com as faces dos elementos Globais: $\sigma_{y y}$ - Cisa- \\
\hline
\end{tabular}

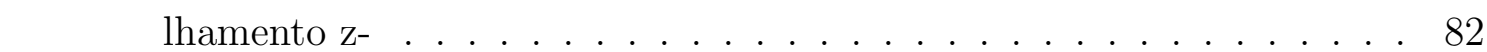

4.40 P2 contendo nós enriquecidos via técnica Global-Local em modelos de trinca coincidente com as faces dos elementos Globais: Abertura de Trinca - Cisalhamento $\mathrm{z}-$. . . . . . . . . . . . . . . . . . . . . . 82

4.41 P2 contendo nós enriquecidos via técnica Global-Local em modelos de trinca no interior dos elementos Globais: Energia de deformação -

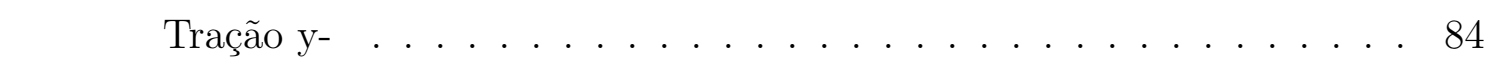

4.42 P2 contendo nós enriquecidos via técnica Global-Local em modelos de trinca no interior dos elementos Globais: $\sigma_{y y}$ - Tração y- . . . . . . 84

4.43 P2 contendo nós enriquecidos via técnica Global-Local em modelos de trinca no interior dos elementos Globais: Abertura de Trinca - Tração $\mathrm{y}-\ldots \ldots \ldots \ldots \ldots$

4.44 P2 contendo nós enriquecidos via técnica Global-Local em modelos de trinca no interior dos elementos Globais: Energia de deformação -

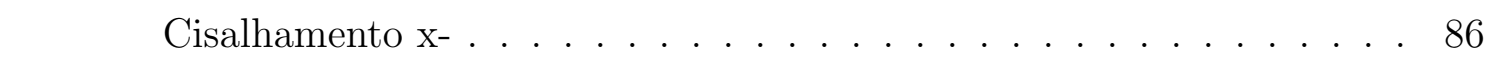

4.45 P2 contendo nós enriquecidos via técnica Global-Local em modelos

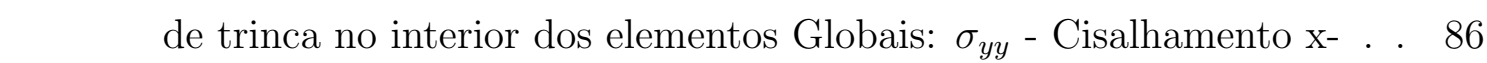

4.46 P2 contendo nós enriquecidos via técnica Global-Local em modelos de trinca no interior dos elementos Globais: Abertura de Trinca Cisalhamento $\mathrm{x}-$. . . . . . . . . . . . . . . . . 86

4.47 P2 contendo nós enriquecidos via técnica Global-Local em modelos de trinca no interior dos elementos Globais: Energia de deformação - Cisalhamento $\mathrm{z}-\ldots \ldots \ldots$. . . . . . . . . . . . . . . 87

4.48 P2 contendo nós enriquecidos via técnica Global-Local em modelos

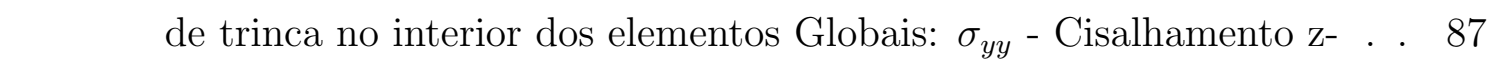

4.49 P2 contendo nós enriquecidos via técnica Global-Local em modelos de trinca no interior dos elementos Globais: Abertura de Trinca Cisalhamento $\mathrm{z}$. . . . . . . . . . . . . . . . . . . . . . 88 


\section{Lista de Figuras}

1.1 Exemplo de discretização de modelo com malha 3D (Adaptada) (Strou-

boulis et al.[2000). . . . . . . . . . . . . . . . . 2

2.1 Partição da Unidade (Barros, 2002). . . . . . . . . . . . . . . . 8

2.2 Estratégia de enriquecimento da nuvem $\omega_{j}$ via MEFG (Barros, 2002). 9

2.3 Eixos em três dimensões associados com a borda (Duarte et al., [2000). 11

2.4 Estratégia Global Local (Adaptada) (Alves, 2012). . . . . . . . . . . . 16

2.5 Domínios Global e Local de um problema genérico com os respectivos

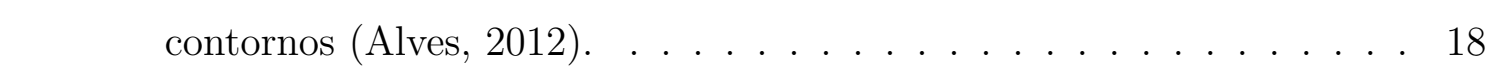

3.1 Diagrama UML do Núcleo Numérico do INSANE (Alves, [2012). . . . 24

3.2 Diagrama de Montagem de Matriz de Rigidez no INSANE (Adaptada) (Alves, 2012). . . . . . . . . . . . . . . . 27

3.3 Diagrama de Montagem de Matriz de Rigidez na Classe GFemParametric, usando a técnica Global-Local (Adaptada) (Alves, 2012). . . . 28

$3.4 \quad$ Diagrama da Classe EnrichedShape. . . . . . . . . . . . . . . . . . . 30

3.5 Diagrama da Classe EnrichmentType. . . . . . . . . . . . . . . . . . 31

$3.6 \quad$ Diagrama da Classe GFemAssembler. . . . . . . . . . . . . . . . . . 32

3.7 Diagrama da Classe GFemParametric. . . . . . . . . . . . . . . 33

$3.8 \quad$ Diagrama da Classe EquivalentNodalGeneralValue. . . . . . . . . . . . 35

3.9 Ordem das condições de contorno no arquivo de entrada de acordo com as faces do elemento hexaédrico. . . . . . . . . . . . . . . . . . . 40

4.1 Problema Abordado - P1. . . . . . . . . . . . . . . . . . 41

4.2 Problema Abordado - P2. . . . . . . . . . . . . . . . . . . . . 42

4.3 MG1 - Malha Global de 250 elementos com 6 nós que descrevem a trinca duplicados. . . . . . . . . . . . . . . . . . . . . . . . . . . 44

$4.4 \quad$ MG2 - Malha Global de 250 elementos sem nós duplicados. . . . . . . 45 
4.5 MG3 - Malha Global de 275 elementos sem nós duplicados. . . . . . . 45

4.6 MG4 - Malha Global de 250 elementos com 1 nó que descreve a trinca duplicado. . . . . . . . . . . . . . . . . . . 46

4.7 Ilustração, em azul, do subdomínio Local, imerso no domínio Global da Figura 4.4 . . . . . . . . . . . . . . . . . . . . . . . . . . . . . 46

4.8 Ilustração, em azul, do subdomínio Local, imerso no domínio Global da Figura 4.5 . . . . . . . . . . . . . . . . . . . . . . . . . . 47

$4.9 \quad$ ML1 - Elementos locais de dimensões (0.500 x $0.500 \times 0.500)$. . . . . 48

4.10 ML2 - Elementos locais de dimensões $(0.250 \times 0.250 \times 0.250)$. . . . . 48

4.11 ML3 - Elementos locais de dimensões (0.200 x $0.200 \times 0.200)$. . . . . 49

4.12 ML4 - Elementos locais de dimensões (0.125 x $0.125 \times 0.250)$. . . . . 49

4.13 ML5 - Elementos locais de dimensões (0.100 x $0.100 \times 0.250)$. . . . . 50

4.14 Malha do software $A N S Y S^{(\mathrm{R})}$ usada para construir a solução de refe-

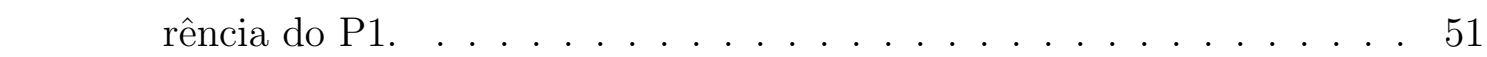

4.15 Desenho esquemático dos nós a serem enriquecidos do modelo. . . . . 52

4.16 Desenho esquemático dos nós a serem enriquecidos do modelo. . . . . 56

4.17 Desenho esquemático dos nós a serem enriquecidos do modelo. . . . . 63

4.18 Variação de $\sigma_{y y}$ ao longo da coordenada $x$ em $y=5$ e $z=0$ - Tração -

4.19 Variação de $\sigma_{y y}$ ao longo da coordenada $x$ em $y=5$ e $z=0$ - Cisalha- mento em x. . . . . . . . . . . . . . . . . . . 75

4.20 Variação de $\sigma_{y y}$ ao longo da coordenada $x$ em $y=5$ e $z=0$ - Cisalhamento em z. . . . . . . . . . . . . . . . . . . . . 76

4.21 Malha do software $A N S Y S^{(\mathrm{R})}$ usada para construir a solução de referência do P2. . . . . . . . . . . . . . . . . . . . . 76

4.22 Desenho esquemático dos nós a serem enriquecidos do modelo. . . . . 77

4.23 Desenho esquemático dos nós a serem enriquecidos do modelo. . . . . 83

4.24 Variação de $\sigma_{y y}$ ao longo da coordenada $x$ em $y=5$ e $z=5$ - Tração em y. . . . . . . . . . . . . . . . . . . . 89

4.25 Variação de $\sigma_{y y}$ ao longo da coordenada $x$ em $y=5$ e $z=5$ - Cisalhamento em x. . . . . . . . . . . . . . . . . . . . . . . 89

4.26 Variação de $\sigma_{y y}$ ao longo da coordenada $x$ em $y=5$ e $z=5$ - Cisalha-

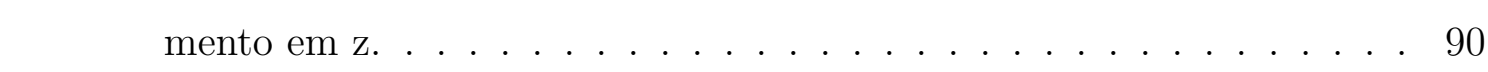


B.1 Fluxo de funcionamento do programa de conversão de malhas: $A N S Y S^{\mathrm{R}}$ para INSANE. . . . . . . . . . . . . . . . . . . . . . . . 101

B.2 Diagrama de Classes do Sistema de conversão de Malhas: ANSYS(R) para INSANE. . . . . . . . . . . . . . . . . . . . . . . . . . . 102 


\section{Resumo}

O Método dos Elementos Finitos Generalizados (MEFG) foi consolidado no campo científico como uma ferramenta muito útil na resolução de modelos estruturais complexos usando uma abordagem aproximada efetiva para representar a propagação de trincas e outros microdefeitos. Trata-se de uma formulação não-convencional do Método dos Elementos Finitos (MEF), na medida em que há a expansão do campo de soluções a partir da utilização de funções de enriquecimento associadas aos nós. As funções de enriquecimento podem ser funções singulares derivadas de deduções analíticas, funções polinomiais ou mesmo funções resultantes de outros processos de solução, como a estratégia Global-Local. O INSANE (INteractive Structural ANalysis Environment) é uma plataforma computacional em desenvolvimento do Departamento de Engenharia de Estruturas (DEES) da Universidade Federal de Minas Gerais (UFMG) e tem como objetivo analisar estruturas de interesse da engenharia. Em sua atual versão, é capaz de resolver problemas através de diversos modelos de análise de qualquer dimensão utilizando o MEFG. Este trabalho propõe a expansão do sistema para contemplar a possibilidade de utilizar diferentes funções de enriquecimento em modelos tridimensionais, como, por exemplo, funções que contêm singularidades e aquelas obtidas com a abordagem da técnica Global-Local. Os exemplos numéricos da Mecânica de Fratura Elástica Linear são apresentados para validar a implementação proposta.

Palavras-Chave: Método dos Elementos Finitos (MEF), Enriquecimento com partição da unidade, Método dos Elementos Finitos Generalizados (MEFG), Estratégia Global-Local, INSANE. 


\begin{abstract}
The Generalized Finite Element Method (GFEM) was consolidated in the scientific field as a very useful tool in the resolution of complex structural models using an effective approximate approach to represent the propagation of cracks and other micro-defects. This is a non-conventional formulation of the Finite Element Method (FEM), in that there is an expansion of the solution space from the use of enrichment functions associated with the nodes. The enrichment functions can be singular functions derived from analytic deductions, polynomial functions, or even functions resulting from other solution processes, such as the Global-Local strategy. The INSANE (INteractive Structural ANalysis Environment) is a computational platform of the Department of Structural Engineering (DEES) of the Federal University of Minas Gerais (UFMG) and aims to analyze structures of engineering interest. In its current version, it is able to solve problems through several analysis models of any dimension using GFEM. This work proposes the expansion of the system to consider the possibility of using different enrichment functions in three-dimensional models, such as functions that contain singularities and those obtained under the GlobalLocal technique approach. Numerical examples from the Linear Elastic Fracture Mechanics are presented to validate the proposed implementation.
\end{abstract}

Keywords: Finite Element Method (FEM), Enrichment with Partition of the Unit, Generalized Finite Element Method (GFEM), Global-Local Strategy, INSANE. 


\section{Agradecimentos}

Primeiramente agradeço a Deus pelos dons da sabedoria e da persistência, indispensáveis para a conclusão de mais uma etapa da minha vida acadêmica.

Aos meus pais e ao meu marido pela paciência e auxílio durante toda a jornada.

Ao Professor Barros, F. B., pelo compromisso, sabedoria e dedicação manifestados durante a orientação deste trabalho e, principalmente pelo apoio despendido durante os momentos de dificuldade e que foram fundamentais para a conclusão desse projeto.

Aos professores do PROPEEs pelos ensinamentos acadêmicos compartilhados em sala de aula e também fora dela.

Aos profissionais do DEES e PROPEEs, pela solicitude e dedicação em suas atividades.

Aos amigos de pós-graduação, pelos companheirismo, união e troca de experiências, durante toda a trajetória que culmina na conclusão desse Mestrado.

A FAPEMIG pelo apoio financeiro durante a vigência da bolsa de Mestrado. 


\section{Capítulo 1}

\section{Introdução}

\subsection{Contextualização}

De acordo com Fish e Belytschko (2007), muitos fenômenos da engenharia como, por exemplo, da engenharia de estruturas em geral, podem ser descritos em termos de equações diferenciais parciais. Para modelos mais simples, soluções analíticas podem ser facilmente encontradas. A maior parte, porém, dos problemas de interesse são compostos por geometrias altamente complexas o que inviabiliza a busca pela solução analítica via soluções das equações diferenciais do modelo.

O método dos Elementos Finitos (MEF) é uma estratégia para solução aproximada, geralmente numérica, muito utilizada nos casos complexos descritos anteriormente, pois o modelo é dividido em elementos e neles as equações diferenciais parciais são resolvidas de forma aproximada descrevendo a solução total do sistema. Do ponto de vista da engenharia, essa ferramenta pode ser utilizada para resolver problemas de análise de tensão-deformação, transferência de calor, escoamento de fluido, propagação de trincas e várias outras simulações computacionais (Fish e Belytschko, 2007).

A Figura 1.1 mostra um exemplo de um modelo composto por uma malha em três dimensões. Nota-se que o componente apresenta reentrâncias, buracos e descontinuidades, o que para a resolução via MEF com alto grau de precisão é necessária uma malha muito refinada. Isto significa aumentar o número de elementos, o número de nós e, por consequência, o número de graus de liberdade do modelo, elevando 
muito o custo computacional da análise.

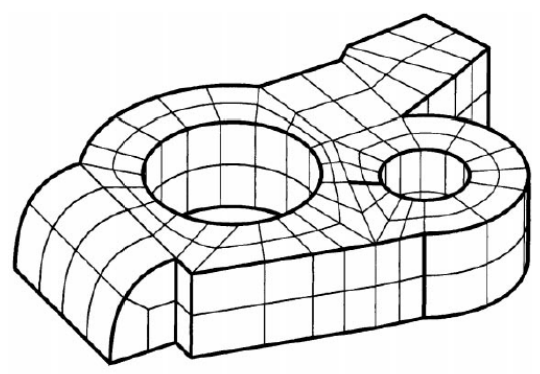

Figura 1.1: Exemplo de discretização de modelo com malha 3D (Adaptada) (Strouboulis et al., 2000).

Uma alternativa ao MEF, que pode ser considerada uma formulação não-convencional do mesmo, é o Método dos Elementos Finitos Generalizados (MEFG), (Strouboulis et al., 2000), que trata a presença de singularidades no campo de tensões, não pelo refinamento da malha, mas sim pelo enriquecimento da função de forma associadas aos nós que estão próximos a essas singularidades com funções previamente conhecidas. Cria-se, então, um novo espaço de solução enriquecido a partir de uma base de funções ou um conjunto de soluções particulares conhecidas a priori, reduzindo os custos computacionais envolvidos no processo.

O MEFG pode ter sua utilização associada à da técnica Global-Local, conforme proposto por Duarte e Kim (2008). Esta técnica, dentro da abordagem do MEFG, consiste na formulação de uma função de enriquecimento obtida a partir de funções de soluções locais e essas são utilizadas como enriquecimento nas funções de forma associada aos nós. Desdobramentos da técnica incorporada ao MEFG foram estudados em O'Hara et al. (2016) e Li e Duarte (2018), demonstrando sua aplicabilidade e eficiência em diversos cenários da engenharia.

De acordo com Fonseca (2008), o Sistema INSANE (INteractive Structural ANalysis Environment), desenvolvido no Departamento de Engenharia de Estruturas (DEES) da Universidade Federal de Minas Gerais (UFMG), é um software que tem o objetivo de ser capaz de resolver diversos modelos via aproximações numéricas. É um 
programa concebido para ser dinâmico, possibilitando, portanto, várias expansões e está aberto para que com pequenas modificações novos métodos sejam agregados ao seu arcabouço numérico. Na presente versão do sistema INSANE, o Método dos Elementos Finitos Generalizados foi implementado para diversos modelos de análise e quaisquer dimensões segundo Alves et al. (2013). A expansão do sistema INSANE para a realização de análises considerando-se a estratégia global-local, conforme Kim et al. (2010), foi contemplada também por Alves et al. (2013). Esta implementação, contudo, encontra-se limitada a problemas bidimensionais, assim como a utilização do enriquecimento com soluções definidas para a vizinhança da ponta de trinca para problemas da Mecânica da Fratura Linear Elástica.

Outras ampliações no sistema INSANE foram realizadas no que diz respeito à utilização do MEFG aliado a técnica Global-Local aplicada a problemas bidimensionais. Em Malekan et al. (2016) o sistema foi ampliado para contemplar a análise via modelos de placas considerando a abordagem de Reissner-Midlin e em Malekan et al. (2018) houve a expansão para contemplar a análise de propagação de trincas em meios compostos por materiais elásticos lineares e também por materiais não-lineares.

Propõe-se, no presente trabalho, apresentar uma nova expansão do sistema INSANE, generalizando-o, de tal forma, que problemas tridimensionais da Mecânica da Fratura Linear Elástica possam ser analisados adequadamente pelo Método dos Elementos Finitos Generalizados.

Inicialmente, a referida expansão foi realizada através da adaptação do sistema para a resolução de problemas em três dimensões, enriquecido com as expressões que representam a solução na vizinhança de uma trinca em meio linear elástico, como sugeridas por Duarte et al. (2000). Tais funções são capazes de descrever os três modos de abertura de trinca. Em um segundo passo, foi feita a generalização no que se refere à dimensão do problema analisado, da estratégia Global-Local para a obtenção de funções resultantes da solução numérica de um ou mais problemas 
locais, e enriquecedoras da aproximação do problema. Pela própria forma como o sistema foi concebido, foi possível aproveitar a estrutura existente e com modificações pontuais e mapeáveis alcançar o resultado desejado.

\section{$1.2 \quad$ Justificativa}

Na vivência da engenharia, tem-se uma constante busca das melhores formas de representação da realidade por meio de modelos tratáveis e solucionáveis da maneira mais simples e com resultados fiéis ao que se espera ocorrer na prática. Estruturas complexas como barragens, peças com reentrâncias e furos, quando apresentam trincas precisam de tratamento e modelagem especial para caracterizar melhor o fenômeno de concentrações de tensões e fissuração ao qual estão submetidas.

Diante dessa perspectiva, o presente trabalho torna-se relevante, porque se propõe a expandir a plataforma INSANE e, assim, possibilitá-lo a resolver problemas em três dimensões submetidos a concentrações de tensões e trincas. Concentração de tensões podem ocorrer em barragens com trincas em superfícies e suportes mecânicos complexos, por exemplo.

Desta maneira, ampliando-se as possibilidades de modelagem computacional contribui-se para a evolução da engenharia na medida que consegue-se simular melhor a realidade de diversas estruturas.

\subsection{Objetivos}

\subsubsection{Objetivo Geral}

O objetivo geral dessa dissertação de Mestrado em Engenharia de Estruturas se sustenta na viabilização de modelagens numéricas em três dimensões para estruturas sujeitas a concentração de tensões, em particular, produzidas pela presença de trinca em um meio elástico-linear. Para tanto, pretende-se utilizar o Método dos Elementos Finitos Generalizados e a técnica Global-Local. 


\subsubsection{Objetivos Específicos}

O objetivo específico consiste na expansão do sistema INSANE para que o enriquecimento com soluções previamente conhecidas ou com aquelas obtidas pela estratégia Global-Local possa ser utilizado para a análise de problemas tridimensionais.

\subsection{Metodologia}

Esse trabalho foi dividido em três grandes partes, discutidas nos capítulos seguintes, conforme organização proposta para o texto: Revisão bibliográfica para a construção da base teórica do problema que será abordado; Estudo e expansão do sistema INSANE; Validação da implementação pela aferição dos resultados de análises numéricas.

\subsection{Organização do Texto}

Neste trabalho, além da introdução realizada no Capítulo 1, são apresentados no Capítulo 2 conceitos e informações relevantes para o entendimento das análises feitas e da proposta deste trabalho, como os fundamentos e formulação do MEFG e da técnica Global-Local. No Capítulo 3, são apresentadas as principais informações do sistema INSANE e as mais importantes modificações realizadas para a correta análise de problemas em três dimensões. No Capítulo 44 exemplos de simulações numéricas são apresentados, comparando-se os resultados obtidos de soluções de referência com aqueles encontrados via MEFG e enriquecidos com funções especiais para a Mecânica da Fratura Linear Elástica e pela técnica Global-Local. Por último, no Capítulo 5, as conclusões são apresentadas juntamente com o planejamento para o prosseguimento deste trabalho. 


\section{Capítulo 2}

\section{Método dos Elementos Finitos Generalizados}

Com o objetivo de contextualizar a proposta de trabalho e ratificar sua relevância, apresenta-se os principais aspectos inerentes ao Método dos Elementos Finitos Generalizados. A Seção 2.1 descreve os principais aspectos do Método dos Elementos Finitos Generalizados. Complementando a teoria do MEFG, a Seção 2.2 apresenta a formulação clássica do mesmo. Alguns tipos de funções que podem ser utilizadas como funções de enriquecimento locais são apresentados na Seção 2.3. Por fim, como o trabalho objetiva a resolução de problemas via MEFG utilizando a técnica GlobalLocal, como forma de enriquecimento, descreve-se na Seção 2.4 a referida técnica e na Seção 2.5 é apresentada a sua formulação.

\subsection{Conceitos Gerais}

O Método dos Elementos Finitos Generalizados (MEFG) começou a ser desenvolvido sob diversas denominações, dentre elas "Método dos Elementos Finitos Especiais", (Babuška et al., 1994), "Método das nuvens", (Duarte, 1996), "Método dos Elementos Finitos da Partição da Unidade", (Babuška e Melenk, 1997), e outros. Ademais de certas particularidades, o que esses métodos têm em comum e que os torna tratáveis com certa igualdade é o fato de se utilizarem de funções do tipo Partição da Unidade para gerar o espaço de solução enriquecido pelo produto com outras funções definidas de acordo com o tipo de problema analisado (Duarte et al., 
2000).

Paralelamente ao desenvolvimento do MEFG, o Método dos Elementos Finitos Estendido (XFEM) foi proposto por Belytschko e Black (1999). No XFEM também se utiliza a técnica de enriquecimento através do conceito da Partição da Unidade. Este enriquecimento, porém, era realizado em apenas poucas regiões da malha, onde a solução apresentava comportamento que a aproximação convencional do MEF não era capaz de representar adequadamente. Diversos trabalhos foram, então, apresentados no contexto da Mecânica da Fratura, para a simulação do campo de tensões singular na ponta da trinca e, entre os primeiros, podem ser citados (Moës et al., 1999), (Dolbow et al., 2000) e (Stazi et al., 2003). Ainda que tenha havido uma certa distinção inicial na forma de se aplicar a técnica de enriquecimento, se reconhece atualmente que ambas as denominações, MEFG e XFEM, referem-se a métodos equivalentes, (Fries e Belytschko, 2010). Neste trabalho, será adotada, contudo, apenas uma denominação, MEFG, para abranger ambos os casos.

No MEFG, a depender da característica do problema, funções devidamente escolhidas, polinomiais ou não, multiplicam as funções de Partição da Unidade, aumentando a base de aproximação de elementos finitos já existente, expandindo o espaço de solução (Strouboulis et al., 2000). As funções de Partição da Unidades, discutidas na próxima seção, tipicamente utilizadas são as próprias funções de forma do MEF, de modo a facilitar a integração numérica e conseguir recuperar a imposição direta das condições de contorno do modelo.

\subsection{Formulação do Método dos Elementos Finitos Generalizados}

A formulação do MEFG baseia-se no conceito da Partição da Unidade (PU). Uma definição rigorosa para estas funções pode ser encontrada em Oden e Reddy (2011). No contexto do MEFG, esta definição é flexibilizada e são utilizadas funções, como as de Lagrange lineares, representadas por $N_{j}(\boldsymbol{x})$ associadas a cada nó, que 
somam a unidade, para o problema com $n$ pontos nodais:

$$
\sum_{j=1}^{n} N_{j}(\boldsymbol{x})=1
$$

Para ilustrar tais funções, apresenta-se a Figura 2.1, para o caso unidimensional. Nela o suporte $\omega_{j}$ da função $N_{j}(\boldsymbol{x})$ corresponde aos elementos $\beta-1$ e $\beta$. O termo suporte, também passível de ser denominado nuvem, representa o conjunto de elementos finitos que possuem o mesmo ponto nodal $\boldsymbol{x}_{j}$ (Barros, 2002).

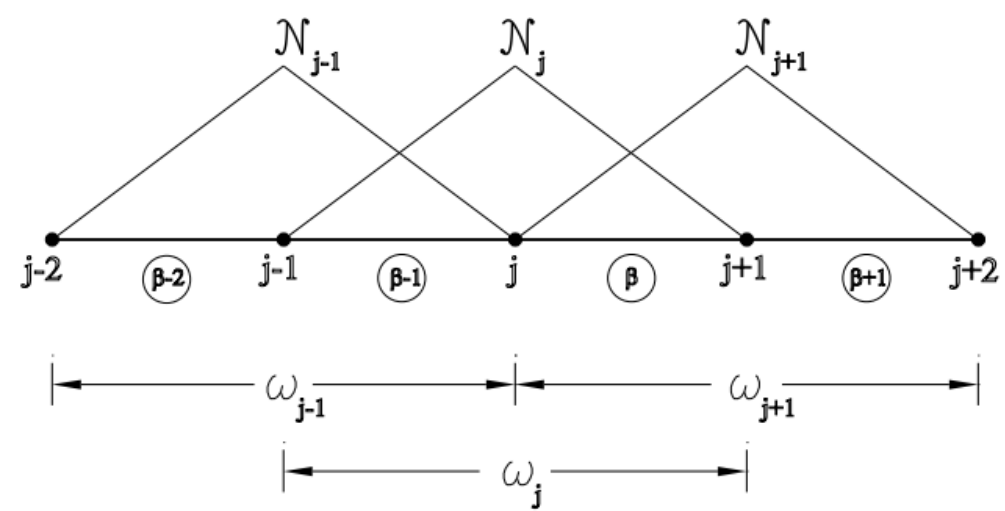

Figura 2.1: Partição da Unidade (Barros, 2002).

Segundo Alves (2012), um conjunto de funções de enriquecimento local, $L_{j i}(\boldsymbol{x})$, que são específicas para cada problema a ser analisado, é composta por $q_{j}$ funções linearmente independentes para cada nó $\boldsymbol{x}_{j}$, com suporte na nuvem de elementos $\omega_{j}$ :

$$
\left\{L_{j i}(\boldsymbol{x})\right\}_{i=1}^{q}=\left\{L_{j 1}(\boldsymbol{x}), L_{j 2}(\boldsymbol{x}), \ldots, L_{j q}(\boldsymbol{x})\right\}, \quad \text { com } \quad L_{j 1}(\boldsymbol{x})=1
$$

O conjunto de funções de enriquecimento local multiplica a PU a fim de criar o conjunto de funções enriquecidas, $\phi_{j i}(\boldsymbol{x})$ (Alves, 2012):

$$
\left\{\phi_{j i}(\boldsymbol{x})\right\}_{i=1}^{q}=N_{j}(\boldsymbol{x}) \times\left\{L_{j i}(\boldsymbol{x})\right\}_{i=1}^{q}
$$

sem somatório em j.

A título de ilustração, apresenta-se uma malha convencional de elementos finitos bidimensional na Figura 2.2 a, na qual define-se uma nuvem de elementos $\omega_{j}$ em 
que todos os elementos concorrem no ponto nodal $\boldsymbol{x}_{j}$. A Figura $2.2 \mathrm{~b}$ mostra a PU, a Figura 2.2 c traz a função de enriquecimento Local, e por fim a Figura $2.2 \mathrm{~d}$ apresenta a multiplicação entre a partição da unidade e a função de enriquecimento local formando a função de $\phi_{j i}(\boldsymbol{x})$ de enriquecimento do método (Alves, 2012).

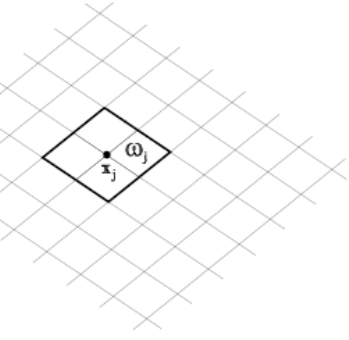

(a) Nuvem $\omega_{j}$

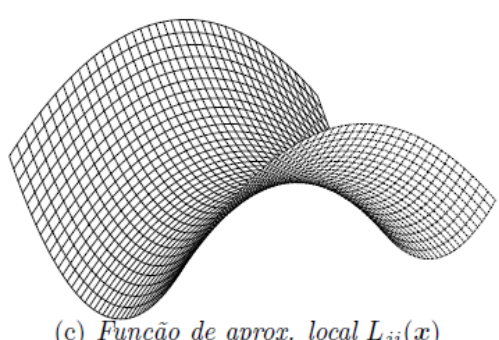

(c) Função de aprox. local $L_{j i}(x)$

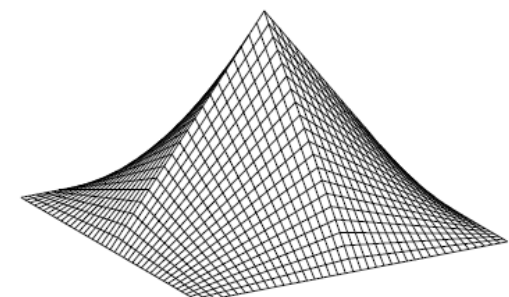

(b) Função $P U \mathcal{N}_{j}(x)$

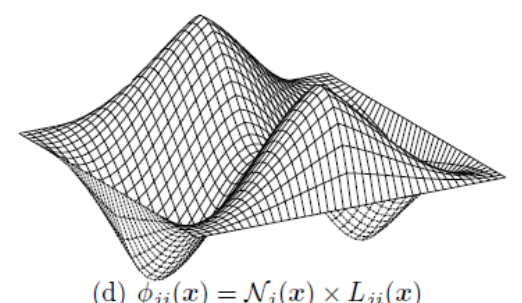

(d) $\phi_{j i}(x)=\mathcal{N}_{j}(x) \times L_{j i}(x)$

Figura 2.2: Estratégia de enriquecimento da nuvem $\omega_{j}$ via MEFG (Barros, 2002).

Com base na formulação apresentada, uma aproximação genérica $\tilde{\boldsymbol{u}}(\boldsymbol{x})$ é obtida através da combinação linear das funções de forma:

$$
\tilde{\boldsymbol{u}}(\boldsymbol{x})=\sum_{j=1}^{n} N_{j}(\boldsymbol{x})\left\{\boldsymbol{u}_{j}+\sum_{i=2}^{q} L_{j i}(\boldsymbol{x}) \boldsymbol{b}_{j i}\right\}
$$

onde $\boldsymbol{u}_{j}$ e $\boldsymbol{b}_{j i}$ são parâmetros nodais associados com cada componente $N_{j}(\boldsymbol{x})$ do MEF e $N_{j}(\boldsymbol{x}) \cdot L_{j i}(\boldsymbol{x})$ do MEFG, respectivamente.

Devido à forma como o enriquecimento é realizado, ou seja, de maneira independente em cada elemento, mesmo se os tipos de enriquecimentos forem diferentes entre os elementos da malha constrói-se uma aproximação "sem costura". Isso significa que não há a necessidade de se estabelecer condições de restrição que garantam a continuidade entre os campos aproximadores de cada elemento (Duarte et al., 2000). 


\subsection{Funções de Enriquecimento}

As funções de enriquecimento utilizadas no MEFG podem ser quaisquer, tais como uma função polinomial, uma função representando uma singularidade, ou até mesmo uma função advinda de um outro processo de solução resolvido a priori, como por exemplo a técnica Global-Local, proposta por Duarte e Kim (2008) quando aliada ao MEFG. A técnica Global-Local é muito utilizada nos casos em que há fenômenos geradores de concentração de tensão nos modelos analisados.

\subsubsection{Funções de Enriquecimento Polinomiais}

Funções de aproximação polinomiais são, em geral, adequadas para descrever soluções de comportamento suave. Segundo Duarte et al. (2000), o enriquecimento da PU com funções polinomiais constrói um espaço de solução com características equivalentes àquele obtido com elementos de elevada ordem no MEF. Diferentemente, contudo, no MEFG, é possível que diferentes nós estejam associados com funções de forma com diferentes ordens polinomiais.

Uma formulação, sugerida por Duarte et al. (2000), para as funções de aproximação polinomial é:

$$
\left\{L_{j i}(\boldsymbol{x})\right\}_{i=1}^{4}=\left\{1,\left(\frac{\left(x-x_{j}\right)}{h_{j}}\right),\left(\frac{\left(y-y_{j}\right)}{h_{j}}\right),\left(\frac{\left(z-z_{j}\right)}{h_{j}}\right)\right\}
$$

Na Equação (2.5), $\boldsymbol{x}_{j}=\left(x_{j}, y_{j}, z_{j}\right)$ são as coordenadas do nó $j$ e $h_{j}$ é o diâmetro da circunferência que circunscreve o maior elemento finito que compartilha o nó j. Esse formato de equação de aproximação polinomial visa a redução de erros de arredondamento durante a análise numérica (Duarte et al., 2000).

\subsubsection{Funções de Enriquecimento com Derivadas Singulares}

Alguns problemas contêm características, tais como cantos, reentrâncias e trincas que são muito pobremente descritos via MEFG com enriquecimento polinomial. 
Nesses casos, convém utilizar funções com singularidades em suas derivadas ou descontínuas para melhor descrever os campos de tensão e deslocamento que não se comportam de forma suave.

Um tipo de função de enriquecimento possível de ser utilizada é a função de forma customizada para trincas em três dimensões. Ela foi proposta por Duarte et al. (2000) e trata-se de uma extensão do conhecimento das equações de elasticidade já utilizada em modelos de duas dimensões (Szabo e Babuška, 1988).

Para o entendimento das funções de singularidade mencionadas, considera-se um modelo, cuja borda está representada na Figura 2.3. Nela a abertura de trinca é dada pelo ângulo $2 \pi-\alpha$ e associado à borda tem-se o eixo Cartesiano Local $(\xi, \eta, \zeta)$ e o eixo Cilíndrico Local $\left(r, \theta, \zeta^{\prime}\right)$, ambos com a mesma origem $\left(O_{x}, O_{y}, O_{z}\right)$, (Duarte et al., 2000).

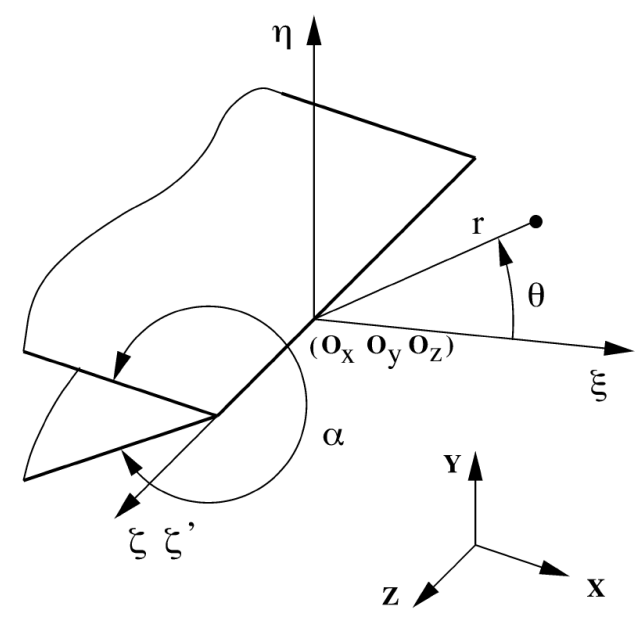

Figura 2.3: Eixos em três dimensões associados com a borda (Duarte et al., 2000).

Na vizinhança da borda, o campo de deslocamentos $\boldsymbol{u}\left(r, \theta, \zeta^{\prime}\right)$ pode ser descrito como:

$\mathbf{u}\left(r, \theta, \zeta^{\prime}\right)=\left\{\begin{array}{c}u_{\xi}(r, \theta) \\ u_{\eta}(r, \theta) \\ u_{\zeta}(r, \theta)\end{array}\right\}=\sum_{j=1}^{\infty}\left[A_{j}^{(1)}\left\{\begin{array}{c}u_{\xi j}^{(1)}(r, \theta) \\ u_{\eta j}^{(1)}(r, \theta) \\ 0\end{array}\right\}+A_{j}^{(2)}\left\{\begin{array}{c}u_{\xi j}^{(2)}(r, \theta) \\ u_{\eta j}^{(2)}(r, \theta) \\ 0\end{array}\right\}+A_{j}^{(3)}\left\{\begin{array}{c}0 \\ 0 \\ u_{\zeta j}^{(3)}(r, \theta)\end{array}\right\}\right]$ 
Na Equação (2.6), $\left(r, \theta, \zeta^{\prime}\right)$ dizem respeito ao eixo Cilíndrico Local mostrado na Figura 2.3, $u_{\xi}(r, \theta), u_{\eta}(r, \theta)$ e $u_{\zeta}(r, \theta)$ são os componentes do vetor $\boldsymbol{u}$ nas direções $\xi-, \eta$ - e $\zeta$ - respectivamente, os índices (1), (2) e (3) referem-se às contribuições associadas aos modos I, II e III de abertura de trinca.

Considerando que o modelo está livre de tração na face em que ocorre a trinca e desconsiderando as forças de corpo, tem-se que $u_{\xi j}^{(1)}, u_{\eta j}^{(1)}, u_{\xi j}^{(2)}$ e $u_{\eta j}^{(2)}$ :

$$
\begin{aligned}
& u_{\xi j}^{(1)}(r, \theta)=\frac{r_{j}^{\lambda_{j}^{(1)}}}{2 G}\left\{\left[\kappa-Q_{j}^{(1)}\left(\lambda_{j}^{(1)}+1\right)\right] \cos \lambda_{j}^{(1)} \theta-\lambda_{j}^{(1)} \cos \left(\lambda_{j}^{(1)}-2\right) \theta\right\} \\
& u_{\xi j}^{(2)}(r, \theta)=\frac{r^{\lambda_{j}^{(2)}}}{2 G}\left\{\left[\kappa-Q_{j}^{(2)}\left(\lambda_{j}^{(2)}+1\right)\right] \operatorname{sen} \lambda_{j}^{(2)} \theta-\lambda_{j}^{(2)} \operatorname{sen}\left(\lambda_{j}^{(2)}-2\right) \theta\right\} \\
& u_{\eta j}^{(1)}(r, \theta)=\frac{r^{\lambda_{j}^{(1)}}}{2 G}\left\{\left[\kappa+Q_{j}^{(1)}\left(\lambda_{j}^{(1)}+1\right)\right] \operatorname{sen} \lambda_{j}^{(1)} \theta+\lambda_{j}^{(1)} \operatorname{sen}\left(\lambda_{j}^{(1)}-2\right) \theta\right\} \\
& u_{\eta j}^{(2)}(r, \theta)=-\frac{r_{j}^{\lambda_{j}^{(2)}}}{2 G}\left\{\left[\kappa+Q_{j}^{(2)}\left(\lambda_{j}^{(2)}+1\right)\right] \cos \lambda_{j}^{(2)} \theta+\lambda_{j}^{(2)} \cos \left(\lambda_{j}^{(2)}-2\right) \theta\right\}
\end{aligned}
$$

Para o caso de trincas $\alpha=2 \pi$, desta maneira tem-se $\lambda_{j}^{(1)}=\lambda_{j}^{(2)}=\lambda_{j}$ :

$$
\lambda_{1}=\frac{1}{2}, \quad \lambda_{j}=\frac{j+1}{2} \quad j \geq 2
$$

As constantes do material $\kappa$ e $G$ :

$$
\kappa=3-4 \nu
$$




$$
G=\frac{E}{2(1+\nu)}
$$

Onde $\nu$ é o coeficiente de Poisson, E é o módulo de elasticidade longitudinal do material e G é o módulo de elasticidade transversal. A definição dessas constantes da maneira proposta, assume estado plano de deformação como uma boa aproximação para o estado de tensão na proximidade da trinca tridimensional, segundo Duarte et al. (2000).

Para trincas, os parâmetros $Q_{j}^{1}$ e $Q_{j}^{2}$ :

$$
\begin{aligned}
& Q_{j}^{1}= \begin{cases}-1 & \mathrm{j}=3,5,7, \ldots \\
-\Lambda_{j}^{(1)} & \mathrm{j}=1,2,4,6, \ldots\end{cases} \\
& Q_{j}^{2}= \begin{cases}-1 & \mathrm{j}=1,2,4,6, \ldots \\
-\Lambda_{j}^{(2)} & \mathrm{j}=3,5,7, \ldots\end{cases}
\end{aligned}
$$

Nas Equações 2.14 e 2.15 a variável $\Lambda_{j}^{(s)}$ :

$$
\Lambda_{j}^{(s)}=\frac{\lambda_{j}^{(s)}-1}{\lambda_{j}^{(s)}+1} \quad s=1,2
$$

Para a composição da parcela do vetor de deslocamento $\boldsymbol{u}$ na direção $\zeta$-, obtida a partir da expansão do modelo 2D para o modelo 3D, conforme mencionado anteriormente, tem-se $u_{\zeta j}^{(3)}$, considerando novamente que a face da trinca está livre de tração e desconsiderando forças de corpo:

$$
u_{\zeta j}^{(3)}= \begin{cases}\frac{r^{\lambda_{j}^{(3)}}}{2 G} \operatorname{sen} \lambda_{j}^{(3)} \theta & \mathrm{j}=1,3,5, \ldots \\ \frac{r^{\lambda_{j}^{(3)}}}{2 G} \cos \lambda_{j}^{(3)} \theta & \mathrm{j}=2,4,6, \ldots\end{cases}
$$

Sendo que, $\lambda_{j}^{(3)}$ :

$$
\lambda_{j}^{(3)}=\frac{j \pi}{\alpha} \quad j=1,2, \ldots
$$


Por fim, faz-se necessária a transformação de coordenadas para o Sistema Global $x, y, z$. Transforma-se primeiramente as coordenadas do vetor $\boldsymbol{u}$ Cilíndricas $\left(r, \theta, \zeta^{\prime}\right)$ para Coordenadas Cartesianas Locais $(\xi, \eta, \zeta)$. Posteriormente de coordenadas Cartesianas Locais para as coordenadas Cartesianas Globais $x, y, z$.

As funções de aproximação Local são:

$$
\left[\begin{array}{ll}
u_{x 1}^{(1)} & u_{x 1}^{(2)} \\
u_{y 1}^{(1)} & u_{y 1}^{(2)} \\
u_{z 1}^{(3)} & u_{z 2}^{(3)}
\end{array}\right]=R_{2}\left\{\begin{array}{cc}
\tilde{u}_{\xi 1}^{(1)} & \tilde{u}_{\xi 1}^{(2)} \\
\tilde{u}_{\eta 1}^{(1)} & \tilde{u}_{\eta 1}^{(2)} \\
\tilde{u}_{\zeta 1}^{(3)} & \tilde{u}_{\zeta 2}^{(3)}
\end{array}\right\}
$$

Sendo que:

$$
R_{2}=\left(R_{2}^{-1}\right)^{T}
$$

Na Equação (2.19), as componentes do vetor $\tilde{u}$ representam o vetor já com essas descritas no Sistema Global $(x, y, z)$ e a matriz da esquerda representa as funções de aproximação locais a serem utilizadas no MEFG. Além disso, os índices superiores entre parênteses indicam o modo de abertura de trinca representado pela equação de deslocamento em questão e os índices inferiores, que acompanham o sentido do deslocamento avaliado, dizem respeito ao termo da série utilizado na aproximação. É importante ressaltar que somente as funções que descrevem os deslocamentos representativos do Modo III de abertura de trinca que utilizam o segundo termo da série de aproximação. Na Equação 2.20, $R_{2}^{-1}$ é a matriz de transformação de coordenadas cujas linhas são os vetores bases do Sistema de Coordenadas Locais $(\xi, \eta, \zeta)$, Duarte et al. 2000).

\subsection{Método dos Elementos Finitos Generalizados - Global-Local}

Segundo Duarte e Kim (2008), a eficácia do MEFG está intimamente ligada a escolha das funções de enriquecimento mais adequadas para determinado problema. Dentro desse contexto, é proposto o MEFG acrescido da técnica Global-Local, no 
qual uma função de enriquecimento personalizada é criada a partir da análise local das regiões de concentração de tensões do problema e essa é utilizada dentro da análise via MEFG do problema completo. Trata-se de um recurso importante, porque muitas vezes funções de enriquecimento polinomiais e singulares não são capazes de descrever de maneira satisfatória o comportamento de determinadas estruturas ou particularidades das mesmas.

A técnica Global-Local consiste em realizar três etapas distintas e complementares. Na primeira etapa soluciona-se um problema denominado "global", trata-se, preferencialmente, um problema com malha de discretização grosseira que compreende todo o domínio do modelo e, geralmente, não são descritos os fenômenos geradores das concentrações de tensões, ou seja, nenhuma singularidade precisa ser descrita, via enriquecimento, nessa etapa. Em seguida, na segunda etapa, define-se o problema denominado "local" que abrange a região onde se estima que vão ocorrer as concentrações de tensão, refina-se a malha dessa região e aplicam-se como condições de contorno os deslocamentos e/ou tensões calculadas no problema "global" neste problema "local" que, nesta etapa, é resolvido em separado. Por fim, na última etapa, a solução numérica "local" pode ser utilizada para enriquecer o domínio "global" com o objetivo de realizar uma análise final do problema (Alves, 2012).

A Figura 2.4 mostra, resumidamente, as etapas da estratégia Global-Local. Notase ainda na Figura 2.4, que deve ser transmitida a solução do problema global como condições de contorno para o domínio local. Estas condições de contorno podem ser de Neumann, Dirichlet ou Cauchy. As condições de contorno de Neumann estão relacionadas a imposição de tensões, as de Dirichlet fazem menção a imposição de deslocamentos e as de Cauchy são um misto desses dois casos. A transmissão pode ser feita via método da penalidade e diversos estudos foram realizados a fim de se chegar à conclusão de qual a melhor forma de transmitir essas condições de contorno, tais como em Kim et al. (2010) e Alves (2012).

Para reduzir erros advindos da utilização da solução de um problema Global com 


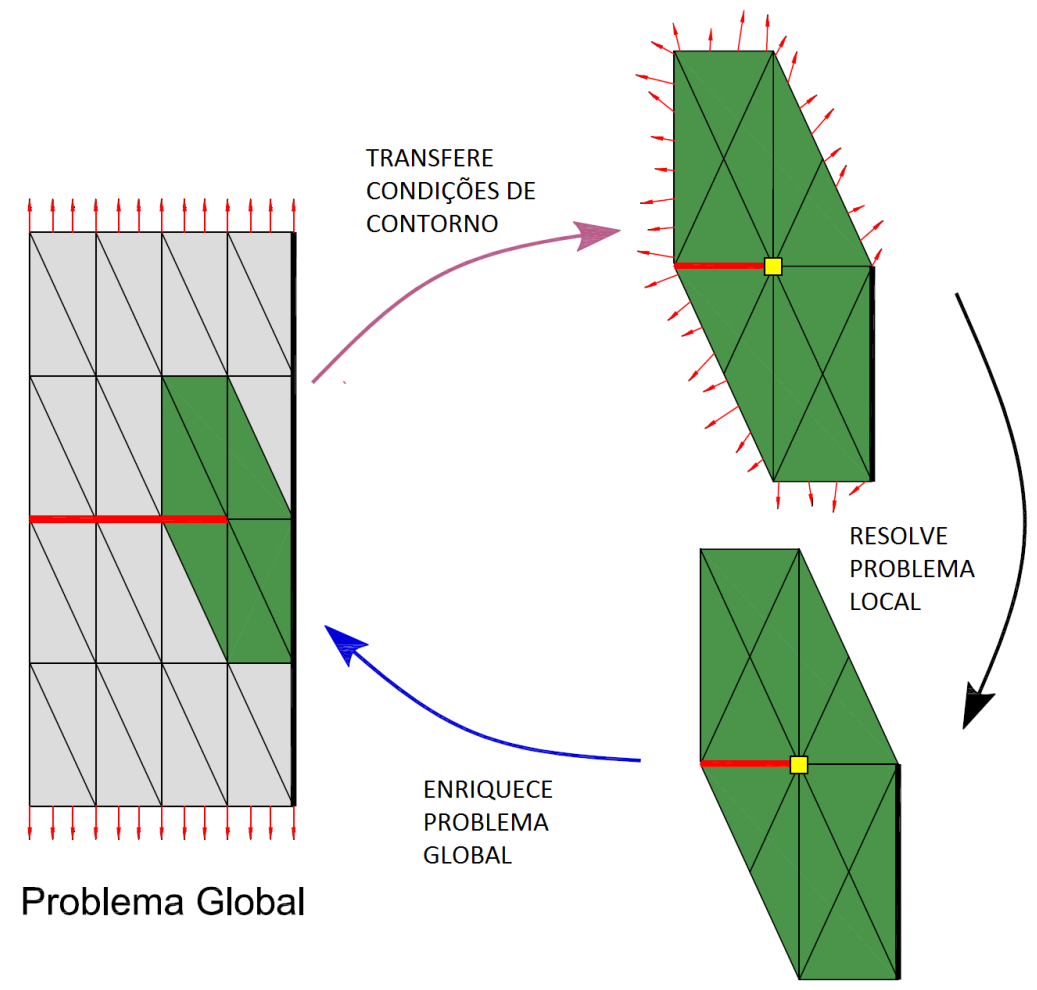

Figura 2.4: Estratégia Global Local (Adaptada) (Alves, 2012).

malha grosseira, a imposição das condições de contorno para o problema Local, utilizando a técnica Global-Local pode ser feito de forma iterativa. Assim, na primeira iteração, o modelo local será analisado considerando-se as condições de contorno retiradas do problema global com aproximação grosseira. Depois de obtida a solução do problema global enriquecido, esse agora servirá de base para a descrição de novas condições de contorno e o problema Local será reprocessado e assim o problema global será novamente solucionado com esse novo enriquecimento. Esse processo se repete quantas vezes for necessário. Pode-se impor uma tolerância a ser alcançada pela norma de energia, por exemplo, para determinar o fim do mesmo. Tal processo iterativo é muito útil e pode ser utilizado até mesmo no caso de trincas coesivas em que se deseja modelar o amolecimento do material à medida que a trinca se propaga Kim e Duarte, 2015). Em geral, poucas iterações no processo Global-Local são necessárias até se alcançar a convergência de resultados, em Gupta et al. (2012) é possível observar que em média duas iterações são suficientes. 


\subsection{Formulação da Técnica Global- Local}

A formulação dos três problemas que envolvem a técnica Global-Local, ainda que semelhantes, apresenta particularidades que merecem ser destacadas e que facilitam o entendimento de cada uma das etapas de resolução do problema, isoladamente. Por esse motivo, trata-se nessa seção as formulações do problema Global, Local e Global Enriquecidos de maneira separada.

Adota-se, neste trabalho, o Princípio dos Trabalhos Virtuais (PTV) para a formulação da forma fraca do problema de valor de contorno para cada uma das três etapas de solução. Por PTV, entende-se:

Numa estrutura em equilíbrio, ao se impor um campo de deslocamentos virtuais compativeis, o trabalho realizado pelas forças reais externas sobre os deslocamentos virtuais é igual ao trabalho das tensões reais internas sobre as deformações virtuais (Pitangueira, 2016).

Resume-se o PTV na seguinte equação:

$$
\delta W_{i}=\delta W_{e}
$$

onde $\delta W_{i}$ é o trabalho das forças internas e $\delta W_{e}$ é o trabalho das forças externas.

\subsubsection{Problema Global}

Para a solução do problema global, via MEFG utiliza-se a Equação (2.21). Considera-se também o problema de elasticidade bidimensional, cujo contorno do domínio global é decomposto em $\partial \Omega_{G}=\partial \Omega_{G}^{u} \cup \partial \Omega_{G}^{\sigma} \operatorname{com} \partial \Omega_{G}^{u} \cap \partial \Omega_{G}^{\sigma}=\oslash$, sendo $u$ e $v$ referentes às regiões em que as condições de contorno de Dirichlet e Neumann são respectivamente aplicadas. A Figura 2.5 apresenta esses contornos, para um modelo hipotético, que mostra uma chapa, que em seu centro há uma trinca horizontal e está submetida a uma força distribuída em parte do contorno $\partial \Omega_{G}^{\sigma}$ e também há uma restrição em seu lado direito, ou seja, no contorno $\partial \Omega_{G}^{u}$. 


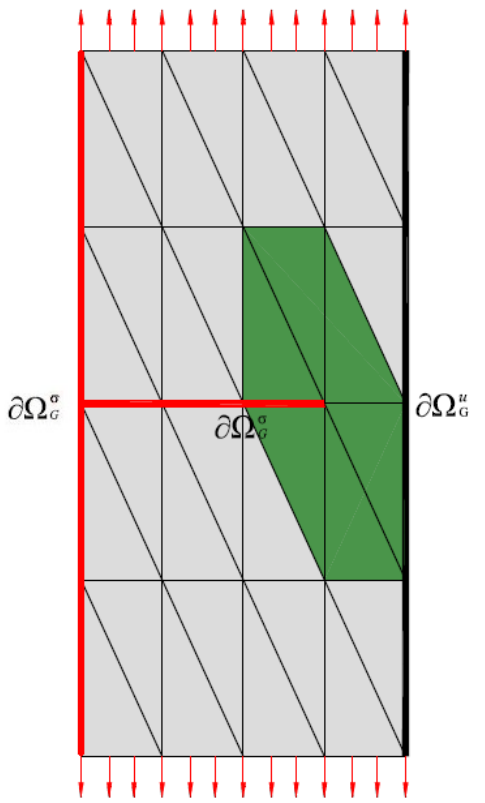

$\partial \Omega_{C}$

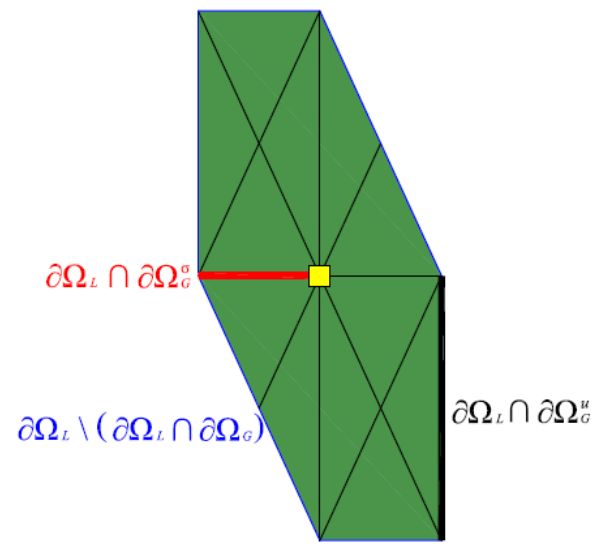

$\partial \Omega_{L}$

Figura 2.5: Domínios Global e Local de um problema genérico com os respectivos contornos (Alves, 2012).

Considerando-se ausentes as forças de corpo, as equações de equilíbrio para o problema global, em tensões, são representas como:

$$
\nabla \cdot \boldsymbol{\sigma}=\mathbf{0} \quad \text { em } \quad \Omega_{G}
$$

Na Equação 2.22), as relações constitutivas são dadas pela lei de Hooke generalizadas, uma vez que se considera material elástico-linear. Assim, o tensor de tensões $\boldsymbol{\sigma}=\boldsymbol{C}: \boldsymbol{\epsilon}$, onde $\boldsymbol{C}$ é o tensor de Hooke e $\boldsymbol{\epsilon}$ é o tensor de deformações.

Conforme Figura 2.5, as condições de contorno são prescritas em $\partial \Omega_{G}$ :

$$
\begin{gathered}
\boldsymbol{u}=\overline{\boldsymbol{u}} \quad \text { em } \quad \partial \Omega_{G}^{u} \\
\boldsymbol{\sigma} \cdot \boldsymbol{n}=\overline{\boldsymbol{t}} \quad \text { em } \quad \partial \Omega_{G}^{\sigma}
\end{gathered}
$$

onde $\boldsymbol{n}$ é o vetor unitário normal para $\partial \Omega_{G}^{\sigma}$ e $\overline{\boldsymbol{t}}$ e $\overline{\boldsymbol{u}}$ são, respectivamente, carregamentos e deslocamentos prescritos. 
Além das condições de contorno descritas nas Equações (2.22), (2.23) e (2.24), utiliza-se a solução $\boldsymbol{u}$ aproximada por $\tilde{\boldsymbol{u}}_{G}^{0}$ através da Equação 2.4), chega-se assim na solução para o problema Global:

$$
\begin{array}{r}
\text { Encontre } \tilde{\boldsymbol{u}}_{G}^{0} \in \tilde{\chi}_{G}^{0}\left(\Omega_{G}\right) \subset \mathcal{H}^{1}\left(\Omega_{G}\right) \forall \boldsymbol{v}_{G}^{0} \in \tilde{\chi}_{G}^{0}\left(\Omega_{G}\right) \\
\int_{\Omega_{G}} \boldsymbol{\sigma}\left(\tilde{\boldsymbol{u}}_{G}^{0}\right): \boldsymbol{\epsilon}\left(\boldsymbol{v}_{G}^{0}\right) d \boldsymbol{x}+\eta \int_{\partial \Omega_{G}^{u}} \tilde{\boldsymbol{u}}_{G}^{0} \cdot \boldsymbol{v}_{G}^{0} d S=\int_{\partial \Omega_{G}^{\sigma}} \overline{\mathbf{t}} \cdot \boldsymbol{v}_{G}^{0} d S+\eta \int_{\partial \Omega_{G}^{u}} \overline{\boldsymbol{u}} \cdot \boldsymbol{v}_{G}^{0} d S
\end{array}
$$

$\mathrm{Na}$ Equação (2.25), à esquerda da igualdade está o trabalho das forças internas e à direita o das forças externas, adicionados às parcelas referentes ao método de penalidade. Tem-se que $\tilde{\chi}_{G}^{0}\left(\Omega_{G}\right)$ é a discretização de $\mathcal{H}^{1}\left(\Omega_{G}\right)$, um espaço de Hilbert de ordem 1 definido em $\Omega_{G}$, construído pelo método discreto utilizado (MEF ou MEFG). Os símbolos $\boldsymbol{\epsilon}$ e $\boldsymbol{\sigma}$ correspondem aos tensores que representam o campo de deformações e do campo de tensões, respectivamente, já $\eta$ é o parâmetro de penalidade e considera-se que as condições de contorno de Dirichlet são impostas. Além disso, é importante ressaltar que embora a Figura 2.5, ilustre um exemplo bidimensional, a equação aqui apresentada é para modelos tridimensionais uma vez que a integral $d S$ percorre toda a superfície do contorno em questão.

Nesta primeira etapa, a função enriquecedora $L_{j i}$ na Equação (2.4) pode ser qualquer função, como por exemplo uma função polinomial ou singular, ou até mesmo não ser utilizada nenhuma função, desde que:

$$
L_{j i}(\boldsymbol{x})=0 \longrightarrow \tilde{\boldsymbol{u}}\left(\boldsymbol{x}_{j}\right)=\boldsymbol{u}_{j}
$$

Ou seja, pode-se criar um problema global inicial enriquecido de forma a melhorar a transmissão de condições de contorno para o problema Local, caso seja de interesse.

\subsubsection{Problema Local}

Considera-se, inicialmente, o subdomínio Local $\Omega_{L}$ que está contido no domínio Global $\Omega_{G}$. O problema Local é resolvido no domínio $\Omega_{L}$ depois que a primeira etapa 
global foi resolvida e se dispõe da solução global inicial $\tilde{\boldsymbol{u}}_{G}^{0}$. Nesta segunda etapa, busca-se a solução do problema local $\tilde{\boldsymbol{u}}_{L}$, dada pela Equação (2.4). Os contornos do domínio Local são compreendidos pelos domínios: $\partial \Omega_{L} \cap \partial \Omega_{G}^{u}, \partial \Omega_{L} \cap \partial \Omega_{G}^{\sigma}$ e $\partial \Omega_{L} \backslash\left(\partial \Omega_{L} \cap \partial \Omega_{G}\right)$, a Figura 2.5 ilustra esses contornos.

Também utilizando o PTV e, consequentemente, a Equação 2.21 e acrescentando as grandezas oriundas do problema Global a formulação do problema Local, segue:

$$
\begin{array}{r}
\text { Encontre } \tilde{\boldsymbol{u}}_{L} \in \tilde{\chi}_{L}\left(\Omega_{L}\right) \subset \mathcal{H}^{1}\left(\Omega_{L}\right) \forall \boldsymbol{v}_{L} \in \tilde{\chi}_{L}\left(\Omega_{L}\right) \\
\int_{\Omega_{L}} \boldsymbol{\sigma}\left(\tilde{\boldsymbol{u}}_{L}\right): \boldsymbol{\epsilon}\left(\boldsymbol{v}_{L}\right) d \boldsymbol{x}+\eta \int_{\partial \Omega_{L} \cap \partial \Omega_{G}^{u}} \tilde{\boldsymbol{u}}_{L} \cdot \boldsymbol{v}_{L} d S+\kappa \int_{\partial \Omega_{L} \backslash\left(\partial \Omega_{L} \cap \partial \Omega_{G}\right)} \tilde{\boldsymbol{u}}_{L} \cdot \boldsymbol{v}_{L} d S= \\
\int_{\partial \Omega_{L} \cap \partial \Omega_{G}^{\sigma}} \overline{\boldsymbol{t}} \cdot \boldsymbol{v}_{L} d S+\eta \int_{\partial \Omega_{L} \cap \partial \Omega_{G}^{u}} \overline{\boldsymbol{u}} \cdot \boldsymbol{v}_{L} d S+\int_{\partial \Omega_{L} \backslash\left(\partial \Omega_{L} \cap \partial \Omega_{G}\right)}\left(\boldsymbol{t}\left(\tilde{\boldsymbol{u}}_{G}^{0}\right)+\kappa \tilde{\boldsymbol{u}}_{G}^{0}\right) \cdot \boldsymbol{v}_{L} d S
\end{array}
$$

Na Equação (2.27), à esquerda da igualdade está o trabalho das forças internas e à direita o das forças externas, adicionados às parcelas referentes ao método de penalidade. Tem-se que $\tilde{\chi}_{L}\left(\Omega_{L}\right)$ é a discretização de $\mathcal{H}^{1}\left(\Omega_{L}\right)$, um espaço de Hilbert de ordem 1 definido em $\Omega_{L}$, construído pelo método discreto utilizado (MEF ou MEFG). Já $L$ refere-se aos parâmetros Locais e $G$ aos parâmetros Globais, $\eta$ é o parâmetro de penalidade e $\kappa$ é o parâmetro de Cauchy.

Para a formulação do problema Local, segundo Kim et al. (2010), se define que tipo de condições de contorno serão transmitidas do problema Global para o Problema Local. Conforme mencionado anteriormente podem ser transmitidos três tipos de condições de contorno, são elas:

- Condições de contorno de Neumann: são transmitidas informações de tensões do elemento global para o elemento local. Nesse caso utiliza-se $\kappa=0$.

- Condições de contorno de Dirichlet: são transmitidas informações de deslocamentos do elemento global para o elemento local. Nesse caso utiliza-se $\kappa=\eta$ $\gg 1$. Desta maneira, a transmissão de tensões torna-se irrelevante. 
- Condições de contorno de Cauchy: equivale a combinação dos dois tipos anteriores. Nesse caso utiliza-se $0<\kappa<\eta$.

Segundo Duarte e Kim (2008), uma boa aproximação para o parâmetro de penalidade $(\eta)$ é:

$$
\eta=10^{8} \cdot E \cdot J
$$

onde $E$ é o módulo de elasticidade do material e $J$ é o Jacobiano da transformação do elemento global que origina o elemento local da malha, respectivamente.

Segundo Kim et al. (2010), uma boa aproximação para o parâmetro de Cauchy $(\kappa)$ é:

$$
\kappa=\frac{E}{\sqrt[n]{V_{0} J}}
$$

onde $E$ é o módulo de elasticidade do material, $n$ é a dimensão do problema analisado, $V_{0}$ e $J$ são o volume e o Jacobiano da transformação do elemento global que origina o elemento local da malha, respectivamente.

\subsubsection{Problema Global Enriquecido}

De posse da solução $\tilde{\boldsymbol{u}}_{L}$, retorna-se ao problema global a fim de utilizar essa solução como enriquecimento da PU deste mesmo problema global e assim obter a sua solução $\tilde{\boldsymbol{u}}_{G}^{E}$.

As funções de forma do problema Global enriquecido são agora modificadas, adicionalmente, pela solução do problema global:

$$
\left\{\phi_{j i}(\boldsymbol{x})\right\}_{i=1}^{q}=N_{j}(\boldsymbol{x}) \times\left\{1, L_{j 2}(\boldsymbol{x}), \ldots, L_{j q}(\boldsymbol{x}), \tilde{\boldsymbol{u}}_{L}\right\}
$$

Utiliza-se novamente a formulação do PTV através da Equação (2.21), substituindo a solução $\boldsymbol{u}$ por $\tilde{\boldsymbol{u}}_{G}^{E}$ :

$$
\text { Encontre } \tilde{\boldsymbol{u}}_{G}^{E} \in \tilde{\chi}_{G}^{E}\left(\Omega_{G}\right) \subset \mathcal{H}^{1}\left(\Omega_{G}\right) \forall \boldsymbol{v}_{G}^{E} \in \tilde{\chi}_{G}^{E}\left(\Omega_{G}\right)
$$




$$
\int_{\Omega_{G}} \boldsymbol{\sigma}\left(\tilde{\boldsymbol{u}}_{G}^{E}\right): \boldsymbol{\epsilon}\left(\boldsymbol{v}_{G}^{E}\right) d \boldsymbol{x}+\eta \int_{\partial \Omega_{G}^{u}} \tilde{\boldsymbol{u}}_{G}^{E} \cdot \boldsymbol{v}_{G}^{E} d S=\int_{\partial \Omega_{G}^{\sigma}} \overline{\mathbf{t}} \cdot \boldsymbol{v}_{G}^{E} d S+\eta \int_{\partial \Omega_{G}^{u}} \overline{\boldsymbol{u}} \cdot \boldsymbol{v}_{G}^{E} d S
$$

Na Equação (2.31), à esquerda da igualdade está o trabalho das forças internas e à direita o das forças externas, adicionados às parcelas referentes ao método de penalidade. Tem-se que $\tilde{\chi}_{G}^{E}\left(\Omega_{G}\right)$ é a discretização de $\mathcal{H}^{1}\left(\Omega_{G}\right)$, um espaço de Hilbert de ordem 1 definido em $\Omega_{G}$, construído, neste caso, pelas funções de aproximação originais do problema global, acrescidas daquelas enriquecidas com a solução do problema local.

Por fim, a solução $\tilde{\boldsymbol{u}}_{G}^{E}$ será:

$$
\tilde{\boldsymbol{u}}_{G}^{E}(\boldsymbol{x})=\sum_{j=1}^{n} N_{j}(\boldsymbol{x})\left\{\boldsymbol{u}_{j}+\sum_{i=2}^{q} L_{j i}(\boldsymbol{x}) b_{j i}+\tilde{\boldsymbol{u}}_{L} \boldsymbol{c}_{j}\right\}
$$

onde $\boldsymbol{c}_{j}$ é um parâmetro nodal relacionado ao número de graus de liberdade acrescido ao problema Global em virtude da solução do problema Local. 


\section{Capítulo 3}

\section{Implementação Computacional}

\subsection{Principais Aspectos do Sistema INSANE}

O INSANE (INteractive Structural ANalysis Environment) é um sistema computacional em desenvolvimento do Departamento de Engenharia de Estruturas (DEES) da Universidade Federal de Minas Gerais (UFMG), implementado em linguagem de programação JAVA e que utiliza o paradigma da Programação Orientada a Objetos (POO) (Fonseca, 2008). O INSANE foi expandido no trabalho de Alves (2012) para permitir análises pelo MEFG e também considerando a abordagem Global-Local. Ainda que concebida de forma genérica, a expansão realizada por Alves (2012) ficou restrita aos modelos de análise de barra unidimensionais, de estado plano de tensão e de deformação e tridimensionais. O enriquecimento com funções representativas do campo de tensões singulares na vizinhança da ponta de uma trinca, bem como o uso da técnica Global-Local, foram validados apenas para os problemas de estado plano de tensão e de deformação. Em Malekan et al. (2016) aquela implementação foi expandida e também validada para modelos de placa, considerando a abordagem de Reissner-Mindlin. Coube ao presente trabalho, conforme detalhado a seguir, finalizar a expansão e realizar a validação destas estratégias de enriquecimento para modelos tridimensionais. Resta ainda a generalização e validação do MEFG utilizando funções de aproximação local contendo singularidades e também da estratégia Global-Local para modelos tridimensionais.

O INSANE pode ser dividido em três aplicações, pré-processador, processador e 
pós-processador. O primeiro e o último são responsáveis, respectivamente, pelas entradas e saídas de dados do programa, via interface-gráfica e arquivo, ou seja, fazem a interação homem-máquina. Já o processador é a parte do programa responsável pela resolução dos modelos já que representa o núcleo numérico do sistema para os diversos métodos de resolução, como, por exemplo, o próprio MEFG. A estrutura do núcleo numérico é composta pelas interfaces Assembler e Persistence e as classes abstratas Model e Solution. Através do diagrama de classes Unifield Modeling Language (UML) apresentado na Figura 3.1 é possível observar esses componentes e a relação existente entre eles (Fonseca, 2008).

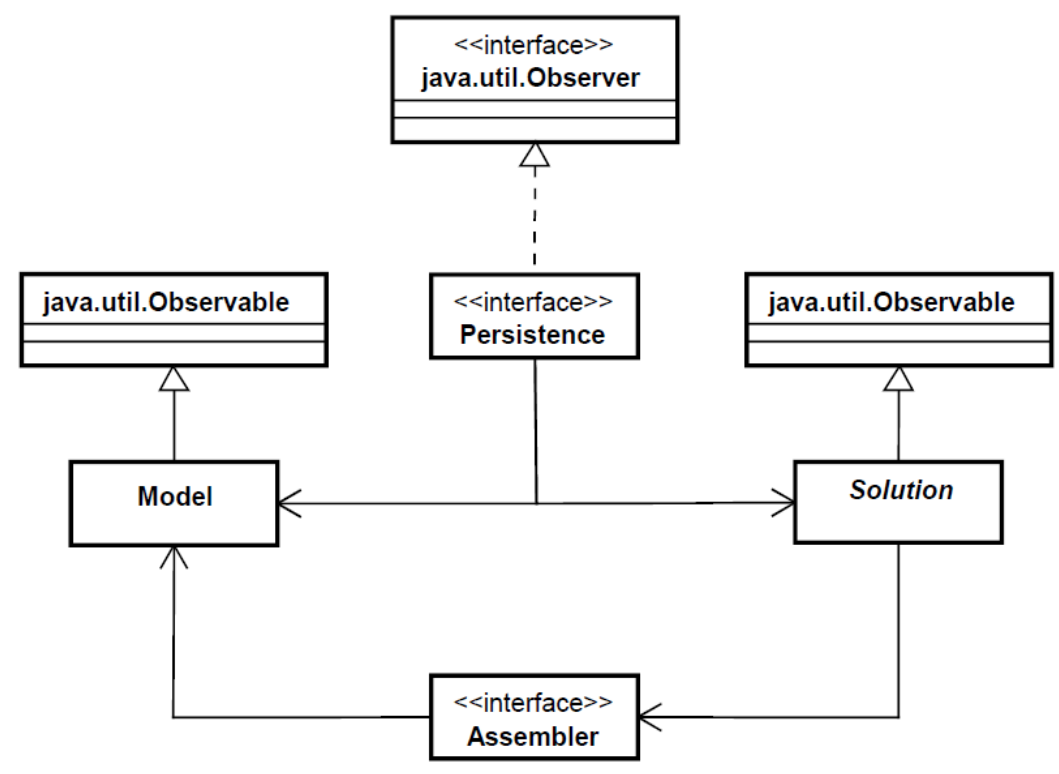

Figura 3.1: Diagrama UML do Núcleo Numérico do INSANE (Alves, 2012).

A interface Assembler é responsável pela montagem do sistema de equações matricial que resolve aproximadamente um problema de valor de contorno e de valor inicial. Para o caso específico do MEFG, a classe GFemAssembler que implementa Assembler. O sistema matricial de segunda ordem a ser montado é apresentado na equação:

$$
A \ddot{X}+B \dot{X}+C X=D
$$

Na Equação (3.1), $\boldsymbol{A}, \boldsymbol{B}$ e $\boldsymbol{C}$ são matrizes, $\boldsymbol{D}$ é um vetor e $\boldsymbol{X}$ representa o vetor 
solução do sistema, contemplando o caso geral de um problema de valor inicial e de contorno.

Segundo Alves (2012), simplificando para o caso de análise estrutural estática, os dois primeiros termos são eliminados e as matrizes e vetores resultantes são mostrados nas equações:

$$
\begin{gathered}
{\left[\begin{array}{ll}
\boldsymbol{C}_{u u} & \boldsymbol{C}_{u p} \\
\boldsymbol{C}_{p u} & \boldsymbol{C}_{p p}
\end{array}\right]\left\{\begin{array}{l}
\boldsymbol{X}_{u} \\
\boldsymbol{X}_{p}
\end{array}\right\}=\left\{\begin{array}{l}
\boldsymbol{R}_{p} \\
\boldsymbol{R}_{u}
\end{array}\right\}-\left\{\begin{array}{l}
\boldsymbol{F}_{p} \\
\boldsymbol{F}_{u}
\end{array}\right\}} \\
\left\{\begin{array}{l}
\boldsymbol{R}_{p} \\
\boldsymbol{R}_{u}
\end{array}\right\}=\left\{\begin{array}{l}
\boldsymbol{N}_{p} \\
\boldsymbol{N}_{u}
\end{array}\right\}+\left\{\begin{array}{l}
\boldsymbol{E}_{p} \\
\boldsymbol{E}_{u}
\end{array}\right\}
\end{gathered}
$$

Na Equação (3.2), $\boldsymbol{C}$ representa a matriz de rigidez, $\boldsymbol{X}$ o vetor de deslocamentos, $\boldsymbol{R}$ o vetor de forças nodais equivalente aos esforços externos e $\boldsymbol{F}$ o vetor de forças nodais equivalente aos esforços internos. Na Equação (3.3), há a decomposição do vetor $\boldsymbol{R}$, que se separa nas parcelas $\boldsymbol{N}$ que representa as forças aplicadas diretamente nos nós e $\boldsymbol{E}$ que inclui as forças ou deslocamentos nodais equivalentes. É importante mencionar que os índices $u$ e $p$ significam incógnitos e prescritos, respectivamente.

A classe abstrata Model organiza a forma como são armazenadas as informações referentes ao modelo discreto. Estende-se dela a classe GFemModel, específica do método MEFG.

A interface Persistence faz a comunicação entre a Classe Abstrata Model e a Classe Abstrata Solution a partir da interpretação de dados de entrada e o fornecimento de dados de saída para outras aplicações. Ela já está equipada para atender ao MEFG (Alves, 2012).

A classe abstrata Solution reúne os recursos necessários para a solução do sistema matricial. Na abordagem do MEFG, dependendo do tipo de enriquecimento nodal utilizado, é possível que seja criada uma matriz de rigidez positiva semi-definida tornando a solução do sistema existente, porém não única. Exige-se, neste caso, a 
aplicação de procedimentos especiais para a solução deste tipo de problema (Strouboulis et al., 2000) que se encontram implementados em Solution.

Uma classe abstrata importante para esse trabalho é a EnrichmentType. A referida classe reúne, de forma geral, os métodos necessários para realizar o enriquecimento das funções de forma via MEFG, independentemente do tipo de função de enriquecimento local utilizada. Nela é possível chamar métodos que retornam as funções de enriquecimento multiplicadoras da PU e suas derivadas nas três direções.

Os diversos tipos de enriquecimento das funções de forma estendem da classe EnrichmentType e são utilizados na composição das funções de forma enriquecidas. As funções de forma enriquecidas são montadas na classe EnrichedShape.

A Figura 3.2 mostra, resumidamente, como se dá o processamento no INSANE da montagem da matriz de rigidez de um modelo para o MEFG, considerando que os dados de entrada já foram fornecidos pelo ator através de arquivo texto ou entrada gráfica.

Na Figura 3.2 os números e letras representam:

1 - Montar/Retornar a Matriz de rigidez para o modelo.

2 - Montar/Retornar a Matriz de rigidez para cada elemento.

$3 \boldsymbol{a}$ - Consultar elemento e retornar tipo de modelo de análise.

$4 \boldsymbol{a}$ - Consultar/Retornar tipo de modelo de análise.

$3 \boldsymbol{b}$ - Consultar elemento e retornar coordenadas naturais e propriedades dos materiais.

$\boldsymbol{4} \boldsymbol{b}$ - Consultar degeneração e retornar coordenadas naturais e propriedades dos materiais.

$3 c$ - Consultar elemento e retornar função de forma e derivadas.

$4 c$ - Informar incidência e retornar função de forma e derivadas.

$5 \boldsymbol{c}$ - Consultar/Retornar Partição da Unidade.

$\boldsymbol{6 c}$ - Consultar cada nó e retornar função de enriquecimento. 


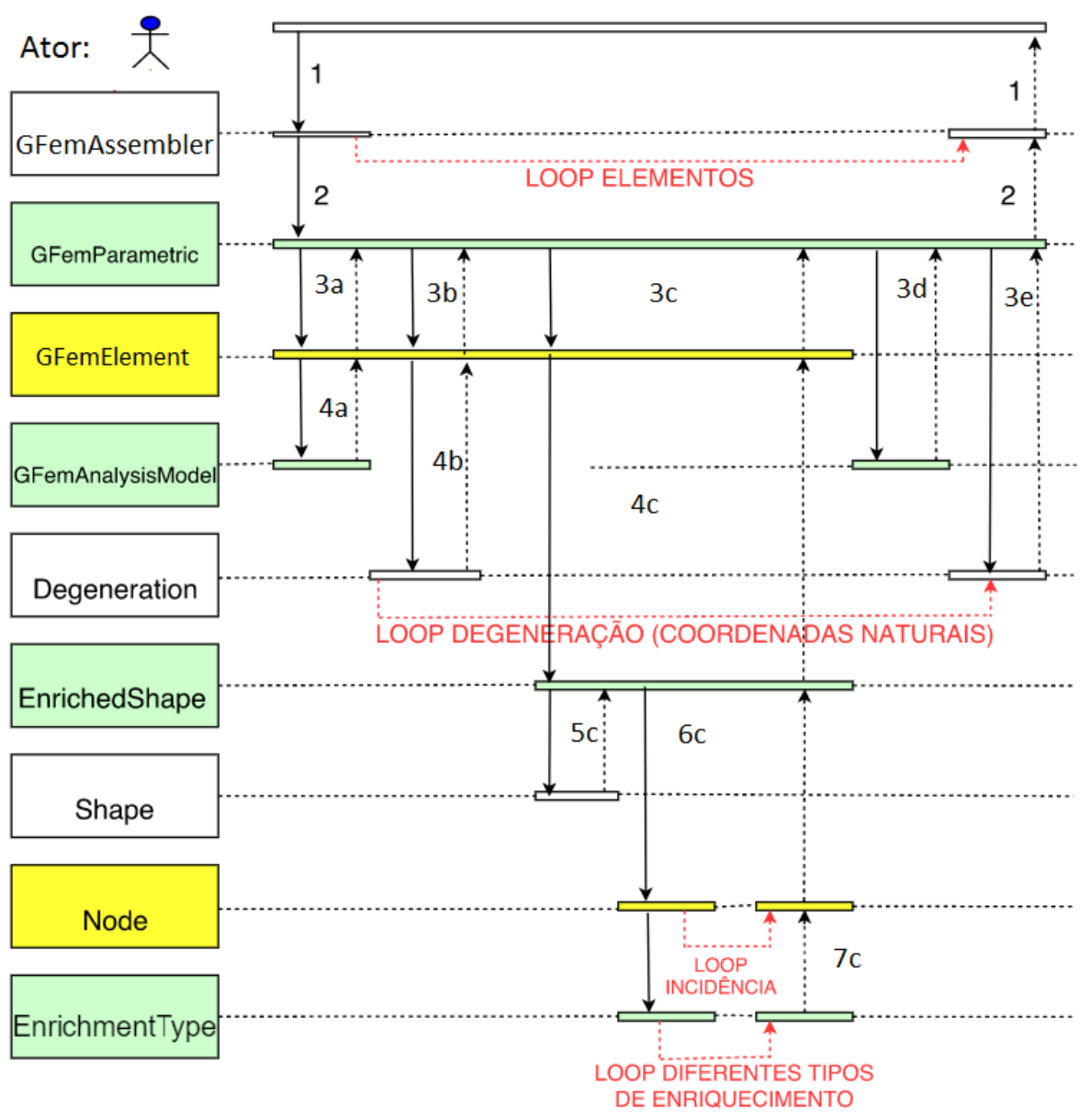

Figura 3.2: Diagrama de Montagem de Matriz de Rigidez no INSANE (Adaptada) (Alves, 2012).

$\boldsymbol{7 c}$ - Consultar cada tipo de enriquecimento e retornar a função de enriquecimento.

$3 \boldsymbol{d}$ - Fornecer função de forma e derivadas e retornar matriz B, fator de integração e Jacobiano da transformação.

$3 \boldsymbol{e}$ - Consultar degeneração e retornar função peso.

Ainda na Figura 3.2 as classes ilustradas, não mencionadas no texto até este momento, são descritas de forma simplificada a seguir (Alves, 2012):

Degeneration - Representa os pontos de integração e propriedades geométricas.

Shape - Representa a função de forma do elemento.

Node - Representa a entidade nó e as informações discretas associadas a ele. 
GFemElement - Representa o elemento finito.

GFemAnalysisModel - Representa o modelo de análise do elemento.

GFemParametric - Responsável pelas informações dos elementos paramétricos.

A Figura 3.3 apresenta, de forma concisa, como se constrói a montagem da matriz de rigidez dentro da classe GFemParametric no caso do enriquecimento via estratégia Global-Local, para a terceira etapa da técnica, problema Global enriquecido. Nas outras duas etapas, o procedimento é o mesmo mostrado na Figura 3.2. Os números apresentados na Figura 3.3 representam:

1 - Montar/Retornar a Matriz de rigidez para o modelo.

2 - Montar/Retornar a Matriz de rigidez para cada elemento.

3 - Consultar/Retornar função de forma e derivadas.

4 - Consultar/Retornar cada tipo de enriquecimento.

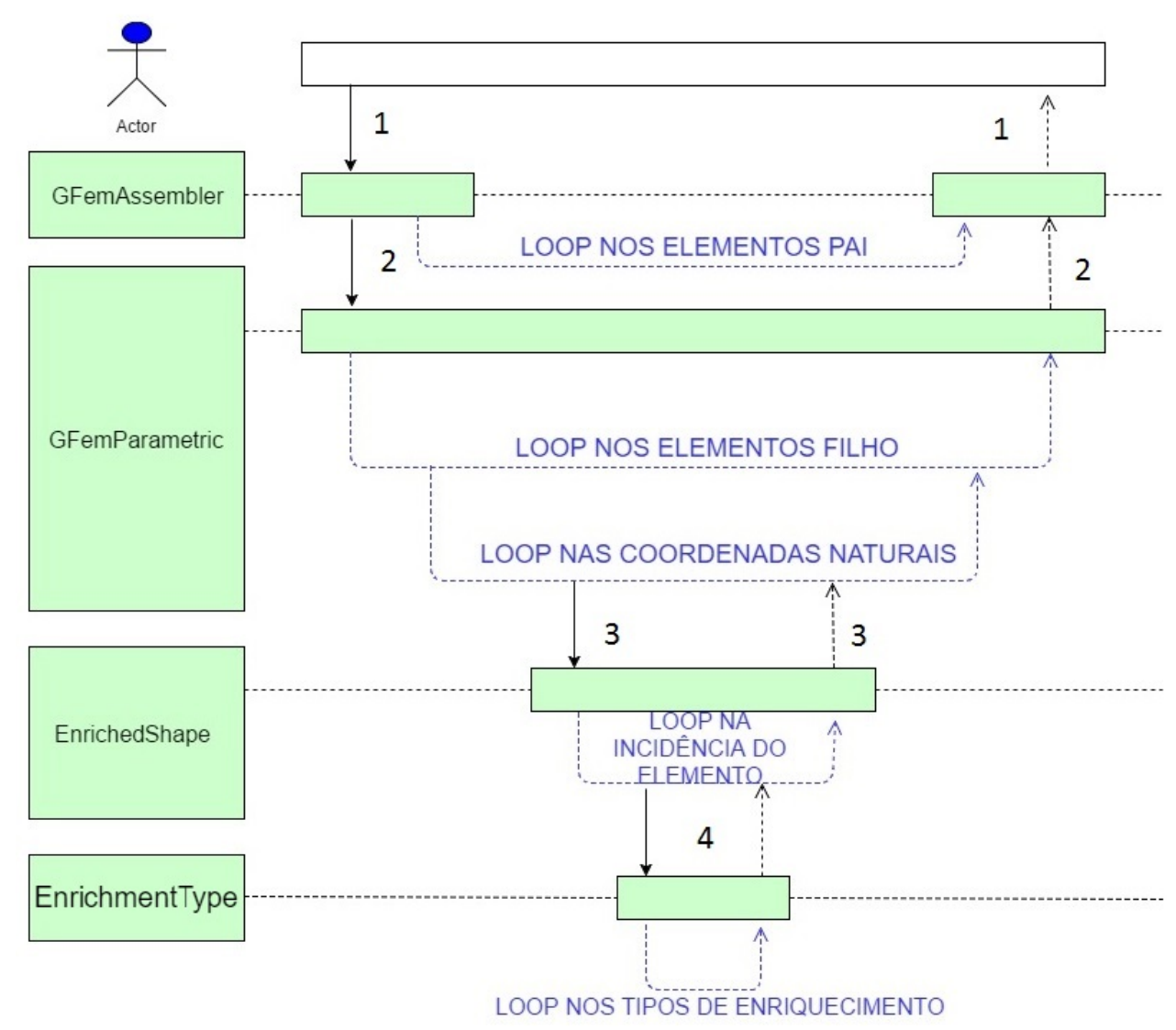

Figura 3.3: Diagrama de Montagem de Matriz de Rigidez na Classe GFemParametric, usando a técnica Global-Local (Adaptada) (Alves, 2012). 


\subsection{Ampliação do Sistema INSANE}

A ampliação do Sistema INSANE para abranger a possibilidade de utilização do enriquecimento da aproximação via funções com derivadas singulares e via técnica Global-Local, para problemas tridimensionais, será dividida em três grupos nesse texto. O primeiro diz respeito a uma ampliação operacional, que possibilita múltiplos enriquecimentos nodais, a segunda trata da implementação das funções de singularidade que descrevem o comportamento da solução na vizinhança da frente de uma trinca e a terceira da utilização da técnica Global-Local no MEFG. Todas essas abordagens não são dissociadas, e podem ser até mesmo utilizadas de maneira integrada na resolução de modelos estruturais. A fim de facilitar o entendimento, uma seção adicional introdutória mostrará as principais classes a serem alteradas, bem como o seu funcionamento.

\subsubsection{Visão Geral das Classes a serem Alteradas}

A primeira implementação está associada à classe EnrichedShape. Conforme citado na Seção 3.1, essa classe é a responsável pela construção das funções de forma associadas aos nós no MEFG. A Figura 3.4 mostra o diagrama da classe EnrichedShape com os principais métodos necessários ao funcionamento do enriquecimento das funções de forma, que foram ampliados para modelos tridimensionais.

O método "getShapeFunction" calcula, para o elemento passado como parâmetro, em um determinado ponto (ponto de Gauss no caso da construção da matriz de rigidez, por exemplo), a função de forma associada aos nós desse elemento. É realizado um laço sobre os nós da incidência do elemento, calculada as funções de PU associadas a cada um desses nós e, em seguida, procede-se com um novo laço pelos tipos de enriquecimento que cada nó possui a fim de, através deles, construir as funções de forma enriquecidas, adicionando-as às funções de PU. Semelhantemente funciona o método "getDerivedShapeFunction", com a diferença que agora são calculadas as derivadas das funções de forma. 


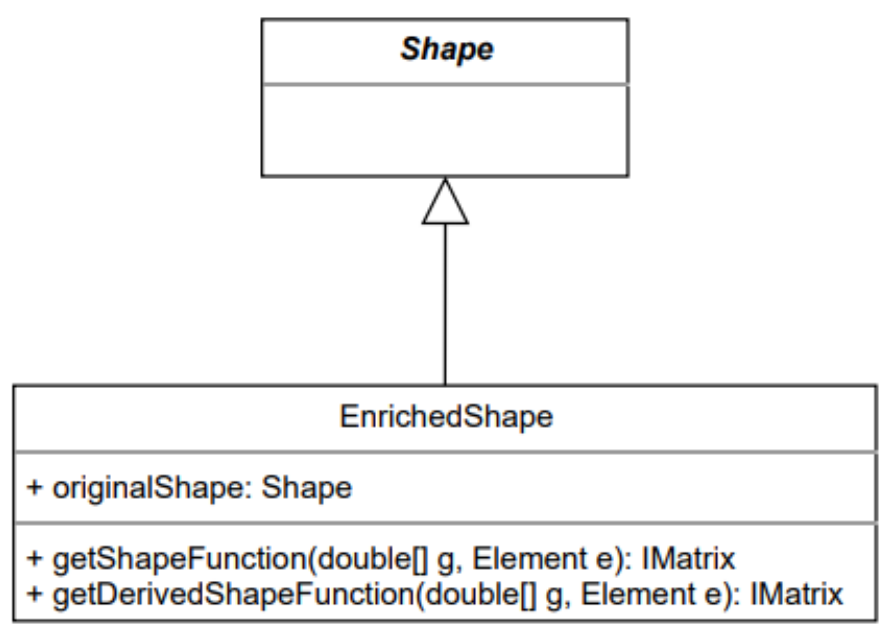

Figura 3.4: Diagrama da Classe EnrichedShape.

A segunda intervenção concentra-se na classe abstrata EnrichmentType responsável, conforme citado na Seção 3.1, por guardar as principais informações necessárias ao enriquecimento das funções de forma e suas derivadas via MEFG. Como existem vários tipos de enriquecimentos diferentes possíveis de serem utilizados, diversas são as classes que estendem de EnrichmentType, esse trabalho concentra-se nas classes CrackEnrichmentModeI, CrackEnrichmentModeII e GlobalLocalEnrichment, sendo que esta última diz respeito a terceira fase de implementação. A Figura 3.5 mostra o diagrama das classes mencionadas, bem como os principais métodos necessários ao seu funcionamento.

A Classe CrackEnrichmentModeI possibilita o enriquecimento das funções de forma dos nós através de funções que contêm singularidade e descrevem o comportamento na vizinhança da ponta de uma trinca trabalhando em Modo I de abertura. Para tanto, no método "getEnrichmentMultipliers" estão implementadas as Equações (2.7) e 2.9), para $j=1$ e nos métodos "getXDerivedEnrichmentMultipliers" e "getYDerivedEnrichmentMultipliers" as derivadas dessas equações.

De maneira semelhante, a Classe CrackEnrichmentModeII possibilita o enriquecimento das funções de forma dos nós através de funções que contêm singularidade e descrevem o comportamento na vizinhança da ponta de uma trinca trabalhando 


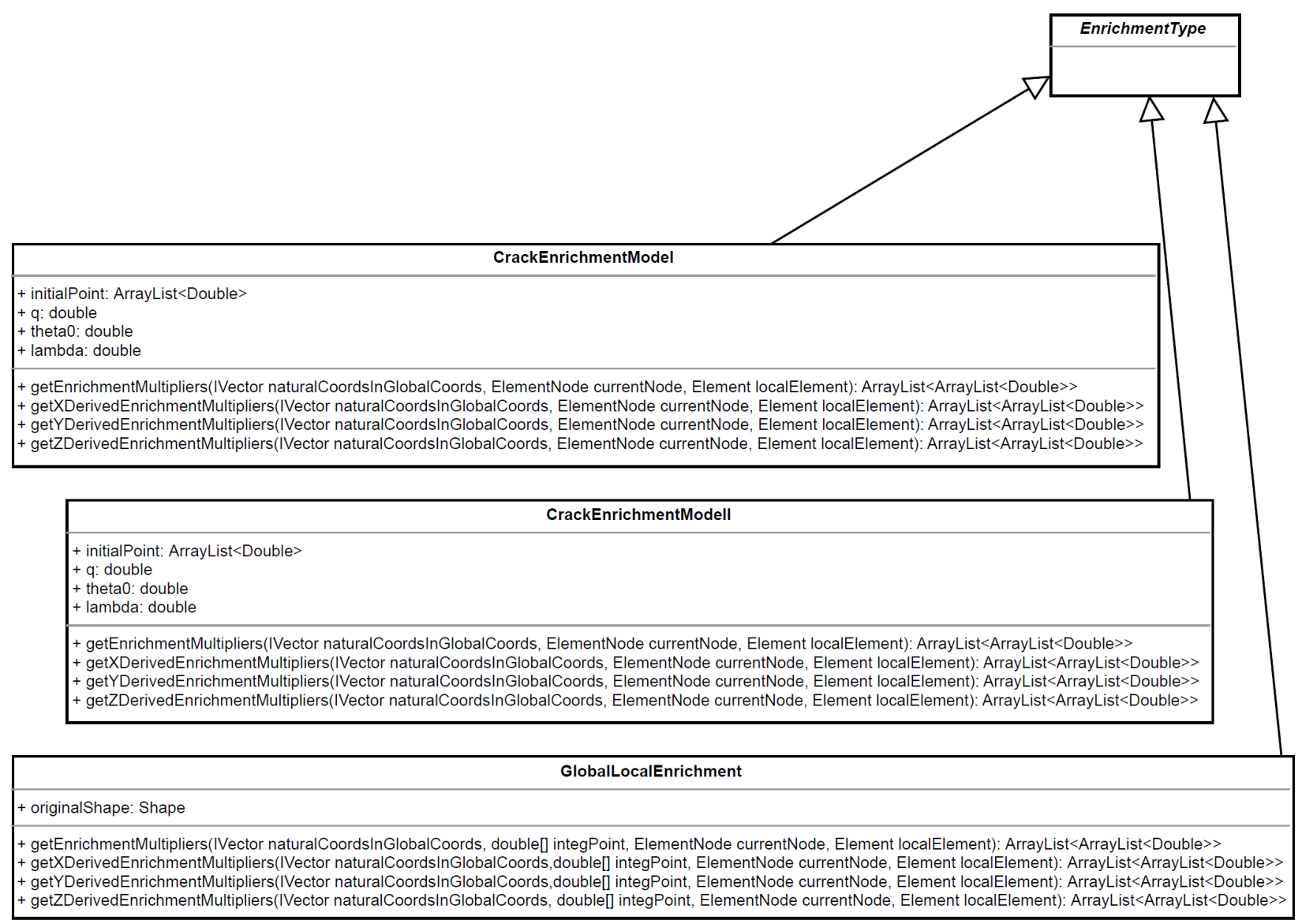

Figura 3.5: Diagrama da Classe EnrichmentType.

em Modo II de abertura. Para tanto, no método "getEnrichmentMultipliers" estão implementadas as Equações (2.8) e 2.10), para $j=1$ e nos métodos "getXDerivedEnrichmentMultipliers" e "getYDerivedEnrichmentMultipliers" as derivadas dessas equações.

A terceira e última etapa de implementação, refere-se a técnica Global-Local. A construção da matriz de rigidez e do vetor de forças nodais equivalentes acontecem conforme fluxo demonstrado na Figura 3.3. Alguns detalhes desse fluxo merecem ser ressaltados, pois são fundamentais para a generalização tridimensional.

A Classe GFemAssembler, cujo diagrama de Classes está representado na Figura 3.6. possui dois métodos importantes, pois são os responsáveis pela construção da matriz de rigidez do modelo e pela construção do vetor de forças nodais equivalentes, são eles, respectivamente, "getCuu" e "getEp". 


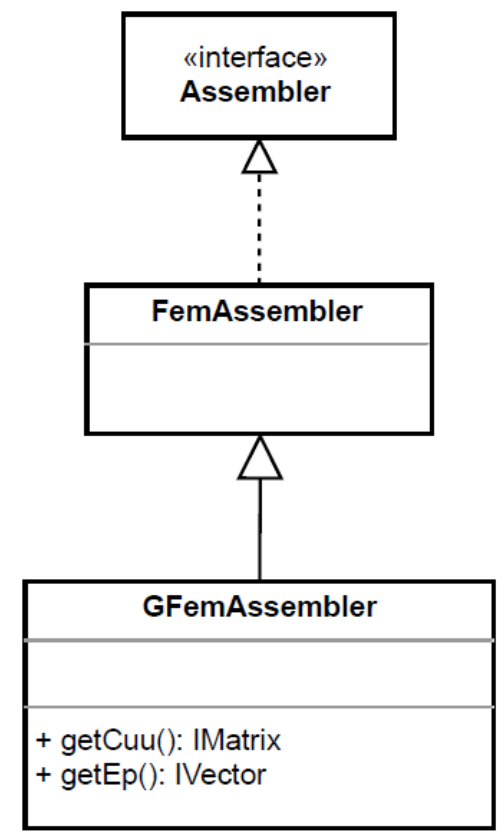

Figura 3.6: Diagrama da Classe GFemAssembler.

O método "getCuu" pode ser dividido em três parcelas que compõem a rigidez total do modelo. A primeira compreende a contribuição de rigidez do próprio elemento, tendo o seu cálculo semelhante ao do MEFG. A segunda diz respeito a contribuição de rigidez que algum nó possa apresentar. Já a terceira, e mais importante para a implementação do Global-Local 3D, diz respeito a parcela de rigidez que é agregada devido ao método da penalidade descrito na Seção 2.4 e equacionado na Seção 2.5.

O método "getEp" pode ser dividido em duas parcelas que compõem o vetor de forças nodais equivalentes totais do modelo. A primeira compreende a contribuição de forças nodais equivalentes do próprio elemento de acordo com as cargas nele aplicadas, tendo o seu cálculo semelhante ao do MEFG. Já a segunda, e mais importante para a implementação do Global-Local 3D, diz respeito a parcela de força nodal equivalente que é agregada devido ao método da penalidade descrito na Seção 2.4 e equacionado na Seção 2.5 .

Os dois métodos da Classe GFemAssembler, aqui descritos, precisam, em seu funcionamento, de métodos da Classe GFemParametric, para, dentre outras coisas, construir a parcela do vetor de forças nodais equivalentes e da matriz de rigidez 
referente ao método da penalidade. O diagrama da Classe GFemParametric está representando na Figura 3.7 bem como os métodos acionados no cumprimento das tarefas descritas anteriormente.

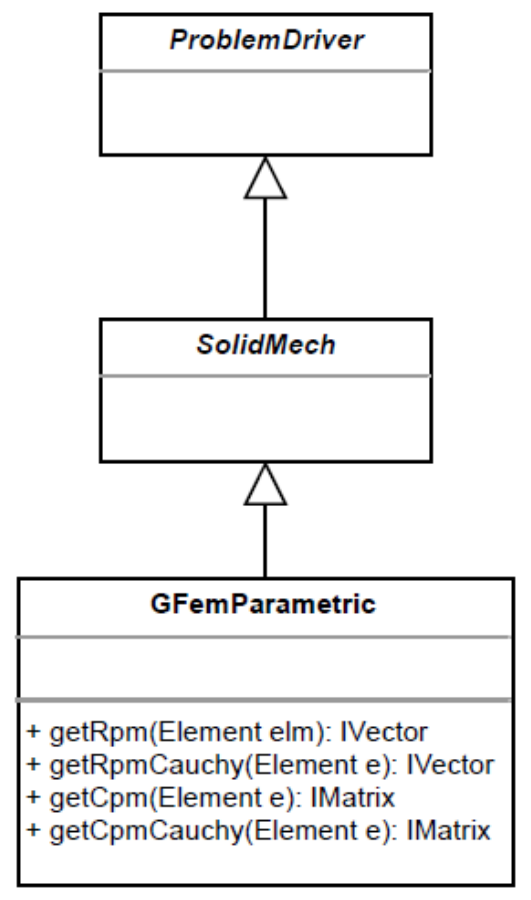

Figura 3.7: Diagrama da Classe GFemParametric.

O método "getRpm", usado quando apenas as condições de Dirichlet são consideradas, adiciona ao vetor de forças nodais equivalentes termos associados ao parâmetro de penalidade. Esses termos são oriundos das parcelas de deslocamentos prescritos e deslocamentos transferidos da imposição das condições de contorno da técnica Global-Local. Eles compõem a Equação 2.27), através das seguintes parcelas mostradas na equação:

$$
\eta \int_{\partial \Omega_{L} \cap \partial \Omega_{G}^{u}} \overline{\boldsymbol{u}} \cdot \boldsymbol{v}_{L} d S+\kappa \int_{\partial \Omega_{L} \backslash\left(\partial \Omega_{L} \cap \partial \Omega_{G}\right)} \tilde{\boldsymbol{u}}_{G}^{0} \cdot \boldsymbol{v}_{L} d S
$$

onde $\kappa=\eta$.

O mesmo acontece com o método correlato, "getRpmCauchy", que permite a aplicação das condições de Cauchy ou de Neumman. Neste método, os deslocamentos transferidos são penalizados pelo parâmetro de Cauchy $\kappa \neq \eta$ e, também, existe o 
termo oriundo das forças prescritas. Todos esses termos compõem a Equação 2.27), através das seguintes parcelas mostradas na equação:

$$
\eta \int_{\partial \Omega_{L} \cap \partial \Omega_{G}^{u}} \overline{\boldsymbol{u}} \cdot \boldsymbol{v}_{L} d S+\int_{\partial \Omega_{L} \backslash\left(\partial \Omega_{L} \cap \partial \Omega_{G}\right)}\left(\boldsymbol{t}\left(\tilde{\boldsymbol{u}}_{G}^{0}\right)+\kappa \tilde{\boldsymbol{u}}_{G}^{0}\right) \cdot \boldsymbol{v}_{L} d S
$$

onde $\kappa \neq \eta$.

O método "getCpm" é empregado no caso em que apenas as condições de Dirichlet são aplicadas e adiciona à matriz de rigidez termos associados ao parâmetro de penalidade. Esses termos são oriundos das parcelas de deslocamentos prescritos e deslocamentos transferidos da imposição das condições de contorno da técnica Global-Local. Eles compõem a Equação (2.27), através das seguintes parcelas mostradas na equação:

$$
\eta \int_{\partial \Omega_{L} \cap \partial \Omega_{G}^{u}} \tilde{\boldsymbol{u}}_{L} \cdot \boldsymbol{v}_{L} d S+\kappa \int_{\partial \Omega_{L} \backslash\left(\partial \Omega_{L} \cap \partial \Omega_{G}\right)} \tilde{\boldsymbol{u}}_{L} \cdot \boldsymbol{v}_{L} d S
$$

onde $\kappa=\eta$.

O mesmo acontece com o método correlato, "getCpmCauchy", que é usado no caso da aplicação das condições de Neumman ou Cauchy. Para isso, a mesma Equação (3.6) é empregada, fazendo-se $\kappa \neq \eta$. Ele compõe a Equação (2.27), através das parcelas mostradas na Equação $(3.6) \operatorname{com} \kappa \neq \eta$.

A Classe EquivalentNodalGeneralValue é responsável por montar os termos de rigidez e de força nodal equivalente relacionados ao método da penalidade e a imposição das condições de contorno via Técnica Global-Local. A Figura 3.8 mostra os métodos dessa classe que realizam essas tarefas.

Os métodos da Classe EquivalentNodalGeneralValue e suas atribuições são:

- getGFemEquivalentNodalValueFromElement - Responsável pela montagem do vetor de forças nodais equivalentes oriundo da transferência das condições de contorno de Dirichlet do problema Global para o Local.

- getCauchyIntegral - Responsável pela montagem do vetor de forças nodais 


\begin{tabular}{|l|}
\hline \multicolumn{1}{|c|}{ EquivalentNodalGeneralValue } \\
\hline + element: Element \\
\hline + getGFemEquivalentNodalValuesFromElement(): IVector \\
+ getCauchylntegral(): IVector \\
+ getStiffnessMatrixPMFromElement(): IMatrix \\
+ getStiffnessMatrixCauchy(): IMatrix
\end{tabular}

Figura 3.8: Diagrama da Classe EquivalentNodalGeneralValue.

equivalentes oriundo da transferência das condições de contorno de Cauchy do problema Global para o Local.

- getStiffnessMatrixPMFromElement - Responsável pela montagem da Matriz de Rigidez oriunda da transferência das condições de contorno de Dirichlet do problema Global para o Local.

- getStiffnessMatrixCauchy - Responsável pela montagem da Matriz de Rigidez oriunda da transferência das condições de contorno de Cauchy do problema Global para o Local.

Por fim, a Classe GlobalLocalEnrichment possibilita o enriquecimento das funções de forma através da utilização dos deslocamentos do modelo Local como forma de enriquecimento do modelo Global, nos nós desejados. Para tanto, o método "getEnrichmentMultipliers" calcula o multiplicador, ou seja, a função de enriquecimento a ser calculada no ponto em que a função de forma é construída e que irá multiplicar a PU neste mesmo ponto, que irá enriquecer a função de forma e os métodos "getXDerivedEnrichmentMultipliers" e "getYDerivedEnrichmentMultipliers" os multiplicadores que enriquecem as suas derivadas.

\subsubsection{Generalização da Construção das Funções de Forma Enriquecidas}

Um mesmo nó pode ser submetido a diversos tipos de enriquecimento, podendo, ao mesmo tempo ser enriquecido polinomialmente, com funções de trinca e com 
a técnica Global-Local, por exemplo. Para tanto, foi preciso generalizar a Classe EnrichedShape, para que a mesma contemple essa funcionalidade para modelos tridimensionais.

Conforme diagrama da Classe EnrichedShape apresentado na Figura 3.4, os métodos "getShapeFunction" e "getDerivedShapeFunction" agora percorrem um laço por todos os tipos de enriquecimentos associados a cada nó da incidência do elemento argumento da classe, e calcula as funções enriquecedoras, adicionando-as em uma lista a fim de construir todas as funções de forma e suas derivadas enriquecidas, respectivamente, tudo isso nas três dimensões, " $x$ ", " $y$ " e " $z$ ".

\subsubsection{Generalização das Funções Representativas do Com- portamento na Vizinhança da Frente de uma Trinca}

O sistema INSANE já possuía implementado duas classes responsáveis por fazer o enriquecimento das funções de forma através de funções que contém singularidades que descrevem uma trinca, são elas CrackEnrichmentModeI e CrackEnrichmentModeII, já discutidas na Seção 3.2.1. Porém, tais classes somente eram capazes de enriquecer nós de modelos em duas dimensões. Nesse trabalho, optou-se por ampliar essas classes possibilitando um tratamento mais genérico, compreendendo adicionalmente, modelos tridimensionais.

Conforme apresentado na Figura 3.5, a classe CrackEnrichmentModeI estende da classe EnrichmentType e é responsável por guardar as informações referentes as funções que contém singularidades que descrevem uma trinca trabalhando no Modo I. Ela foi estendida para contemplar a descrição de trincas tridimensionais através da combinação com o Modo III de abertura, conforme proposto por Duarte et al. (2000). Assim, a Equação 2.17 para $j=1$ foi implementada no método "getEnrichmentMultipliers" e suas derivadas em relação as três dimensões foram acrescentadas 
ao método "getZDerivedEnrichmentMultipliers". Por sua vez, "getXDerivedEnrichmentMultipliers" e "getYDerivedEnrichmentMultipliers", houve a ampliação da parcela de derivação das funções em relação a " $z$ "'. Ainda conforme apresentado na Figura 3.5, a ampliação da classe CrackEnrichmentModeII segue as mesmas diretrizes da realizada na classe CrackEnrichmentModeI, com a diferença que ela é responsável por guardar as informações referentes as funções que contém singularidades que descrevem uma trinca trabalhando no Modo II e, portanto, a Equação (2.17) para j=2 foi implementada no método "getEnrichmentMultipliers" e suas derivadas em relação as três dimensões foram acrescentadas ao método "getZDerivedEnrichmentMultipliers".

É importante ressaltar que não há uma classe específica para o enriquecimento com funções que contém singularidades que descrevem uma trinca trabalhando em Modo III, devido à forma como o INSANE foi concebido, sendo estritamente necessário que o enriquecimento se dê nas três direções, ainda que com coeficientes diferentes. Desta forma fazem-se necessárias as combinações descritas anteriormente, culminando em apenas duas classes de enriquecimento. O INSANE foi desenvolvido de maneira que todos os processos, como por exemplo, construção da matriz de rigidez, vetor de forças prescritas, ou outros, dependem, direta ou diretamente, da dimensão do problema, logo, para um modelo tridimensional sempre se espera como retorno enriquecimentos com posições múltiplas de três, não sendo possível assim, construir uma função que enriqueça apenas a direção " $z$ ", no estágio atual do sistema. Além disso, as funções referentes ao Modo III de abertura de trinca, conforme Duarte et al. (2000), somente tem parcela não nula referente ao deslocamento no sentido da abertura deste modo, tal como mostrado na Equação (2.6). A inclusão destas funções como um enriquecimento separado dos outros modos e daqueles, sem a inclusão destas parcelas, implicaria em se ter a PU multiplicada por zeros, criando termos nulos na diagonal principal da matriz de rigidez. 


\subsubsection{MEFG com Técnica Global-Local - Tridimensional}

Outra ampliação realizada no sistema INSANE se refere a possibilidade de utilização da técnica Global-Local em modelos tridimensionais. Algumas alterações e acréscimos foram implementados para viabilizar essa funcionalidade. No texto que se segue essas modificações são registradas bem como as classes afetadas.

A solução do problema Global inicial segue da mesma maneira que a proposta por Alves (2012), uma vez que se trata de um problema a ser analisado via MEFG convencional. Nessa primeira etapa do processamento do Global-Local nenhuma modificação foi realizada no sistema INSANE.

A solução do problema Local precisou passar por modificações, para se adequar à análise tridimensional, no que diz respeito à transmissão das condições de contorno do problema global inicial para o problema local. No presente caso, as condições de contorno estão aplicadas em uma superfície e, por esse motivo, a integração numérica, para possibilitar a transferência das mesmas via método da penalidade, é feita na área, conforme Equações (3.4), (3.5) e (3.6).

Conforme mencionado na Seção 3.2.1, a classe responsável pela montagem da parcela do vetor de forças nodais equivalentes e pela montagem da parcela, associada ao método da penalidade, da matriz de rigidez originárias das condições de contorno do problema Global é a EquivalentNodalGeneralValue. Ela foi ampliada para ser capaz de abranger problemas tridimensionais através da modificação dos seguintes métodos, seguindo as mesmas diretrizes apresentadas por Alves (2012):

- getGFemEquivalentNodalValueFromElement - Cumpre a mesma função descrita na Seção 3.2.1, mas agora, em cada face do elemento tridimensional, para cada ponto de Gauss, calcula a contribuição para o vetor de forças nodais equivalentes referente a transferência dos deslocamentos do problema Global para o Local.

- getCauchyIntegral - Cumpre a mesma função descrita na Seção 3.2.1, mas 
agora, em cada face do elemento tridimensional, para cada ponto de Gauss, calcula a contribuição para o vetor de forças nodais equivalentes referente a transferência dos deslocamentos e da tensão de tração (relativa a um vetor perpendicular a face de cálculo) do problema Global para o Local.

- getStiffnessMatrixPMFromElement - Cumpre a mesma função descrita na Seção 3.2.1. mas agora, em cada face do elemento tridimensional, para cada ponto de Gauss, calcula a contribuição para a matriz de rigidez referente a transferência dos deslocamentos do problema Global para o Local.

- getStiffnessMatrixCauchy - Cumpre a mesma função descrita na Seção 3.2.1. mas agora, em cada face do elemento tridimensional, para cada ponto de Gauss, calcula a contribuição para a matriz de rigidez referente a transferência dos deslocamentos e da tensão do problema Global para o Local.

A implementação anteriormente descrita foi feita para elementos hexaédricos de oito nós. Por padronização, no arquivo de entrada, sempre que se deseja que sejam impostas condições de contorno de Dirichlet utiliza-se o código "3", já quando se deseja condições de contorno de Cauchy utiliza-se o código "5", se nenhuma condição de contorno é imposta utiliza-se o código "0". Além disso, também é padronizado no INSANE a ordem em que os nós devem ser descritos no arquivo de entrada para compor a incidência de cada um dos elementos hexaédricos, a Figura 3.9 mostra essa ordem através dos números circulados. A partir da incidência dos nós no elemento, adotou-se nesse trabalho uma convenção em que a ordem das faces que se deve descrever na lista de condições de contorno, por elemento, no arquivo de entrada encontra-se, também, na Figura 3.9, sendo esta ordem representada pelos números não circulados. O Apêndice $\mathrm{A}$ mostra um exemplo de entrada de dados do sistema INSANE, no qual pode ser visualizada as condições de contorno impostas aos elementos locais de acordo com o descrito.

A solução do problema Global Enriquecido demanda que o sistema seja capaz de 

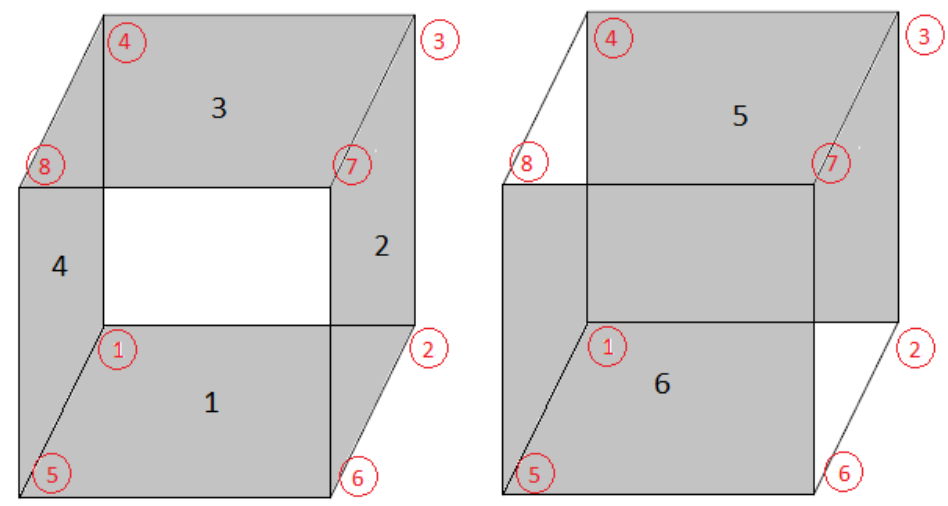

Figura 3.9: Ordem das condições de contorno no arquivo de entrada de acordo com as faces do elemento hexaédrico.

fazer o enriquecimento via técnica Global-Local, nos nós discriminados no arquivo de entrada, nas três direções, a saber, " $x$ ", " $y$ " e " $z$ ". Modificou-se então a classe EnrichedShape, que ao fazer a busca pelo tipo de enriquecimento que determinado nó possui, se ele possuir o enriquecimento do tipo Global-Local, este agora está habilitado a ser aplicado nas três direções dos eixos cartesianos, tanto para as funções de forma quanto para as suas derivadas.

Adicionalmente, a classe GlobalLocalEnrichment também foi modificada, já que agora ele retorna os multiplicadores e as derivadas dos multiplicadores, necessários aos enriquecimentos das funções de forma dos nós, também em três dimensões. Assim, os métodos "getEnrichmentMultipliers", "getXDerivedEnrichmentMultipliers" e "getYDerivedEnrichmentMultipliers" foram alterados para retornarem os multiplicadores e as derivadas em relação a " $x$ " e a " $y$ " nas três direções, respectivamente. E, também, a classe "getZDerivedEnrichmentMultipliers" foi criada para retornar as derivadas em relação a " $z$ " nas três direções. Sendo que o cálculo dos métodos aqui descritos, seguiu as mesmas diretrizes do exposto na Seção 3.2.1. 


\section{Capítulo 4}

\section{Análise de Modelos Estruturais via MEFG e Técnica Global-Local}

\subsection{Problemas Abordados}

Com a finalidade de validar as implementações no sistema INSANE, discutidas na Seção 3.2, dois problemas tridimensionais foram sugeridos. Trata-se de dois blocos idênticos, que diferem apenas da trinca que cada um contém. O primeiro problema foi nomeado "P1" e o segundo "P2", as Figuras 4.1 e 4.2 os ilustram, respectivamente.

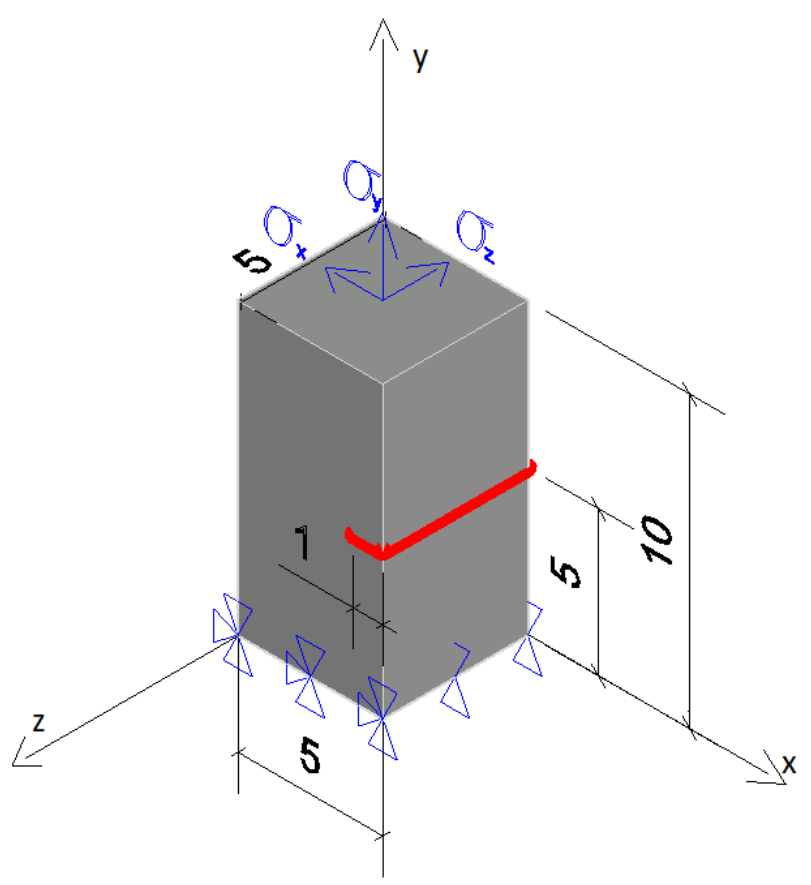

Figura 4.1: Problema Abordado - P1. 


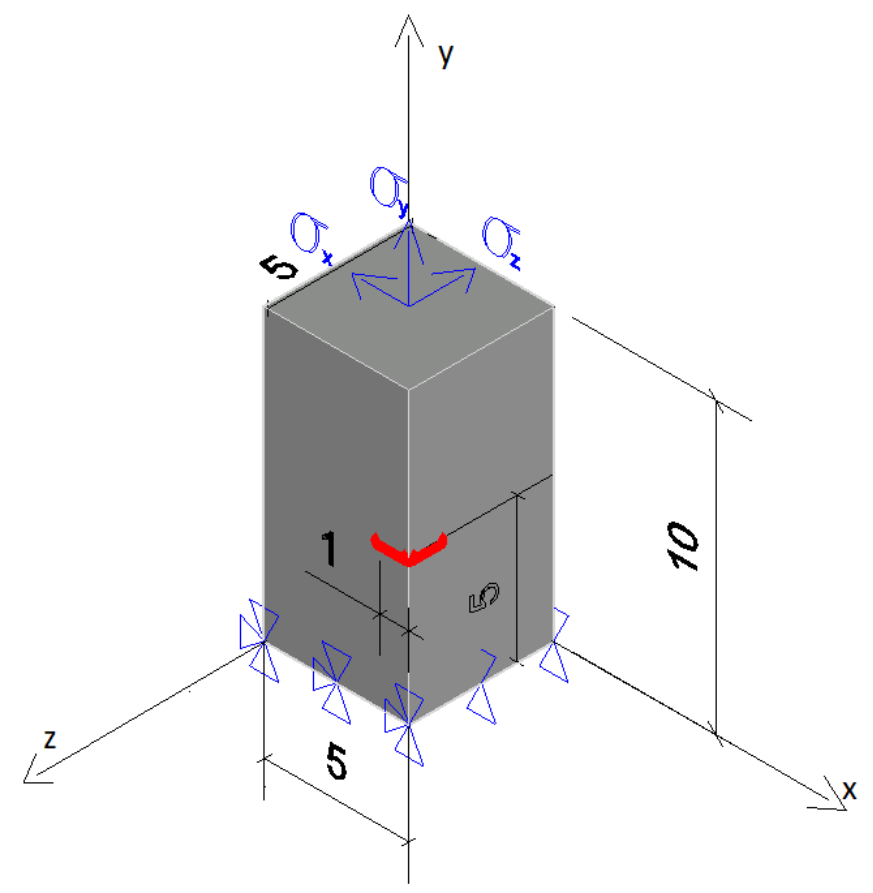

Figura 4.2: Problema Abordado - P2.

Na Figura 4.1, considera-se um bloco de dimensões (10.00 x 5.00 x 5.00) unidades consistentes (u.c.), com uma pré-trinca de dimensões (1.00 x 5.00) u.c.. Ele está completamente restringido na face inferior, tendo, portanto, todos os deslocamentos nesta face impedidos. O material possui módulo de elasticidade $(E)$ igual a 1000 u.c. e módulo de Poisson $(\nu)$ igual a 0.3 . Mostra-se, ainda, os eixos cartesianos, " $x$ ", " $y$ " e " $z$ " adotados, cuja origem encontra-se na face inferior do bloco, no canto anterior esquerdo. Seguindo essa convenção serão abordadas três situações de solicitação na face superior do bloco, uma com a aplicação de tensão de 1 u.c. no sentido negativo de " $x$ " (-1 u.c.), aqui denominada "Cisalhamento em x", outro com a aplicação de tensão de 1 u.c. no sentido positivo de "y" (1 u.c.), aqui denominada "Tração em y", e a última com aplicação de tensão de 1 u.c. no sentido negativo de " $z$ " (-1 u.c.), aqui denominada "Cisalhamento em z".

$\mathrm{Na}$ Figura 4.2, considera-se um bloco com as mesmas dimensões e o mesmo material do utilizado no problema P1, com uma pré-trinca de dimensões (1.00 x 1.00) u.c.. Ele está completamente restringido na face inferior, tendo, portanto, todos os 
deslocamentos nesta face impedidos. Mostra-se, ainda, os eixos cartesianos, " $x$ ", " $y$ " $\mathrm{e}$ " $z$ " adotados, cuja origem encontra-se na face inferior do bloco, no canto anterior esquerdo. Seguindo essa convenção serão abordadas três situações de solicitação na face superior do bloco, uma com a aplicação de tensão de 1 u.c. no sentido negativo de " $x$ " (-1 u.c.), aqui denominada "Cisalhamento em x", outro com a aplicação de tensão de 1 u.c. no sentido positivo de "y" (1 u.c.), "Tração em y", e a última com aplicação de tensão de 1 u.c. no sentido negativo de " $z$ " (-1 u.c.), "Cisalhamento em Z".

A análise desses três tipos de solicitações distintas justifica-se pelo fato de que pretende-se representar a ocorrência dos três modos de abertura de trinca em cada uma das situações. Embora seja esperado que o Modo I de abertura de trinca se sobressaia sobre os outros em todas as situações, devido às dimensões do bloco e vinculação, representa-se com a solicitação em " $x$ " o Modo II de abertura de trinca, com a solicitação em " $y$ " o Modo I e com a solicitação em " $z$ " o Modo III.

Todos os dados apresentados ao longo desse capítulo estão em unidades consistentes (u.c.) e, da mesma forma, os resultados, sendo omitidas, então, as unidades ao longo do texto.

\subsection{Detalhes da Modelagem dos Problemas Abor- dados}

Como resultado de referência para os problemas P1 e P2, foi utilizado o software $A N S Y S^{\circledR}$, utilizando-se de uma malha bastante refinada.

Foram utilizados quatro tipos de malhas globais. A primeira, nomeada MG1, mostrada na Figura 4.3, contém 250 elementos finitos hexaédricos e os nós que demarcam a abertura da trinca estão duplicados. A superfície de trinca coincide com a face de alguns elementos da malha. A segunda, nomeada MG2, mostrada na Figura 4.4, contém os mesmos 250 elementos, sendo, pois, muito semelhante a MG1, tendo como única diferença o fato de que não há nós duplicados, e, portanto, 
nenhuma trinca é descrita nessa malha. A terceira, nomeada MG3, mostrada na Figura 4.5, contém 275 elementos e esta malha não possui nós duplicados, logo, não há descrição de trinca. A quarta, nomeada MG4, mostrada na Figura 4.6, contém 250 elementos finitos hexaédricos, sendo, pois, muito semelhante a MG1, tendo como única diferença o fato de que o nó que demarca a abertura da trinca está duplicado. A superfície de trinca coincide com a face de alguns elementos da malha. Apenas na MG1 e na MG4, a superfície de trinca é descrita geometricamente nas referidas malhas e coincide com as faces dos elementos. Nas outras duas malhas, MG2 e MG3, a descrição da trinca é realizada por meio das funções de enriquecimento, que podem ser as funções de trinca (Seção 2.3.2) ou aquelas obtidas da solução do problema local (Seção 2.5.2). Na MG2 a trinca tem coincidência com as faces dos elementos, já na MG3 a trinca corta o interior dos elementos.

Considerando o número de graus de liberdade (NGL), as malhas MG1, MG2, MG3 e MG4 possuem 1098, 1080, 1188 e 1083, respectivamente.

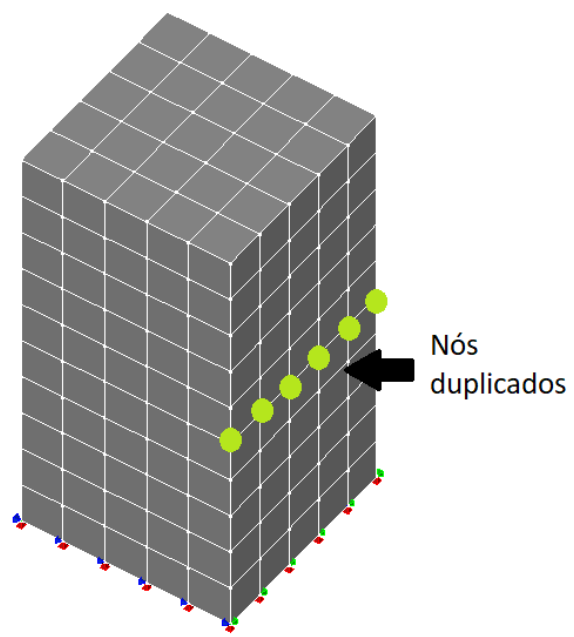

Figura 4.3: MG1 - Malha Global de 250 elementos com 6 nós que descrevem a trinca duplicados.

Com a MG1 e a MG4 foram construídos os modelos, neste trabalho denominados, sem enriquecimento, para P1 e P2, respectivamente. Tratam-se de modelos que 


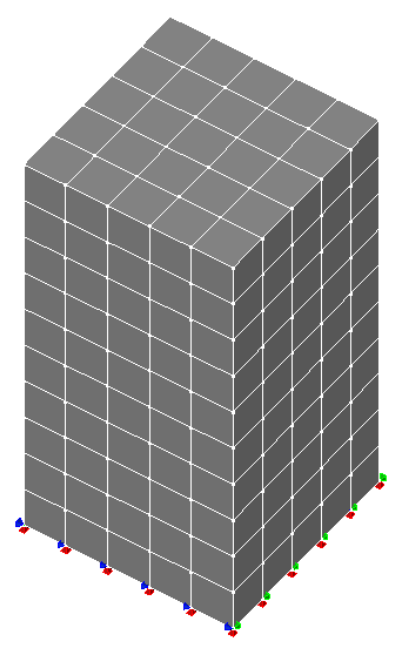

Figura 4.4: MG2 - Malha Global de 250 elementos sem nós duplicados.

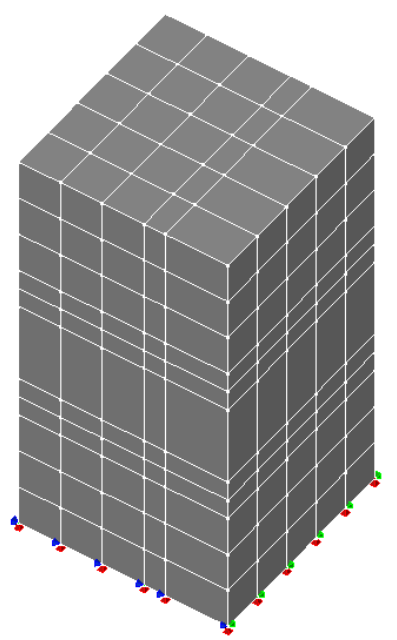

Figura 4.5: MG3 - Malha Global de 275 elementos sem nós duplicados.

apenas contêm a discretização geométrica da trinca, sem nenhum tipo de enriquecimento via funções com derivadas singulares ou oriundas da técnica Global-Local. Para cada um dos carregamentos mostrados nas Figuras 4.1 e 4.2 , para os problemas P1 e P2, respectivamente, foram obtidas as energias de deformação do modelo e nas seções pertinentes esses valores serão apresentados como comparativo para os modelos enriquecidos com funções com derivadas singulares e/ou com a técnica Global-Local.

Para os problemas que utilizam a técnica Global-Local, a posição e tamanho da 


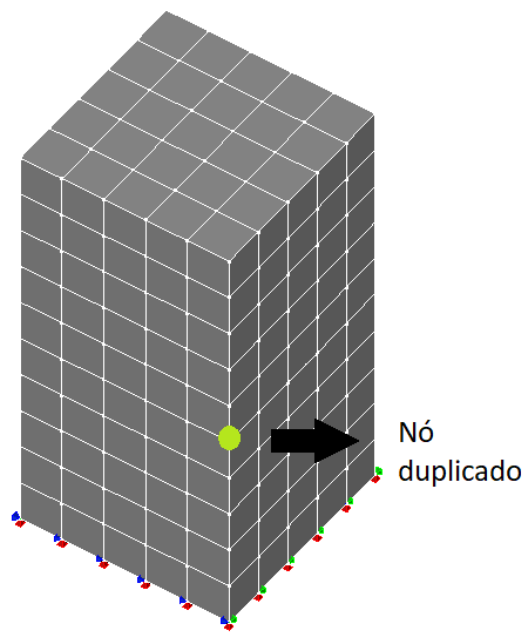

Figura 4.6: MG4 - Malha Global de 250 elementos com 1 nó que descreve a trinca duplicado.

malha local utilizada estão representados nas Figuras 4.7 e 4.8. Ambos os domínios locais têm tamanho de $(3.00 \times 4.00 \times 5.00)$ e se situam entre as coordenadas " $x " 2.00$ e 5.00, as coordenadas " $y$ " 3.00 e 7.00 e as coordenadas " $z$ " 0.00 e 5.00. A diferença entre as imagens aparece no fato que a Figura 4.7 trata do subdomínio Local que reside no domínio Global da Figura 4.4, já a Figura 4.8 trata do subdomínio Local que reside no domínio Global da Figura 4.5.

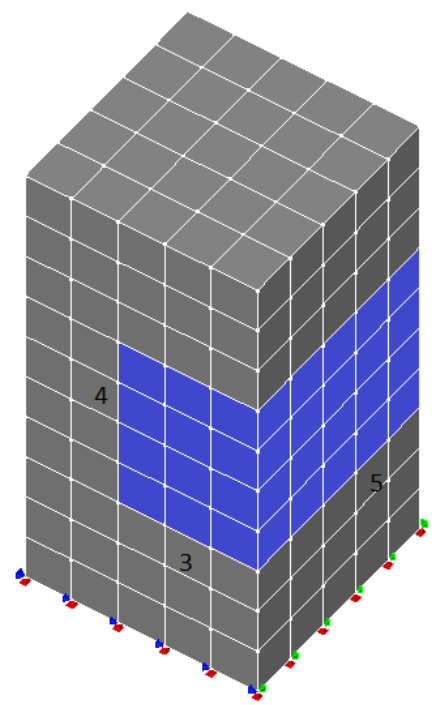

Figura 4.7: Ilustração, em azul, do subdomínio Local, imerso no domínio Global da Figura 4.4 . 


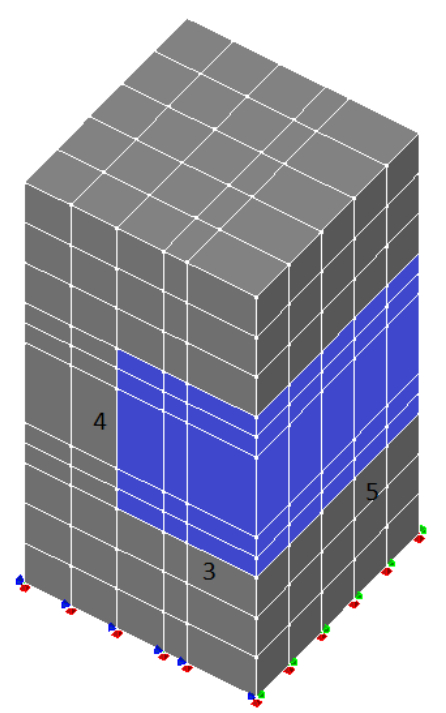

Figura 4.8: Ilustração, em azul, do subdomínio Local, imerso no domínio Global da Figura 4.5 .

Cinco tipos de malhas Locais foram utilizados, em situações diferentes, para discretizar o domínio Local. Essas malhas são ilustradas nas Figuras 4.9, 4.10, 4.11, 4.12 e 4.13 e representam, respectivamente, as malhas denominadas ML1, ML2, ML3, ML4 e ML5, sendo que cada uma delas contém, respectivamente, 480, 3840, 7500, 15360 e 24000 elementos locais.

Considerando o número de graus de liberdade (NGL), as malhas ML1, ML2, ML3, ML4 e ML5 possuem 2145, 14175, 26598, 52479 e 80703, respectivamente.

As malhas locais foram geradas a partir de um sistema desenvolvido utilizando o paradigma da POO, em linguagem de programação JAVA. Sua função é bastante simples, ele visa ler os nós e os elementos de uma malha gerada no software $A N S Y S^{\circledR}$ e transformar essas informações em parte do arquivo de entrada de dados INSANE, criando, assim, a malha de nós e elementos locais para o sistema INSANE. O Apêndice B mostra detalhes desse programa.

Foram realizadas duas iterações no procedimento da técnica Global-Local (conforme Seção 2.4), e apresentam-se nesse trabalho as resoluções da segunda iteração, pois somente até esta iteração, os resultados sofrem variações significativas. Na 


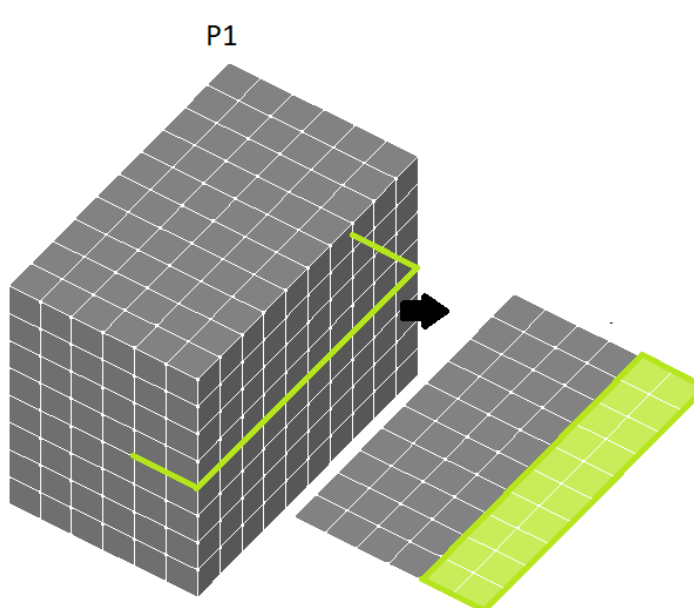

Nós compreendidos nessa face estão duplicados, excetuando-se aqueles coincidentes com a frente de trinca

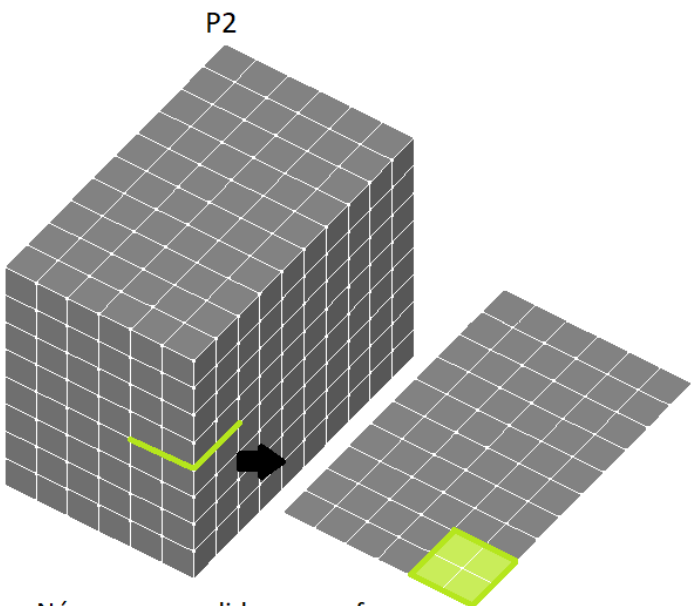

Nós compreendidos nessa face estão duplicados, excetuando-se aqueles coincidentes com a frente de trinca

Figura 4.9: ML1 - Elementos locais de dimensões (0.500 x 0.500 x 0.500).

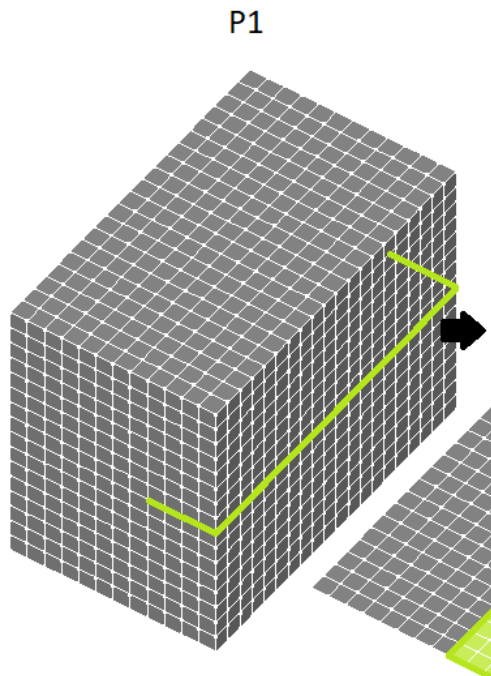

Nós compreendidos nessa face estão duplicados, excetuando-se aqueles coincidentes com a frente de trinca

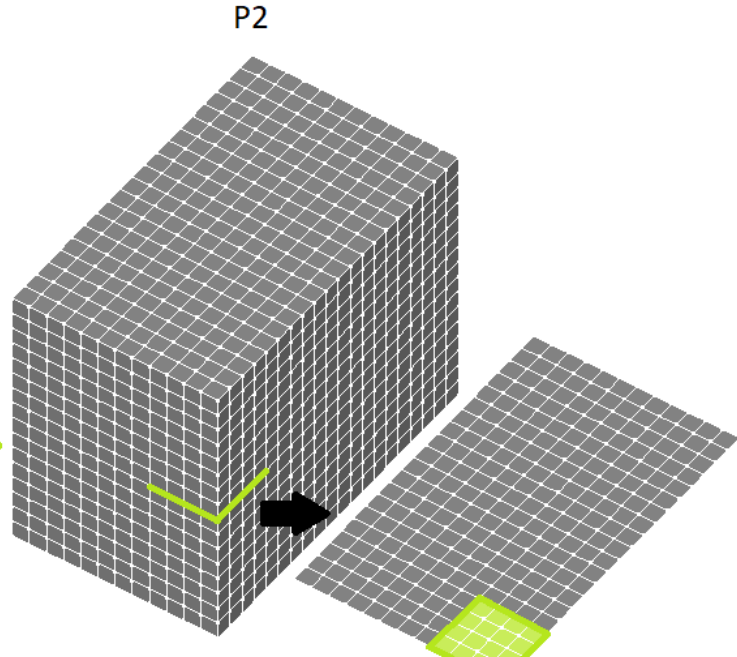

Nós compreendidos nessa face estão duplicados, excetuando-se aqueles coincidentes com a frente de trinca

Figura 4.10: ML2 - Elementos locais de dimensões (0.250 x 0.250 x 0.250).

Seção 4.3.3.5, será apresentada uma análise de sensibilidade a este respeito.

Ainda para os problemas analisados via técnica Global-Local, é importante ressaltar que foram transferidas condições de contorno de Dirichlet e o parâmetro de penalidade, $\eta$, utilizado foi de 1.25E10, calculado de acordo com a Equação (2.28). 

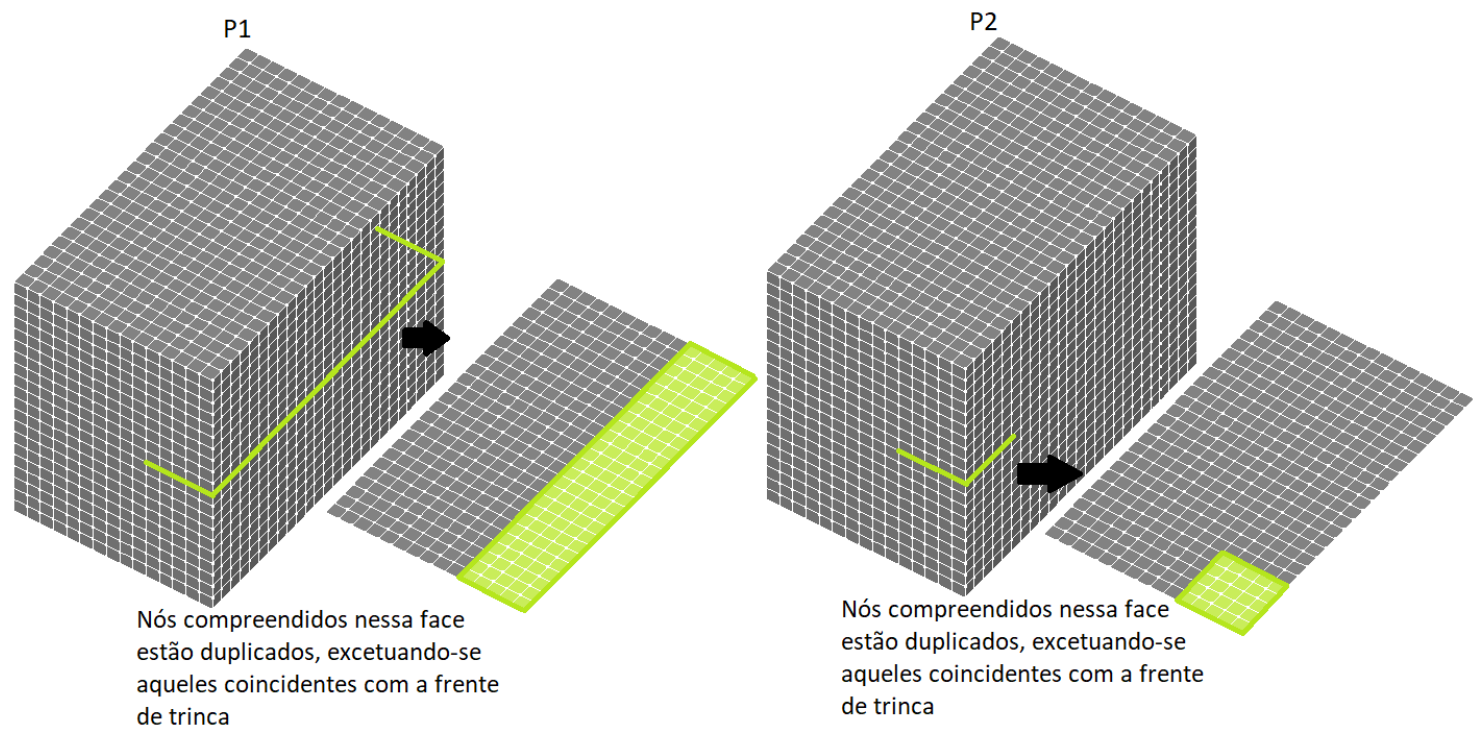

Figura 4.11: ML3 - Elementos locais de dimensões (0.200 x 0.200 x 0.200).
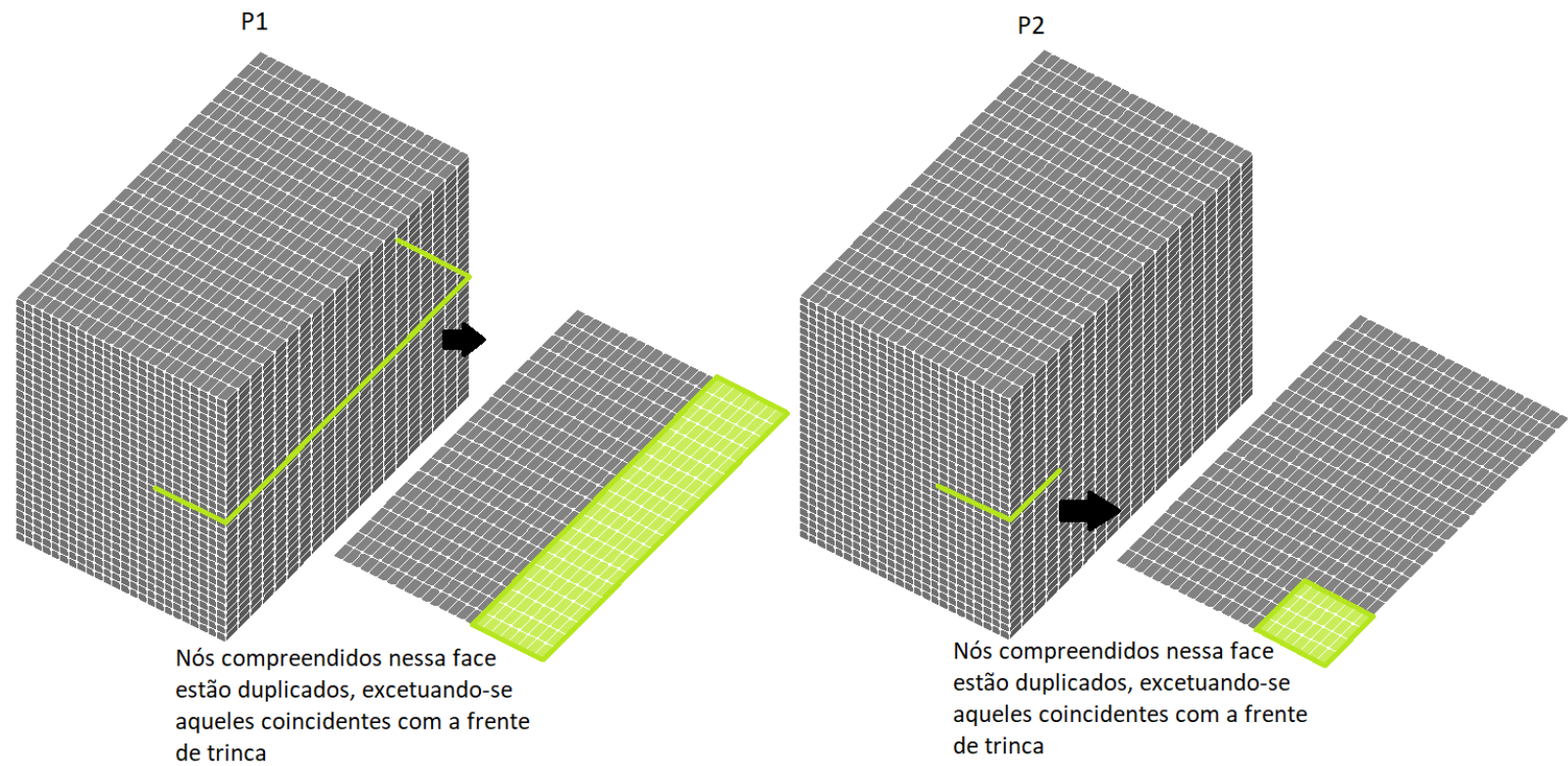

Figura 4.12: ML4 - Elementos locais de dimensões (0.125 x 0.125 x 0.250).

Um teste verificando a influência da variação do parâmetro de penalidade na solução foi realizado e os resultados estão na Seção 4.3.3.4.

Para os modelos analisados no sistema INSANE, foram utilizados 12 x 12 x 12 pontos para a integração pela quadratura de Gauss nos elementos que contêm nós enriquecidos com funções de enriquecimento singulares e $2 \times 2 \times 2$ nos demais. Isso 


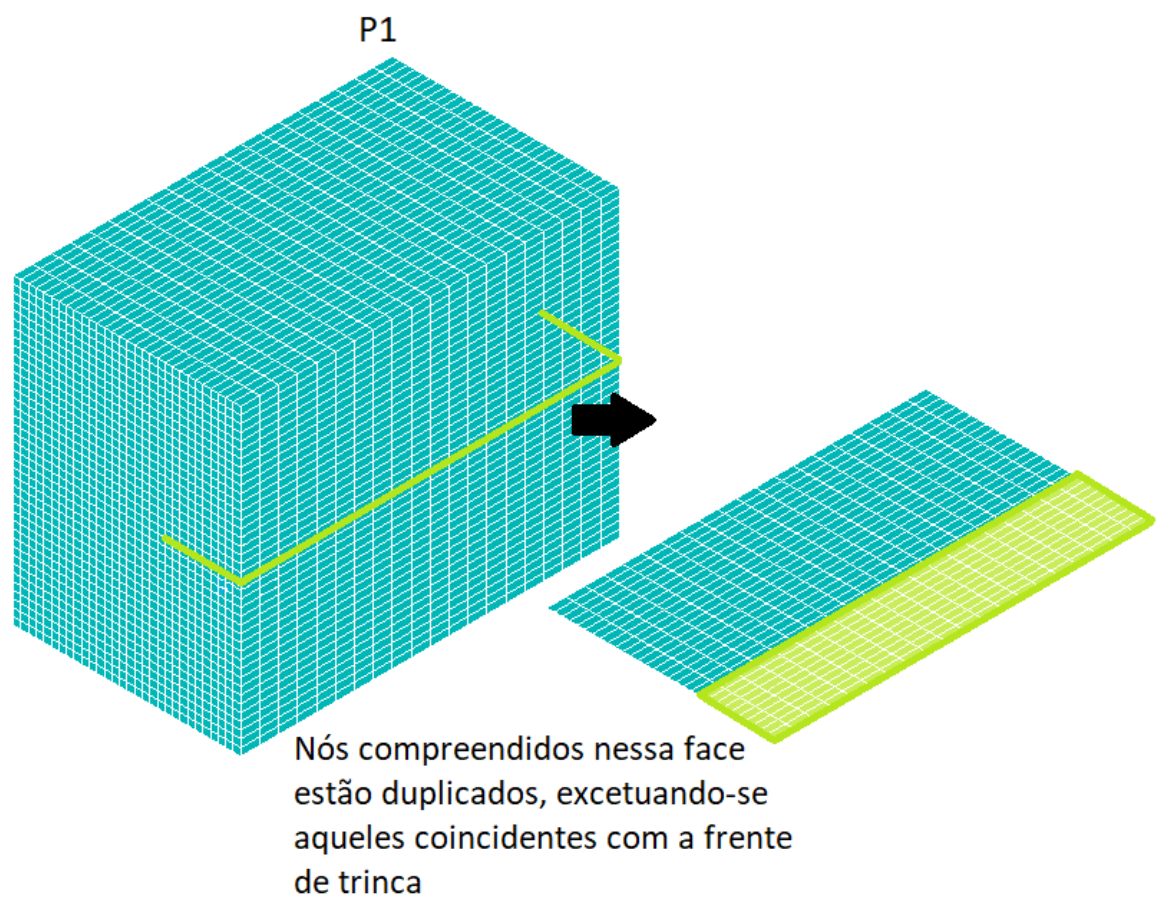

Figura 4.13: ML5 - Elementos locais de dimensões (0.100 x 0.100 x 0.250).

foi feito com o objetivo de minimizar o erro da integração numérica das funções com singularidade. Na Seção 4.3.1.3, será apresentada uma análise de sensibilidade a este respeito.

Foram calculados os valores da diferença relativa percentual dos modelos analisados, com relação à solução de referência, $E_{r}$ :

$$
E_{r}(\%)=100 \cdot \frac{\left|(\bullet)_{r}-(\bullet)_{h}\right|}{\left|(\bullet)_{r}\right|}
$$

Na Equação 4.1), $(\bullet)_{h}$ é a grandeza aproximada pelo MEFG e $(\bullet)_{r}$ a grandeza da solução de referência.

\subsection{Problema 1 - P1}

Conforme mencionado na Seção 4.2, foi utilizado o software $A N S Y S{ }^{\circledR}$ para criar o modelo de referência para o P1. Assim, utilizou-se uma malha de 112382 elementos finitos tetraédricos quadráticos (10 nós), concentrados na vizinhança da frente da superfície de trinca. A Figura 4.14 mostra a malha utilizada no $A N S Y S^{\circledR}$. Os 
resultados encontrados serão apresentados nas seções que se seguem, de acordo com a solicitação aplicada no bloco.

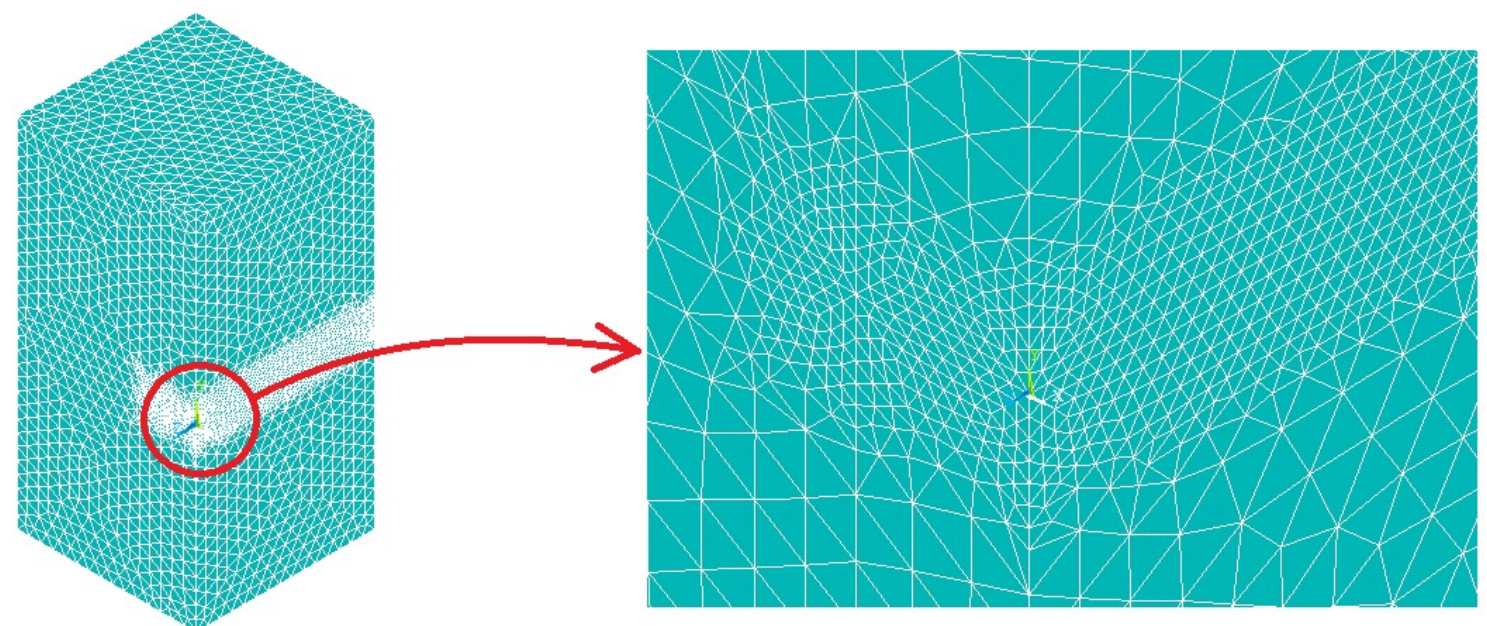

Figura 4.14: Malha do software $A N S Y S^{\circledR}$ usada para construir a solução de referência do P1.

\subsubsection{Enriquecimento com Funções Singulares}

Nessa seção foi utilizada a malha Global MG1, ilustrada na Figura 4.3. Por tratar-se de uma modelagem puramente analisada via MEFG, sem a técnica GlobalLocal, nenhuma malha Local será utilizada. Assim, o estudo concentra-se em verificar o impacto de se enriquecer os nós, próximos a vizinhança da trinca descrita na malha Global, com funções que contêm singularidade.

Foram adotadas três análises, "A", "B"e "C", descritas a seguir. Na análise "A"são utilizadas as funções capazes de descrever o Modo I de abertura de trinca, ou seja, Equações (2.7) e (2.9) para $j=1$, além da primeira parcela da série que descreve o Modo III de abertura de trinca, a saber, Equação (2.17) para $j=1$. Na análise "B"são utilizadas as funções capazes de descrever o Modo II de abertura de trinca, ou seja, Equações (2.8) e 2.10) para $j=1$, além da segunda parcela das funções que descrevem o Modo III de abertura de trinca, a saber, Equação 2.17) para j=2. Já na situação "C"são utilizadas todas as funções que descrevem os três Modos de abertura de trinca. 
Duas quantidades de nós ao redor da superfície da trinca a serem enriquecidos com as funções descritas anteriormente serão testadas, 6 ou 48 nós. A Figura 4.15 mostra a localização desses nós na malha. A configuração de 6 nós enriquecidos, diz respeito àqueles que estão na frente da trinca, já a de 48 nós são todos os nós, compreendidos no domínio local com exceção daqueles que estão duplicados e descrevem a abertura da trinca. Além disso, conforme introdução desse capítulo os três tipos de carregamento aplicado no bloco serão analisados em separado.
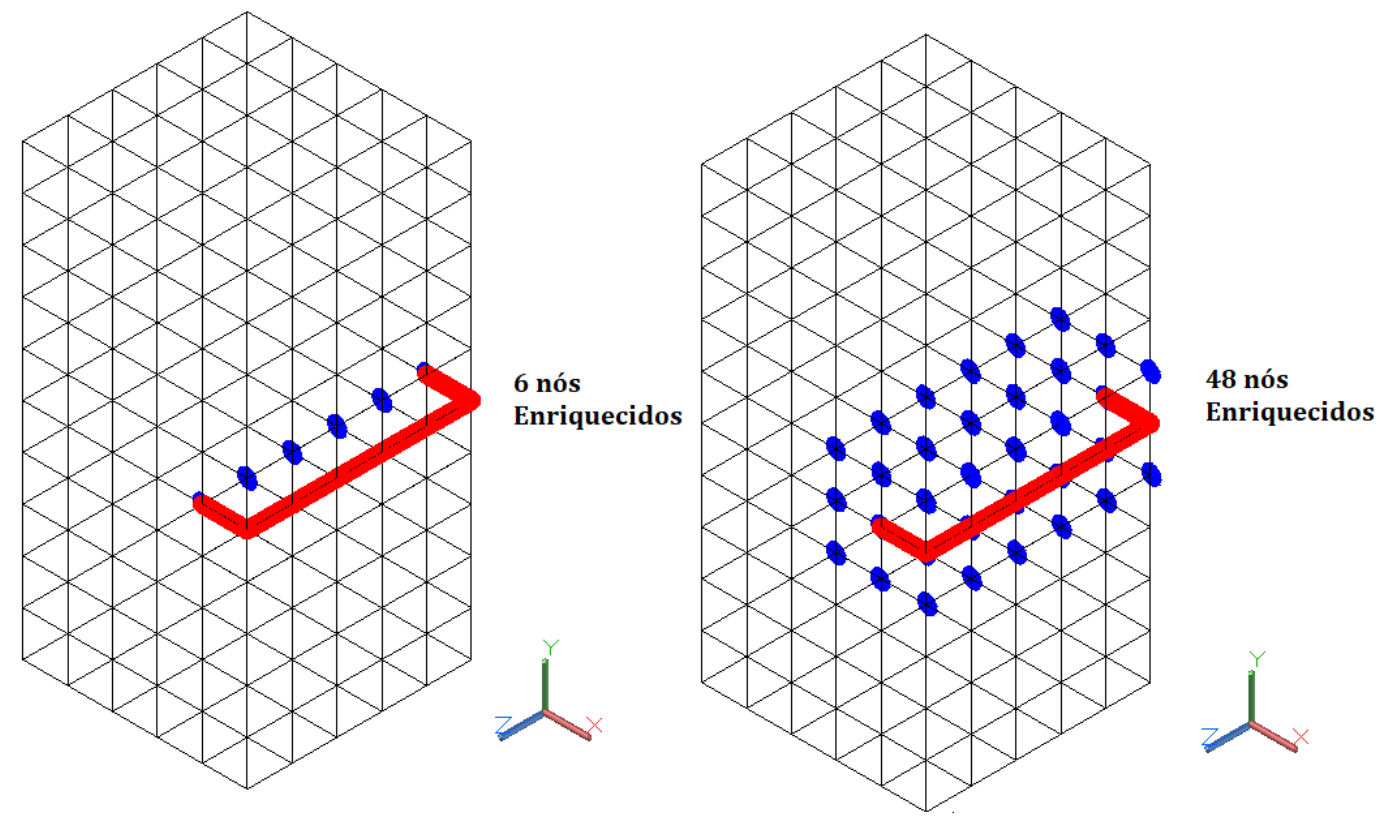

Figura 4.15: Desenho esquemático dos nós a serem enriquecidos do modelo.

\subsubsection{Bloco tracionado em y}

Nesta etapa é considerada a modelagem com a carga de tração de 1 em " $y$ ".

O resultado de referência encontrado no software $A N S Y S^{\circledR}$ para a energia de deformação foi de 0.134346027.

Os valores de energia de deformação para cada uma das análises descritas na Seção 4.3.1 foram reunidos e encontram-se na Tabela 4.1 .

Na Tabela 4.1, os resultados mostram que ao enriquecer mais nós e com todas as funções que descrevem os três modos de abertura de trinca, menor é a diferença 
Tabela 4.1: P1 contendo nós enriquecidos com funções singulares: Energia de deformação - Tração y-

\begin{tabular}{cccc}
\hline Tipo de Modelagem & NGL & Energia & Diferença Energia (\%) \\
\hline Referência & 473610 & 0.134346 & \\
S/ enriquecimento & 1098 & 0.129206 & 3.83 \\
6 nós enriquecidos - A & 1116 & 0.132360 & 1.48 \\
48 nós enriquecidos - A & 1242 & 0.132989 & 1.01 \\
6 nós enriquecidos - B & 1116 & 0.129208 & 3.82 \\
48 nós enriquecidos - B & 1242 & 0.129893 & 3.31 \\
6 nós enriquecidos - C & 1134 & 0.132381 & 1.46 \\
48 nós enriquecidos - C & 1386 & 0.133253 & 0.81 \\
\hline
\end{tabular}

na energia. Percebe-se uma tendência de convergência da solução de referência.

\subsubsection{Bloco submetido a cisalhamento em $\mathrm{x}$}

Nesta etapa é considerada a modelagem com a carga de cisalhamento de $-1 \mathrm{em}$ "x".

O resultado de referência encontrado no software $A N S Y S^{\circledR}$ para a energia de deformação foi de 2.61067621 .

Os valores de energia de deformação para cada uma das análises descritas na Seção 4.3.1 foram reunidos e encontram-se na Tabela 4.2 .

Tabela 4.2: P1 contendo nós enriquecidos com funções singulares: Energia de deformação - Cisalhamento x-

\begin{tabular}{cccc}
\hline Tipo de Modelagem & NGL & Energia & Diferença Energia (\%) \\
\hline Referência & 473610 & 2.610676 & \\
S/ enriquecimento & 1098 & 2.423007 & 7.19 \\
6 nós enriquecidos - A & 1116 & 2.485230 & 4.81 \\
48 nós enriquecidos - A & 1242 & 2.499189 & 4.27 \\
6 nós enriquecidos - B & 1116 & 2.424489 & 7.13 \\
48 nós enriquecidos - B & 1242 & 2.440715 & 6.51 \\
6 nós enriquecidos - C & 1134 & 2.487146 & 4.73 \\
48 nós enriquecidos - C & 1386 & 2.509446 & 3.88 \\
\hline
\end{tabular}

Os resultados mostram que ao enriquecer mais nós e com todas as funções que descrevem os três modos de abertura de trinca, menor é a diferença na energia, de modo semelhante ao já observado na Seção 4.3.1.1, para o bloco tracionado. Embora 
fosse desejado representar o Modo II de abertura de trinca com esse modelo, o enriquecimento das funções de forma associada aos nós próximos a trinca com funções que descrevem esse tipo de abertura não leva aos melhores resultados. Isso ocorre, porque ainda que esse modo de abertura aconteça, ele não se mostra predominante. De fato, o Modo I de abertura de trinca prevalece, devido a própria configuração física do modelo e, portanto, a situação em que as funções de forma associadas aos nós contêm o enriquecimento com as funções que descrevem o Modo I geram resultados mais próximos ao de referência. É importante ressaltar, contudo, que diante do melhor resultado da situação $\mathrm{C}$ conclui-se que os três modos de abertura de trinca estão ocorrendo ao mesmo tempo, ainda que o Modo I seja preponderante.

\subsubsection{Bloco submetido a cisalhamento em $\mathrm{z}$}

Nesta etapa é considerada a modelagem com a carga de cisalhamento de $-1 \mathrm{em}$ "z". Adicionalmente, para esse modelo, será feita uma quarta análise, chamada "D". Ela é semelhante a análise "C", diferindo apenas do fato que o enriquecimento com a equação que descreve o Modo III de abertura de trinca, a saber, Equação 2.17) com j=2, estará bloqueado. Busca-se com esta análise adicional, observar a influência que este segundo termo da série tem sobre a solução total, já que em todas as outras funções, representadas pelas Equações (2.7), 2.8), (2.9) e 2.10) utiliza-se apenas o primeiro termo da série, ou seja, com $j=1$. Além disso, a análise "D" possibilita confirmar a importância de utilização da Equação (2.17) com j=2, já que em Duarte et al. (2000) essa equação é utilizada como forma de enriquecimento para descrever a singularidade causada pela trinca, mas não se corrobora a sua necessidade.

O resultado de referência encontrado no software $A N S Y S^{\circledR}$ para a energia de deformação foi de 2.42946697.

Os valores de energia de deformação para cada uma das análises descritas na Seção 4.3.1 foram reunidos e encontram-se na Tabela 4.3 .

Na Tabela 4.3, os resultados mostram que ao enriquecer mais nós e com todas as funções que descrevem os três modos de abertura de trinca, menor é a diferença 
Tabela 4.3: P1 contendo nós enriquecidos com funções singulares: Energia de deformação - Cisalhamento z-

\begin{tabular}{cccc}
\hline Tipo de Modelagem & NGL & Energia & Diferença Energia (\%) \\
\hline Referência & 473610 & 2.429467 & \\
S/ enriquecimento & 1098 & 2.302912 & 5.21 \\
6 nós enriquecidos - A & 1116 & 2.332592 & 3.99 \\
48 nós enriquecidos - A & 1242 & 2.337279 & 3.79 \\
6 nós enriquecidos - B & 1116 & 2.303573 & 5.18 \\
48 nós enriquecidos - B & 1242 & 2.309136 & 4.95 \\
6 nós enriquecidos - C & 1134 & 2.333715 & 3.94 \\
48 nós enriquecidos - C & 1386 & 2.340461 & 3.66 \\
6 nós enriquecidos - D & 1128 & 2.333129 & 3.97 \\
48 nós enriquecidos - D & 1338 & 2.339114 & 3.72 \\
\hline
\end{tabular}

na energia, de modo semelhante ao já observado nas análises anteriores. Quanto a análise adicional "D", quando comparada a análise "C", foi possível observar que a influência do segundo termo da série da função que descreve o Modo III de abertura de trinca é tanto mais expressiva quanto mais nós são enriquecidos, desta forma não deve ser descartado e comprova-se, assim, a importância da sua utilização indicada por Duarte et al. (2000).

Um estudo, da influência da quantidade dos pontos de integração pela quadratura de Gauss nos elementos que contêm nós enriquecidos, foi realizado. Para tanto foram feitas 4 análises adicionais a análise "C", anteriormente descrita, numeradas de "1" a "4". A análise "1" guarda como única diferença do que está sendo feito a utilização de apenas $4 \times 4 \times 4$ pontos de integração nos referidos elementos. Já a análise "2" utiliza $6 \times 6 \times 6$ pontos nesses elementos. A análise "3" utiliza $8 \times 8 \times 8$ pontos nesses elementos. Por fim, a análise "4" utiliza 10 x 10 x 10 pontos nesses elementos.

Tabela 4.4: P1 contendo nós enriquecidos com funções singulares: Energia de deformação comparando quantidade de pontos de integração - Cisalhamento z-

\begin{tabular}{cccc}
\hline Tipo de Modelagem & NGL & Energia & Diferença Energia (\%) \\
\hline 6 nós enriquecidos - C1 & 1134 & 2.334320 & 3.92 \\
6 nós enriquecidos - C2 & 1134 & 2.333907 & 3.93 \\
6 nós enriquecidos - C3 & 1134 & 2.333792 & 3.94 \\
6 nós enriquecidos - C4 & 1134 & 2.333743 & 3.94 \\
6 nós enriquecidos - C & 1134 & 2.333715 & 3.94 \\
\hline
\end{tabular}


Pela análise da Tabela 4.4, percebe-se que há uma sutil sensibilidade do resultado à quantidade de pontos de integração utilizados no elemento. Desta forma, para minimizar resultados ilusórios de energia, mais altos do que realmente são, decidiu-se utilizar nos elementos que contêm nós enriquecidos com funções que contêm singularidades, $12 \times 12 \times 12$ pontos.

\subsubsection{Enriquecimento com Técnica Global-Local - Trinca Coincidente com as Faces dos Elementos Globais}

Nessa seção foi utilizada a malha Global MG2, ilustrada na Figura 4.4. Trata-se de uma modelagem analisada via MEFG com técnica Global-Local, sem a utilização de enriquecimento com funções que contêm derivadas singulares. Para tanto foram variadas as malhas locais de maneira a observar a influência do refinamento da malha local no resultado do modelo. Além disso, duas quantidades de nós enriquecidos via Global-Local foram estudados, a Figura 4.16 mostra o posicionamento e a quantidade desses nós, a saber, 6 e 54 nós, próximos à frente de trinca. A configuração de 6 nós enriquecidos, diz respeito àqueles que estão na frente de trinca, já a de 54 nós são todos os nós, compreendidos no domínio local.
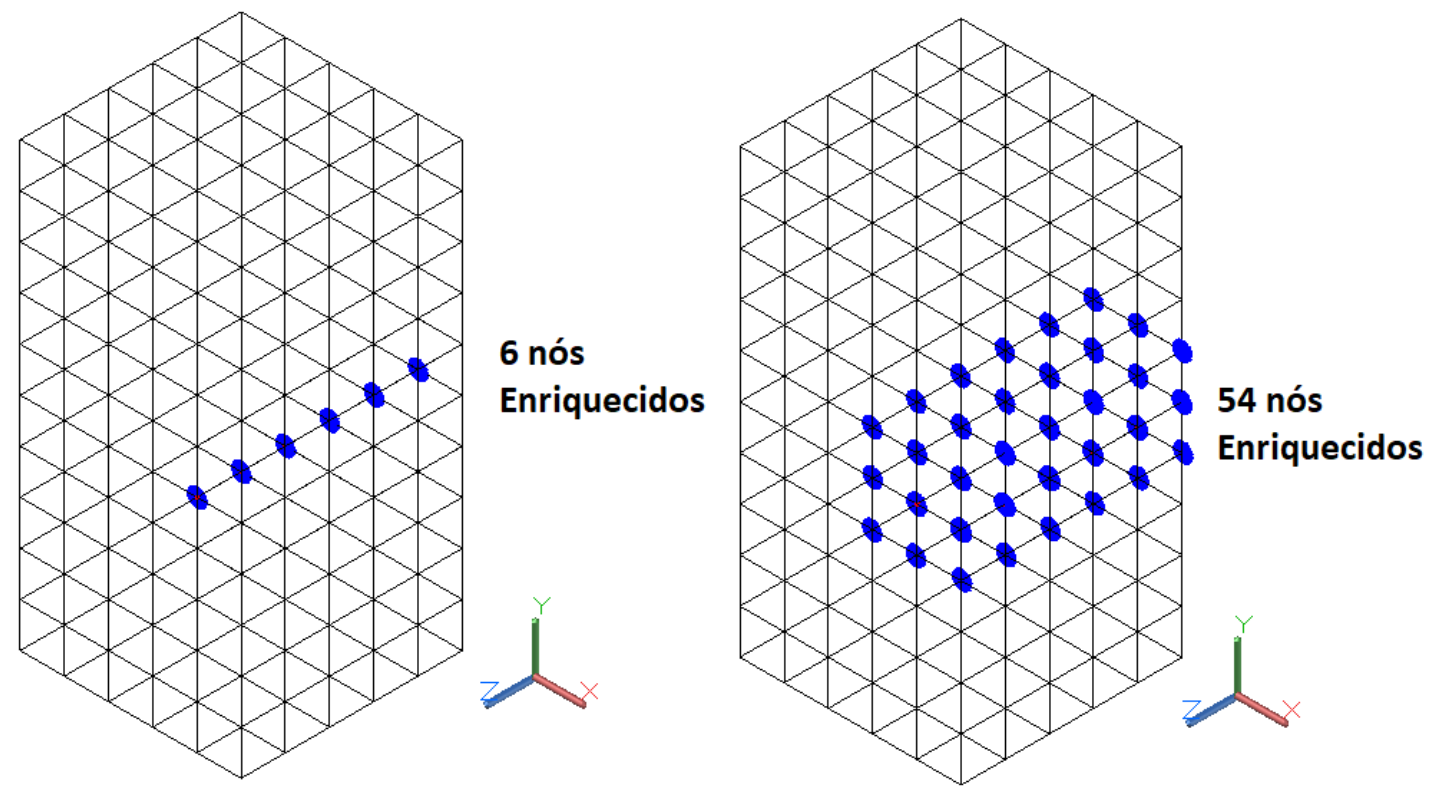

Figura 4.16: Desenho esquemático dos nós a serem enriquecidos do modelo. 
Os modelos foram analisados com as malhas locais, ML1, ML2, ML3, ML4 e ML5, apresentadas nas Figuras 4.9, 4.10, 4.11, 4.12 e 4.13, respectivamente.

\subsubsection{Bloco Tracionado em y}

Nesta etapa é considerada a modelagem com a carga de tração de 1 em " $y$ ".

O resultado de referência encontrado no software ANSYS ${ }^{\circledR}$ para a energia de deformação foi de 0.134346027, conforme já apresentado na Seção 4.3.1.1. A componente de tensão de referência $\sigma_{y y}$, encontrada próxima à superfície de trinca, na coordenada $(3.9995,5.0000,0.0000)$ foi de 5.427. Já a abertura da trinca, em $x=5$ e $z=0$ entre $y=4.999$ e $y=5.001$, no modelo de referência foi de 6.89E-03.

Os valores de energia de deformação, tensão $\sigma_{y y}$ e abertura de trinca para cada uma das análises descritas nessa seção foram reunidos nas Tabelas 4.5, 4.6 e 4.7. respectivamente.

Tabela 4.5: P1 contendo nós enriquecidos via técnica Global-Local em modelos de trinca coincidente com as faces dos elementos Globais: Energia de deformação Tração y-

\begin{tabular}{cccc}
\hline Tipo de Modelagem & NGL & Energia & Diferença Energia (\%) \\
\hline Referência & 473610 & 0.134346 & \\
S/ enriquecimento & 1098 & 0.129206 & 3.83 \\
6 nós enriquecidos - ML1 & 1098 & 0.124098 & 7.63 \\
54 nós enriquecidos - ML1 & 1242 & 0.130325 & 2.99 \\
6 nós enriquecidos - ML2 & 1098 & 0.124322 & 7.46 \\
54 nós enriquecidos - ML2 & 1242 & 0.131401 & 2.19 \\
6 nós enriquecidos - ML3 & 1098 & 0.124376 & 7.42 \\
54 nós enriquecidos - ML3 & 1242 & 0.131648 & 2.01 \\
6 nós enriquecidos - ML4 & 1098 & 0.124463 & 7.36 \\
54 nós enriquecidos - ML4 & 1242 & 0.132038 & 1.72 \\
6 nós enriquecidos - ML5 & 1098 & 0.124494 & 7.33 \\
54 nós enriquecidos - ML5 & 1242 & 0.132174 & 1.62 \\
\hline
\end{tabular}

Nas Tabelas 4.5, 4.6 e 4.7 os resultados mostram que, ao enriquecer mais nós, sobretudo circundando toda a trinca, menor é a diferença na energia, em $\sigma_{y y}$ e na abertura da trinca, calculados, quando comparados à referência. Percebe-se que a solução melhora com o refinamento da malha local, apresentando uma convergência maior para o caso de 54 nós enriquecidos. O modelo global inicial não consegue 
Tabela 4.6: P1 contendo nós enriquecidos via técnica Global-Local em modelos de trinca coincidente com as faces dos elementos Globais: $\sigma_{y y}$ - Tração y-

\begin{tabular}{cccc}
\hline Tipo de Modelagem & NGL & $\sigma_{y y}$ & Diferença $\sigma_{y y}(\%)$ \\
\hline Referência & 473610 & 5.427 & \\
6 nós enriquecidos - ML1 & 1098 & 2.335 & 56.97 \\
54 nós enriquecidos - ML1 & 1242 & 2.830 & 47.85 \\
6 nós enriquecidos - ML2 & 1098 & 2.695 & 50.34 \\
54 nós enriquecidos - ML2 & 1242 & 3.495 & 35.60 \\
6 nós enriquecidos - ML3 & 1098 & 2.845 & 47.58 \\
54 nós enriquecidos - ML3 & 1242 & 3.765 & 30.62 \\
6 nós enriquecidos - ML4 & 1098 & 3.350 & 38.27 \\
54 nós enriquecidos - ML4 & 1242 & 4.710 & 13.21 \\
6 nós enriquecidos - ML5 & 1098 & 3.615 & 33.39 \\
54 nós enriquecidos - ML5 & 1242 & 5.205 & 4.09 \\
\hline
\end{tabular}

Tabela 4.7: P1 contendo nós enriquecidos via técnica Global-Local em modelos de trinca coincidente com as faces dos elementos Globais: Abertura de Trinca -

Tração y-

\begin{tabular}{cccc}
\hline Tipo de Modelagem & NGL & Abertura & Diferença Abertura (\%) \\
\hline Referência & 473610 & $6.89 \mathrm{E}-03$ & \\
6 nós enriquecidos - ML1 & 1098 & $1.00 \mathrm{E}-05$ & 99.85 \\
54 nós enriquecidos - ML1 & 1242 & $5.41 \mathrm{E}-03$ & 21.43 \\
6 nós enriquecidos - ML2 & 1098 & $0.00 \mathrm{E}+00$ & 100.00 \\
54 nós enriquecidos - ML2 & 1242 & $5.95 \mathrm{E}-03$ & 13.59 \\
6 nós enriquecidos - ML3 & 1098 & $0.00 \mathrm{E}+00$ & 100.00 \\
54 nós enriquecidos - ML3 & 1242 & $6.04 \mathrm{E}-03$ & 12.29 \\
6 nós enriquecidos - ML4 & 1098 & $0.00 \mathrm{E}+00$ & 100.00 \\
54 nós enriquecidos - ML4 & 1242 & $6.20 \mathrm{E}-03$ & 9.96 \\
6 nós enriquecidos - ML5 & 1098 & $0.00 \mathrm{E}+00$ & 100.00 \\
54 nós enriquecidos - ML5 & 1242 & $6.25 \mathrm{E}-03$ & 9.24 \\
\hline
\end{tabular}

descrever a descontinuidade dos deslocamentos. Isso ocorre, pois diferentemente da análise da Seção 4.3.1, com as funções singulares, nesta os nós ao longo da superfície de trinca não são duplicados. Assim, apenas quando um número maior de nós são enriquecidos, de tal forma que o suporte de suas funções de PU contenham toda a superfície de trinca (que é o caso dos 54 nós enriquecidos) é que a abertura da trinca de fato pode ser descrita no modelo, assim, na Tabela 4.7, percebe-se que somente o modelo que possui 54 nós enriquecidos via técnica Global-Local consegue descrever a abertura da trinca e essa discretização melhora a medida que se refina a malha 
local.

\subsubsection{Bloco submetido a cisalhamento em $\mathrm{x}$}

Nesta etapa é considerada a modelagem com a carga de tração de -1 em " $x$ ".

O resultado de referência encontrado no software $A N S Y S^{\circledR}$ para a energia de deformação foi de 2.61067621, conforme já apresentado na Seção 4.3.1.2. A componente de tensão de referência $\sigma_{y y}$ encontrada próxima à superfície de trinca, na coordenada $(3.9995,5.0000,0.0000)$ foi de 24.454. Já a abertura da trinca, em $x=5$ e $z=0$ entre $y=4.999$ e $y=5.001$, no modelo de referência foi de 3.51E-02.

Os valores de energia de deformação, tensão $\sigma_{y y}$ e abertura de trinca para cada uma das análises descritas nessa seção foram reunidos nas Tabelas 4.8, 4.9 e 4.10. respectivamente.

Tabela 4.8: P1 contendo nós enriquecidos via técnica Global-Local em modelos de trinca coincidente com as faces dos elementos Globais: Energia de deformação -

Cisalhamento $\mathrm{x}-$

\begin{tabular}{cccc}
\hline Tipo de Modelagem & NGL & Energia & Diferença Energia (\%) \\
\hline Referência & 473610 & 2.610676 & \\
S/ enriquecimento & 1098 & 2.423007 & 7.19 \\
6 nós enriquecidos - ML1 & 1098 & 2.243470 & 14.07 \\
54 nós enriquecidos - ML1 & 1242 & 2.402403 & 7.98 \\
6 nós enriquecidos - ML2 & 1098 & 2.245161 & 14.00 \\
54 nós enriquecidos - ML2 & 1242 & 2.421519 & 7.25 \\
6 nós enriquecidos - ML3 & 1098 & 2.245554 & 13.99 \\
54 nós enriquecidos - ML3 & 1242 & 2.425708 & 7.09 \\
6 nós enriquecidos - ML4 & 1098 & 2.246172 & 13.96 \\
54 nós enriquecidos - ML4 & 1242 & 2.432179 & 6.84 \\
6 nós enriquecidos - ML5 & 1098 & 2.246390 & 13.95 \\
54 nós enriquecidos - ML5 & 1242 & 2.434409 & 6.75 \\
\hline
\end{tabular}

Pela análise das Tabelas 4.8, 4.9 e 4.10, percebe-se que as mesmas conclusões encontradas na Seção 4.3.2.1 aplicam-se ao modelo avaliado nessa seção. 
Tabela 4.9: P1 contendo nós enriquecidos via técnica Global-Local em modelos de trinca coincidente com as faces dos elementos Globais: $\sigma_{y y}$ - Cisalhamento x-

\begin{tabular}{cccc}
\hline Tipo de Modelagem & NGL & $\sigma_{y y}$ & Diferença $\sigma_{y y}(\%)$ \\
\hline Referência & 473610 & 24.454 & \\
6 nós enriquecidos - ML1 & 1098 & 4.890 & 80.00 \\
54 nós enriquecidos - ML1 & 1242 & 11.245 & 54.02 \\
6 nós enriquecidos - ML2 & 1098 & 5.320 & 78.24 \\
54 nós enriquecidos - ML2 & 1242 & 13.500 & 44.79 \\
6 nós enriquecidos - ML3 & 1098 & 5.480 & 77.59 \\
54 nós enriquecidos - ML3 & 1242 & 14.350 & 41.32 \\
6 nós enriquecidos - ML4 & 1098 & 6.035 & 75.32 \\
54 nós enriquecidos - ML4 & 1242 & 17.000 & 30.48 \\
6 nós enriquecidos - ML5 & 1098 & 6.330 & 74.11 \\
54 nós enriquecidos - ML5 & 1242 & 18.400 & 24.76 \\
\hline
\end{tabular}

Tabela 4.10: P1 contendo nós enriquecidos via técnica Global-Local em modelos de trinca coincidente com as faces dos elementos Globais: Abertura de Trinca -

Cisalhamento $\mathrm{x}-$

\begin{tabular}{cccc}
\hline Tipo de Modelagem & NGL & Abertura & Diferença Abertura (\%) \\
\hline Referência & 473610 & $3.51 \mathrm{E}-02$ & \\
6 nós enriquecidos - ML1 & 1098 & $0.00 \mathrm{E}+00$ & 100.00 \\
54 nós enriquecidos - ML1 & 1242 & $2.32 \mathrm{E}-02$ & 33.88 \\
6 nós enriquecidos - ML2 & 1098 & $0.00 \mathrm{E}+00$ & 100.00 \\
54 nós enriquecidos - ML2 & 1242 & $2.50 \mathrm{E}-02$ & 28.75 \\
6 nós enriquecidos - ML3 & 1098 & $0.00 \mathrm{E}+00$ & 100.00 \\
54 nós enriquecidos - ML3 & 1242 & $2.55 \mathrm{E}-02$ & 27.33 \\
6 nós enriquecidos - ML4 & 1098 & $0.00 \mathrm{E}+00$ & 100.00 \\
54 nós enriquecidos - ML4 & 1242 & $2.60 \mathrm{E}-02$ & 25.90 \\
6 nós enriquecidos - ML5 & 1098 & $0.00 \mathrm{E}+00$ & 100.00 \\
54 nós enriquecidos - ML5 & 1242 & $2.62 \mathrm{E}-02$ & 25.33 \\
\hline
\end{tabular}

\subsubsection{Bloco submetido a cisalhamento em $\mathrm{z}$}

Nesta etapa é considerada a modelagem com a carga de tração de -1 em " $z$ ".

O resultado de referência encontrado no software $A N S Y S{ }^{\circledR}$ para a energia de deformação foi de 2.42946697, conforme já apresentado na Seção 4.3.1.3. A componente de tensão de referência $\sigma_{y y}$ encontrada próxima à superfície de trinca, na coordenada $(3.9995,5.0000,0.0000)$ foi de 25.216 . Já a abertura da trinca, em $x=5$ e $z=0$ entre $y=4.999$ e $y=5.001$, no modelo de referência foi de 2.61E-02.

Os valores de energia de deformação, tensão $\sigma_{y y}$ e abertura de trinca para cada 
uma das análises descritas nessa seção foram reunidos nas Tabelas 4.11, 4.12 e 4.13 , respectivamente.

Tabela 4.11: P1 contendo nós enriquecidos via técnica Global-Local em modelos de trinca coincidente com as faces dos elementos Globais: Energia de deformação -

Cisalhamento z-

\begin{tabular}{cccc}
\hline Tipo de Modelagem & NGL & Energia & Diferença Energia (\%) \\
\hline Referência & 473610 & 2.429467 & \\
S/ enriquecimento & 1098 & 2.302912 & 5.21 \\
6 nós enriquecidos - ML1 & 1098 & 2.251815 & 7.31 \\
54 nós enriquecidos - ML1 & 1242 & 2.305138 & 5.12 \\
6 nós enriquecidos - ML2 & 1098 & 2.254337 & 7.21 \\
54 nós enriquecidos - ML2 & 1242 & 2.313527 & 4.77 \\
6 nós enriquecidos - ML3 & 1098 & 2.254927 & 7.18 \\
54 nós enriquecidos - ML3 & 1242 & 2.315349 & 4.70 \\
6 nós enriquecidos - ML4 & 1098 & 2.255874 & 7.15 \\
54 nós enriquecidos - ML4 & 1242 & 2.318139 & 4.58 \\
6 nós enriquecidos - ML5 & 1098 & 2.256214 & 7.13 \\
54 nós enriquecidos - ML5 & 1242 & 2.319104 & 4.54 \\
\hline
\end{tabular}

Tabela 4.12: P1 contendo nós enriquecidos via técnica Global-Local em modelos de trinca coincidente com as faces dos elementos Globais: $\sigma_{y y}$ - Cisalhamento z-

\begin{tabular}{cccc}
\hline Tipo de Modelagem & NGL & $\sigma_{y y}$ & Diferença $\sigma_{y y}(\%)$ \\
\hline Referência & 473610 & 25.216 & \\
6 nós enriquecidos - ML1 & 1098 & 14.200 & 43.69 \\
54 nós enriquecidos - ML1 & 1242 & 13.950 & 44.68 \\
6 nós enriquecidos - ML2 & 1098 & 16.550 & 34.37 \\
54 nós enriquecidos - ML2 & 1242 & 17.450 & 30.80 \\
6 nós enriquecidos - ML3 & 1098 & 17.550 & 30.40 \\
54 nós enriquecidos - ML3 & 1242 & 18.850 & 25.25 \\
6 nós enriquecidos - ML4 & 1098 & 20.350 & 19.30 \\
54 nós enriquecidos - ML4 & 1242 & 22.950 & 8.99 \\
6 nós enriquecidos - ML5 & 1098 & 21.850 & 13.35 \\
54 nós enriquecidos - ML5 & 1242 & 25.150 & 0.26 \\
\hline
\end{tabular}

Pela análise das Tabelas 4.11, 4.12 e 4.13, observa-se que as mesmas conclusões encontradas na Seção 4.3.2.1 aplicam-se ao modelo avaliado nessa seção. 
Tabela 4.13: P1 contendo nós enriquecidos via técnica Global-Local em modelos de trinca coincidente com as faces dos elementos Globais: Abertura de Trinca -

Cisalhamento z-

\begin{tabular}{cccc}
\hline Tipo de Modelagem & NGL & Abertura & Diferença Abertura (\%) \\
\hline Referência & 473610 & $2.61 \mathrm{E}-02$ & \\
6 nós enriquecidos - ML1 & 1098 & $0.00 \mathrm{E}+00$ & 100.00 \\
54 nós enriquecidos - ML1 & 1242 & $2.21 \mathrm{E}-02$ & 15.16 \\
6 nós enriquecidos - ML2 & 1098 & $0.00 \mathrm{E}+00$ & 100.00 \\
54 nós enriquecidos - ML2 & 1242 & $2.37 \mathrm{E}-02$ & 9.02 \\
6 nós enriquecidos - ML3 & 1098 & $0.00 \mathrm{E}+00$ & 100.00 \\
54 nós enriquecidos - ML3 & 1242 & $2.40 \mathrm{E}-02$ & 7.87 \\
6 nós enriquecidos - ML4 & 1098 & $0.00 \mathrm{E}+00$ & 100.00 \\
54 nós enriquecidos - ML4 & 1242 & $2.44 \mathrm{E}-02$ & 6.33 \\
6 nós enriquecidos - ML5 & 1098 & $0.00 \mathrm{E}+00$ & 100.00 \\
54 nós enriquecidos - ML5 & 1242 & $2.45 \mathrm{E}-02$ & 5.95 \\
\hline
\end{tabular}

\subsubsection{Enriquecimento com Técnica Global-Local - Trinca no Interior dos Elementos Globais}

Nessa seção foi utilizada a malha Global MG3, ilustrada na Figura 4.5. Trata-se de uma modelagem analisada via MEFG com técnica Global-Local, sem a utilização de enriquecimento com funções que contêm derivadas singulares. Para tanto foram variadas as malhas locais de maneira a observar a influência do refinamento da malha local no resultado do modelo. Além disso, duas quantidades de nós enriquecidos via Global-Local foram estudados, a Figura 4.17 mostra o posicionamento e a quantidade desses nós, a saber, 24 e 72 nós, próximos à frente de trinca. A configuração de 24 nós enriquecidos, diz respeito àqueles nós que compõem os elementos cortados pela trinca, já a de 72 nós são todos os nós, compreendidos no domínio local.

Os modelos foram analisados com as malhas locais, ML1, ML2, ML4 e ML5, apresentadas nas Figuras 4.9, 4.10, 4.12 e 4.13, respectivamente. A malha ML3 foi descartada nessa análise, pois seus elementos não se encontram completamente aninhados na malha do domínio global.

\subsubsection{Bloco Tracionado em y}

Nesta etapa é considerada a modelagem com a carga de tração de 1 em " $y$ ". 


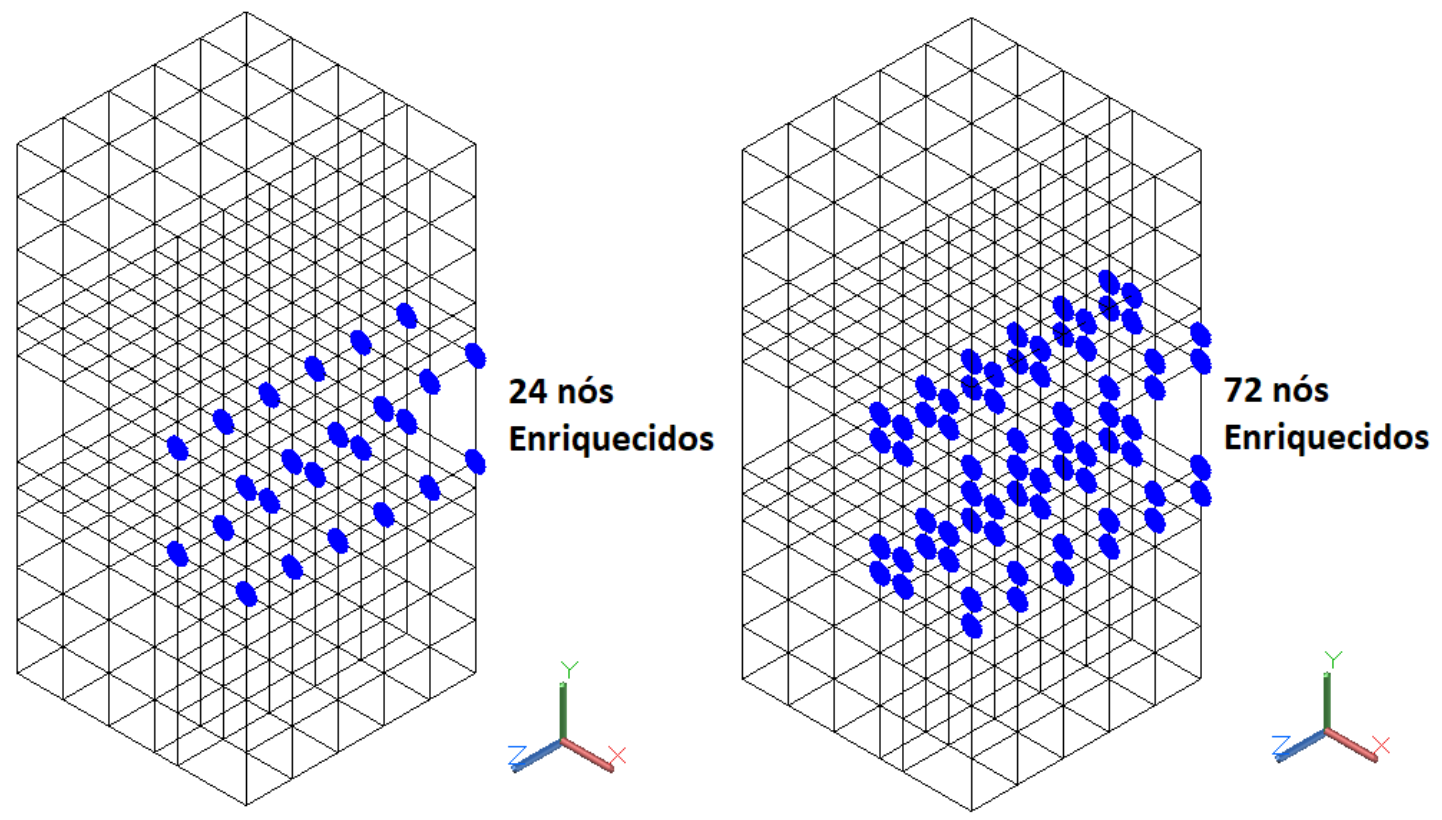

Figura 4.17: Desenho esquemático dos nós a serem enriquecidos do modelo.

O resultado de referência encontrado no software $A N S Y S^{\circledR}$ para a energia de deformação foi de 0.134346027 . A componente de tensão de referência $\sigma_{y y}$, encontrada próxima à superfície de trinca, na coordenada $(3.9995,5.0000,0.0000)$ foi de 5.427. Já a abertura da trinca, em $x=5$ e $z=0$ entre $y=4.999$ e $y=5.001$, no modelo de referência foi de 6.89E-03. Conforme já apresentado na Seção 4.3.2.1.

Os valores de energia de deformação, tensão $\sigma_{y y}$ e abertura de trinca para cada uma das análises descritas nessa seção foram reunidos nas Tabelas 4.14, 4.15 e 4.16 , respectivamente.

Nas Tabelas 4.14, 4.15 e 4.16 os resultados mostram que, ao enriquecer mais nós, menor é a diferença na energia, em $\sigma_{y y}$ e na abertura da trinca calculados, quando comparados à referência. Percebe-se que a solução melhora com o refinamento da malha local, apresentando uma convergência maior para o caso de 72 nós enriquecidos. Diferente do que ocorre na Seção 4.3.2.1, nos modelos desta seção todos os nós que envolvem a trinca estão enriquecidos via técnica Global-Local em ambas as modelagens, 24 e 72 nós enriquecidos, possibilitando a discretização da trinca no modelo global enriquecido. Ainda comparando com a Seção 4.3.2.1, o modelo de 
Tabela 4.14: P1 contendo nós enriquecidos via técnica Global-Local em modelos de trinca no interior dos elementos Globais: Energia de deformação - Tração y-

\begin{tabular}{cccc}
\hline Tipo de Modelagem & NGL & Energia & Diferença Energia (\%) \\
\hline Referência & 473610 & 0.134346 & \\
S/ enriquecimento & 1098 & 0.129206 & 3.83 \\
24 nós enriquecidos - ML1 & 1260 & 0.129250 & 3.79 \\
72 nós enriquecidos - ML1 & 1404 & 0.130112 & 3.15 \\
24 nós enriquecidos - ML2 & 1260 & 0.130334 & 2.99 \\
72 nós enriquecidos - ML2 & 1404 & 0.131278 & 2.28 \\
24 nós enriquecidos - ML4 & 1260 & 0.130932 & 2.54 \\
72 nós enriquecidos - ML4 & 1404 & 0.131934 & 1.80 \\
24 nós enriquecidos - ML5 & 1260 & 0.131056 & 2.45 \\
72 nós enriquecidos - ML5 & 1404 & 0.132072 & 1.69 \\
\hline
\end{tabular}

Tabela 4.15: P1 contendo nós enriquecidos via técnica Global-Local em modelos de trinca no interior dos elementos Globais: $\sigma_{y y}$ - Tração y-

\begin{tabular}{cccc}
\hline Tipo de Modelagem & NGL & $\sigma_{y y}$ & Diferença $\sigma_{y y}(\%)$ \\
\hline Referência & 473610 & 5.427 & \\
24 nós enriquecidos - ML1 & 1260 & 1.945 & 64.16 \\
72 nós enriquecidos - ML1 & 1404 & 2.095 & 61.40 \\
24 nós enriquecidos - ML2 & 1260 & 2.580 & 52.46 \\
72 nós enriquecidos - ML2 & 1404 & 2.820 & 48.04 \\
24 nós enriquecidos - ML4 & 1260 & 3.700 & 31.82 \\
72 nós enriquecidos - ML4 & 1404 & 4.120 & 24.08 \\
24 nós enriquecidos - ML5 & 1260 & 4.160 & 23.35 \\
72 nós enriquecidos - ML5 & 1404 & 4.650 & 14.32 \\
\hline
\end{tabular}

Tabela 4.16: P1 contendo nós enriquecidos via técnica Global-Local em modelos de trinca no interior dos elementos Globais: Abertura de Trinca - Tração y-

\begin{tabular}{cccc}
\hline Tipo de Modelagem & NGL & Abertura & Diferença Abertura (\%) \\
\hline Referência & 473610 & $6.89 \mathrm{E}-03$ & \\
24 nós enriquecidos - ML1 & 1260 & $4.73 \mathrm{E}-03$ & 31.31 \\
72 nós enriquecidos - ML1 & 1404 & $5.17 \mathrm{E}-03$ & 24.92 \\
24 nós enriquecidos - ML2 & 1260 & $5.27 \mathrm{E}-03$ & 23.47 \\
72 nós enriquecidos - ML2 & 1404 & $5.76 \mathrm{E}-03$ & 16.35 \\
24 nós enriquecidos - ML4 & 1260 & $5.51 \mathrm{E}-03$ & 19.98 \\
72 nós enriquecidos - ML4 & 1404 & $6.01 \mathrm{E}-03$ & 12.72 \\
24 nós enriquecidos - ML5 & 1260 & $5.54 \mathrm{E}-03$ & 19.55 \\
72 nós enriquecidos - ML5 & 1404 & $6.07 \mathrm{E}-03$ & 11.85 \\
\hline
\end{tabular}

72 nós, aqui apresentado, mostra-se menos eficiente para gerar melhores resultados do que o modelo daquela seção de 54 nós. Ainda que não haja erros oriundos da integração numérica, uma vez que essa ocorre nos pontos de Gauss dos elementos 
locais, há uma dificuldade inerente ao fato de se descrever uma trinca no interior de um elemento diferentemente do que ocorre no modelo da Seção 4.3.2.1, onde a superfície de trinca coincide com as faces dos elementos globais.

\subsubsection{Bloco submetido a cisalhamento em $\mathrm{x}$}

Nesta etapa é considerada a modelagem com a carga de tração de -1 em " $x$ ".

O resultado de referência encontrado no software $A N S Y S^{\circledR}$ para a energia de deformação foi de 2.61067621. A componente de tensão de referência $\sigma_{y y}$ encontrada próxima à superfície de trinca, na coordenada $(3.9995,5.0000,0.0000)$ foi de 24.454 . Já a abertura da trinca, em $x=5$ e $z=0$ entre $y=4.999$ e $y=5.001$, no modelo de referência foi de 3.51E-02. Conforme já apresentado na Seção 4.3.2.2.

Os valores de energia de deformação, tensão $\sigma_{y y}$ e abertura de trinca para cada uma das análises descritas nessa seção foram reunidos nas Tabelas 4.17, 4.18 e 4.19 , respectivamente.

Tabela 4.17: P1 contendo nós enriquecidos via técnica Global-Local em modelos de trinca no interior dos elementos Globais: Energia de deformação - Cisalhamento x-

\begin{tabular}{cccc}
\hline Tipo de Modelagem & NGL & Energia & Diferença Energia (\%) \\
\hline Referência & 473610 & 2.610676 & \\
S/ enriquecimento & 1098 & 2.423007 & 7.19 \\
24 nós enriquecidos - ML1 & 1260 & 2.317484 & 11.23 \\
72 nós enriquecidos - ML1 & 1404 & 2.345982 & 10.14 \\
24 nós enriquecidos - ML2 & 1260 & 2.329203 & 10.78 \\
72 nós enriquecidos - ML2 & 1404 & 2.361409 & 9.55 \\
24 nós enriquecidos - ML4 & 1260 & 2.335891 & 10.53 \\
72 nós enriquecidos - ML4 & 1404 & 2.370090 & 9.22 \\
24 nós enriquecidos - ML5 & 1260 & 2.337281 & 10.47 \\
72 nós enriquecidos - ML5 & 1404 & 2.371900 & 9.15 \\
\hline
\end{tabular}

Pela análise das Tabelas 4.17, 4.18 e 4.19, percebe-se que as mesmas conclusões encontradas na Seção 4.3.3.1 aplicam-se ao modelo avaliado nessa seção, comparando essa seção com a Seção 4.3 .2 .2 . 
Tabela 4.18: P1 contendo nós enriquecidos via técnica Global-Local em modelos de trinca no interior dos elementos Globais: $\sigma_{y y}$ - Cisalhamento x-

\begin{tabular}{cccc}
\hline Tipo de Modelagem & NGL & $\sigma_{y y}$ & Diferença $\sigma_{y y}(\%)$ \\
\hline Referência & 473610 & 24.454 & \\
24 nós enriquecidos - ML1 & 1260 & 5.800 & 76.28 \\
72 nós enriquecidos - ML1 & 1404 & 6.525 & 73.32 \\
24 nós enriquecidos - ML2 & 1260 & 7.135 & 70.82 \\
72 nós enriquecidos - ML2 & 1404 & 8.295 & 66.08 \\
24 nós enriquecidos - ML4 & 1260 & 9.425 & 61.46 \\
72 nós enriquecidos - ML4 & 1404 & 11.350 & 53.59 \\
24 nós enriquecidos - ML5 & 1260 & 10.340 & 57.72 \\
72 nós enriquecidos - ML5 & 1404 & 12.600 & 48.47 \\
\hline
\end{tabular}

Tabela 4.19: P1 contendo nós enriquecidos via técnica Global-Local em modelos de trinca no interior dos elementos Globais: Abertura de Trinca - Cisalhamento x-

\begin{tabular}{cccc}
\hline Tipo de Modelagem & NGL & Abertura & Diferença Abertura (\%) \\
\hline Referência & 473610 & $3.51 \mathrm{E}-02$ & \\
24 nós enriquecidos - ML1 & 1260 & $1.36 \mathrm{E}-02$ & 61.24 \\
72 nós enriquecidos - ML1 & 1404 & $1.66 \mathrm{E}-02$ & 52.69 \\
24 nós enriquecidos - ML2 & 1260 & $1.47 \mathrm{E}-02$ & 58.11 \\
72 nós enriquecidos - ML2 & 1404 & $1.81 \mathrm{E}-02$ & 48.42 \\
24 nós enriquecidos - ML4 & 1260 & $1.53 \mathrm{E}-02$ & 56.40 \\
72 nós enriquecidos - ML4 & 1404 & $1.88 \mathrm{E}-02$ & 46.42 \\
24 nós enriquecidos - ML5 & 1260 & $1.54 \mathrm{E}-02$ & 56.11 \\
72 nós enriquecidos - ML5 & 1404 & $1.89 \mathrm{E}-02$ & 46.14 \\
\hline
\end{tabular}

\subsubsection{Bloco submetido a cisalhamento em $\mathrm{z}$}

Nesta etapa é considerada a modelagem com a carga de tração de -1 em " $z$ ".

O resultado de referência encontrado no software $A N S Y S^{\circledR}$ para a energia de deformação foi de 2.42946697. A componente de tensão de referência $\sigma_{y y}$ encontrada próxima à superfície de trinca, na coordenada $(3.9995,5.0000,0.0000)$ foi de 25.216. Já a abertura da trinca, em $x=5$ e $z=0$ entre $y=4.999$ e $y=5.001$, no modelo de referência foi de 2.61E-02. Conforme já apresentado na Seção 4.3.2.3.

Os valores de energia de deformação, tensão $\sigma_{y y}$ e abertura de trinca para cada uma das análises descritas nessa seção foram reunidos nas Tabelas 4.20, 4.21 e 4.22 , respectivamente.

Pela análise das Tabelas 4.20, 4.21 e 4.22, se percebe que as mesmas conclusões 
Tabela 4.20: P1 contendo nós enriquecidos via técnica Global-Local em modelos de trinca no interior dos elementos Globais: Energia de deformação - Cisalhamento z-

\begin{tabular}{cccc}
\hline Tipo de Modelagem & NGL & Energia & Diferença Energia (\%) \\
\hline Referência & 473610 & 2.429467 & \\
S/ enriquecimento & 1098 & 2.302912 & 5.21 \\
24 nós enriquecidos - ML1 & 1260 & 2.283670 & 6.00 \\
72 nós enriquecidos - ML1 & 1404 & 2.296087 & 5.49 \\
24 nós enriquecidos - ML2 & 1260 & 2.292092 & 5.65 \\
72 nós enriquecidos - ML2 & 1404 & 2.305197 & 5.12 \\
24 nós enriquecidos - ML4 & 1260 & 2.296319 & 5.48 \\
72 nós enriquecidos - ML4 & 1404 & 2.309844 & 4.92 \\
24 nós enriquecidos - ML5 & 1260 & 2.297174 & 5.45 \\
72 nós enriquecidos - ML5 & 1404 & 2.310786 & 4.89 \\
\hline
\end{tabular}

Tabela 4.21: P1 contendo nós enriquecidos via técnica Global-Local em modelos de trinca no interior dos elementos Globais: $\sigma_{y y}$ - Cisalhamento z-

\begin{tabular}{cccc}
\hline Tipo de Modelagem & NGL & $\sigma_{y y}$ & Diferença $\sigma_{y y}(\%)$ \\
\hline Referência & 473610 & 25.216 & \\
24 nós enriquecidos - ML1 & 1260 & 9.870 & 60.86 \\
72 nós enriquecidos - ML1 & 1404 & 10.545 & 58.18 \\
24 nós enriquecidos - ML2 & 1260 & 13.000 & 48.45 \\
72 nós enriquecidos - ML2 & 1404 & 14.050 & 44.28 \\
24 nós enriquecidos - ML4 & 1260 & 17.750 & 29.61 \\
72 nós enriquecidos - ML4 & 1404 & 19.550 & 22.47 \\
24 nós enriquecidos - ML5 & 1260 & 19.650 & 22.07 \\
72 nós enriquecidos - ML5 & 1404 & 21.750 & 13.75 \\
\hline
\end{tabular}

Tabela 4.22: P1 contendo nós enriquecidos via técnica Global-Local em modelos de trinca no interior dos elementos Globais: Abertura de Trinca - Cisalhamento z-

\begin{tabular}{cccc}
\hline Tipo de Modelagem & NGL & Abertura & Diferença Abertura (\%) \\
\hline Referência & 473610 & $2.61 \mathrm{E}-02$ & \\
24 nós enriquecidos - ML1 & 1260 & $1.86 \mathrm{E}-02$ & 28.60 \\
72 nós enriquecidos - ML1 & 1404 & $1.97 \mathrm{E}-02$ & 24.38 \\
24 nós enriquecidos - ML2 & 1260 & $2.03 \mathrm{E}-02$ & 22.07 \\
72 nós enriquecidos - ML2 & 1404 & $2.14 \mathrm{E}-02$ & 17.85 \\
24 nós enriquecidos - ML4 & 1260 & $2.09 \mathrm{E}-02$ & 19.77 \\
72 nós enriquecidos - ML4 & 1404 & $2.20 \mathrm{E}-02$ & 15.55 \\
24 nós enriquecidos - ML5 & 1260 & $2.11 \mathrm{E}-02$ & 19.00 \\
72 nós enriquecidos - ML5 & 1404 & $2.22 \mathrm{E}-02$ & 14.78 \\
\hline
\end{tabular}

encontradas na Seção 4.3.3.1 aplicam-se ao modelo avaliado nessa seção, comparando essa seção com a Seção 4.3.2.3. 


\subsubsection{Bloco Tracionado em y - Teste sobre o Parâmetro de Penalidade}

Alguns testes, a fim de calibrar os modelos utilizados e verificar outras possibilidades de enriquecimento, foram realizados. O primeiro contempla a variação do parâmetro de penalidade $(\eta)$, mensurando o impacto que este tem sobre a solução.

Para essa seção será utilizada apenas a malha local ML2, apresentada na Figura 4.10 e a configuração de 72 nós enriquecidos via Global-Local, apresentada na Figura 4.17. Além disso, aplicou-se a carga de tração de 1 em " $y$ ".

O resultado de referência encontrado no software $A N S Y S{ }^{\circledR}$ para a energia de deformação foi de 0.134346027. A componente de tensão de referência $\sigma_{y y}$, encontrada próxima à superfície de trinca, na coordenada $(3.9995,5.0000,0.0000)$ foi de 5.427. Já a abertura da trinca, em $x=5$ e $z=0$ entre $y=4.999$ e $y=5.001$, no modelo de referência foi de 6.89E-03. Conforme já apresentado na Seção 4.3.2.1.

O teste sobre o parâmetro de penalidade, foi realizado a partir da consideração do parâmetro $\eta$ calculado pela Equação $(2.28)$, resultando em $\eta=1.25 \mathrm{E} 10$. Para o teste, o problema foi modelado $\operatorname{com} \eta=1.25 \mathrm{E} 11$ e com $\eta=1.25 \mathrm{E} 9$. Esses valores foram escolhidos, porque cobrem a gama de variação de tamanhos dos elementos da malha global formadores da malha local utilizados em todos as modelagens desse trabalho. Características referentes as dimensões dos elementos globais são os únicos dados variáveis nos problemas abordados que influenciam no cálculo do parâmetro de penalidade. Como ponto de partida do teste o problema também foi modelado com o parâmetro $\eta=1.25$, que é um valor bem baixo, pouco representativo para o problema, e por isso se supõe que vá gerar resultados ruins.

Os valores de energia de deformação, tensão $\sigma_{y y}$ e abertura de trinca para cada uma das análises da variação do parâmetro de penalidade foram reunidos nas Tabelas $4.23,4.24$ e 4.25, respectivamente.

Como se nota pelas Tabelas 4.23, 4.24 e 4.25 nenhuma diferença nos resultados foi observada com a variação do parâmetro de penalidade na faixa de $\eta$ entre 1.25E9 até $1.25 \mathrm{E} 11$, somente a solução, com parâmetro de penalidade muito baixo, $\eta=1.25$ 
Tabela 4.23: Teste da variação do parâmetro de penalidade para P1: Energia de deformação - Tração y-

\begin{tabular}{cccc}
\hline Tipo de Modelagem & NGL & Energia & Diferença Energia (\%) \\
\hline Referência & 473610 & 0.134346 & \\
S/ enriquecimento & 1098 & 0.129206 & 3.83 \\
$\eta=1.25$ & 1404 & 0.122756 & 8.63 \\
$\eta=1.25 \mathrm{E} 9$ & 1404 & 0.131278 & 2.28 \\
$\eta=1.25 \mathrm{E} 10$ & 1404 & 0.131278 & 2.28 \\
$\eta=1.25 \mathrm{E} 11$ & 1404 & 0.131278 & 2.28 \\
\hline
\end{tabular}

Tabela 4.24: Teste da variação do parâmetro de penalidade para P1: $\sigma_{y y}$ - Tração y-

\begin{tabular}{cccc}
\hline Tipo de Modelagem & NGL & $\sigma_{y y}$ & Diferença $\sigma_{y y}(\%)$ \\
\hline Referência & 473610 & 5.427 & \\
$\eta=1.25$ & 1404 & 1.010 & 81.39 \\
$\eta=1.25 \mathrm{E} 9$ & 1404 & 2.820 & 48.04 \\
$\eta=1.25 \mathrm{E} 10$ & 1404 & 2.820 & 48.04 \\
$\eta=1.25 \mathrm{E} 11$ & 1404 & 2.820 & 48.04 \\
\hline
\end{tabular}

Tabela 4.25: Teste da variação do parâmetro de penalidade para P1: Abertura de Trinca - Tração y-

\begin{tabular}{cccc}
\hline Tipo de Modelagem & NGL & Abertura & Diferença Abertura (\%) \\
\hline Referência & 473610 & $6.89 \mathrm{E}-03$ & \\
$\eta=1.25$ & 1404 & $8.00 \mathrm{E}-05$ & 98.84 \\
$\eta=1.25 \mathrm{E} 9$ & 1404 & $5.76 \mathrm{E}-03$ & 16.35 \\
$\eta=1.25 \mathrm{E} 10$ & 1404 & $5.76 \mathrm{E}-03$ & 16.35 \\
$\eta=1.25 \mathrm{E} 11$ & 1404 & $5.76 \mathrm{E}-03$ & 16.35 \\
\hline
\end{tabular}

gerou resultados muito ruins. Isso significa que, o parâmetro de penalidade adotado, $\eta=1.25 \mathrm{E} 10$ está adequado, porque está retornando resultados estáveis, não deturpando os resultados e sua ordem de grandeza está compatível com os problemas analisados.

\subsubsection{Bloco Tracionado em y - Teste do Número de Iterações}

Outro teste realizado, com a finalidade de calibrar os modelos que estão sendo realizados, visa verificar a quantidade de iterações, dentro da técnica Global-Local necessárias para minimizar o erro da solução global transferida como condição de contorno para o problema local. 
Para essa seção será utilizada apenas a malha local ML2, apresentada na Figura 4.10 e a configuração de 72 nós enriquecidos via Global-Local, apresentada na Figura 4.17. Além disso, aplicou-se a carga de tração de 1 em " $y$ ".

O resultado de referência encontrado no software $A N S Y S^{\circledR}$ para a energia de deformação foi de 0.134346027. A componente de tensão de referência $\sigma_{y y}$, encontrada próxima à superfície de trinca, na coordenada (3.9995, 5.0000, 0.0000) foi de 5.427. Já a abertura da trinca, em $x=5$ e $z=0$ entre $y=4.999$ e $y=5.001$, no modelo de referência foi de 6.89E-03. Conforme já apresentado na Seção 4.3.2.1.

Os testes foram realizados de maneira a analisar até que ponto a realização de mais ciclos iterativos poderia auxiliar na geração de melhores resultados. Para tanto foram realizados três ciclos da técnica Global-Local no problema abordado nessa seção. Julgou-se necessária a realização desse teste para comprovar se, conforme Gupta et al. (2012), poucas iterações, aproximadamente duas, são suficientes no processo Global-Local para se atingir uma melhora nos resultados e a convergência de soluções.

Os valores de energia de deformação, tensão $\sigma_{y y}$ e abertura de trinca para a análise da influência dos ciclos da técnica Global-Local foram reunidos nas Tabelas 4.26, 4.27, e 4.28, respectivamente.

Tabela 4.26: Teste da influência dos ciclos da técnica Global-Local para P1:

Energia de deformação - Tração y-

\begin{tabular}{cccc}
\hline Tipo de Modelagem & NGL & Energia & Diferença Energia (\%) \\
\hline Referência & 473610 & 0.134346 & \\
S/ enriquecimento & 1098 & 0.129206 & 3.83 \\
Iteração 1 & 1404 & 0.130973 & 2.51 \\
Iteração 2 & 1404 & 0.131278 & 2.28 \\
Iteração 3 & 1404 & 0.131284 & 2.28 \\
\hline
\end{tabular}

Analisando as Tabelas 4.26, 4.27 e 4.28 é possível perceber que há uma maior diferença nos resultados quando se passa da primeira para a segunda iteração, de forma semelhante ao que foi proposto por Gupta et al. (2012). Da segunda para a terceira iteração pouca, ou nenhuma diferença nos valores de energia de deformação, 
Tabela 4.27: Teste da influência dos ciclos da técnica Global-Local para P1: $\sigma_{y y}$ Tração y-

\begin{tabular}{cccc}
\hline Tipo de Modelagem & NGL & $\sigma_{y y}$ & Diferença $\sigma_{y y}(\%)$ \\
\hline Referência & 473610 & 5.427 & \\
Iteração 1 & 1404 & 2.850 & 47.48 \\
Iteração 2 & 1404 & 2.820 & 48.04 \\
Iteração 3 & 1404 & 2.820 & 48.04 \\
\hline
\end{tabular}

Tabela 4.28: Teste da influência dos ciclos da técnica Global-Local para P1: Abertura de Trinca - Tração y-

\begin{tabular}{cccc}
\hline Tipo de Modelagem & NGL & Abertura & Diferença Abertura (\%) \\
\hline Referência & 473610 & $6.89 \mathrm{E}-03$ & \\
Iteração 1 & 1404 & $5.66 \mathrm{E}-03$ & 17.80 \\
Iteração 2 & 1404 & $5.76 \mathrm{E}-03$ & 16.35 \\
Iteração 3 & 1404 & $5.75 \mathrm{E}-03$ & 16.50 \\
\hline
\end{tabular}

tensão $\sigma_{y y}$ e abertura de trinca acontecem, por esse motivo, nesse trabalho, optou-se por utilizar os resultados da segunda iteração da técnica Global-Local.

\subsubsection{Bloco Tracionado em y - Teste do Enriquecimento com Funções Singulares}

Essa análise tem por objetivo unir as técnicas de enriquecimento nodais com funções singulares, no modelo local e utilização da técnica Global-Local, mostrando o poder das duas soluções utilizadas em conjunto. Trata-se de uma avaliação interessante, pois o emprego do enriquecimento nodal utilizando funções com derivadas singulares tem por objetivo substituir o refinamento de malha, na medida em que essas funções são capazes de descrever a singularidade no campo de tensões próximo à frente de trinca, algo que só seria possível através de uma malha muito refinada também nesta região.

Para essa seção será utilizada apenas a malha local ML2, apresentada na Figura 4.10 e a configuração de 72 nós enriquecidos via Global-Local, apresentada na Figura 4.17. Além disso, aplicou-se a carga de tração de 1 em " $y$ ".

O resultado de referência encontrado no software $A N S Y S^{\circledR}$ para a energia de 
deformação foi de 0.134346027. A componente de tensão de referência $\sigma_{y y}$, encontrada próxima à superfície de trinca, na coordenada $(3.9995,5.0000,0.0000)$ foi de 5.427. Já a abertura da trinca, em $x=5$ e $z=0$ entre $y=4.999$ e $y=5.001$, no modelo de referência foi de 6.89E-03. Conforme já apresentado na Seção 4.3.2.1.

No modelo descrito, foi realizado o enriquecimento dos nós da frente de trinca, do modelo local, com as funções que descrevem os três modos de abertura de trinca, são elas (2.7), 2.9), 2.8) e 2.10 para $j=1$ e (2.17) para $j=1$ e $j=2$. Assim, o modelo local adotado possui 14301 graus de liberdade (NGL).

Os valores de energia de deformação, tensão $\sigma_{y y}$ e abertura de trinca para a análise do enriquecimento, com funções singulares, dos nós próximos à frente de trinca no modelo local, foram reunidos nas Tabelas 4.29, 4.30 e 4.31, respectivamente.

Tabela 4.29: Teste do enriquecimento dos nós com funções singulares na malha local para P1: Energia de deformação - Tração y-

\begin{tabular}{cccc}
\hline Tipo de Modelagem & NGL & Energia & Diferença Energia (\%) \\
\hline Referência & 473610 & 0.134346 & \\
S/ enriquecimento Global-Local & 1098 & 0.129206 & 3.83 \\
C/ enriquecimento Global-Local e s/ Singular & 1404 & 0.131278 & 2.28 \\
C/ enriquecimento Global-Local e c/ Singular & 1404 & 0.132181 & 1.61 \\
\hline
\end{tabular}

Tabela 4.30: Teste do enriquecimento dos nós com funções singulares na malha local para P1: $\sigma_{y y}$ - Tração y-

\begin{tabular}{cccc}
\hline Tipo de Modelagem & NGL & $\sigma_{y y}$ & Diferença $\sigma_{y y}(\%)$ \\
\hline Referência & 473610 & 5.427 & \\
C/ enriquecimento Global-Local e s/ Singular & 1404 & 2.820 & 48.04 \\
C/ enriquecimento Global-Local e c/ Singular & 1404 & 23.400 & 331.18 \\
\hline
\end{tabular}

Tabela 4.31: Teste do enriquecimento dos nós com funções singulares na malha local para P1: Abertura de Trinca - Tração y-

\begin{tabular}{cccc}
\hline Tipo de Modelagem & NGL & Abertura & Diferença Abertura (\%) \\
\hline Referência & 473610 & $6.89 \mathrm{E}-03$ & \\
C/ enriquecimento Global-Local e s/ Singular & 1404 & $5.76 \mathrm{E}-03$ & 16.35 \\
C/ enriquecimento Global-Local e c/ Singular & 1404 & $6.09 \mathrm{E}-03$ & 11.56 \\
\hline
\end{tabular}

De acordo com as Tabelas 4.29 e 4.31, é possível notar o impacto favorável do 
enriquecimento do problema local com as funções singulares. Estas funções representam melhor o comportamento da solução na vizinhança da frente de trinca do que se comparadas às aproximações polinomiais. Todavia, na Tabela 4.30, encontra-se um valor de tensão $\sigma_{y y}$ muito mais alto do que, até mesmo, o valor de referência para o caso do modelo enriquecido com as funções singulares. Isso acontece, pois os modelos sem enriquecimento singular, incluindo o modelo de referência, não conseguem descrever tão bem quanto as funções de singularidades, a concentração de tensões na vizinhança da frente de trinca.

Cabe ainda comparar as Tabelas 4.29 e 4.31 com os resultados da Seção 4.3.3.1 das análises feitas com 72 nós enriquecidos das Tabelas 4.14 e 4.16. Nesta seção, as funções singulares enriquecem a malha ML2, produzindo uma solução final, seja em termos de energia, seja de abertura de trinca, mais próxima da referência, do que as quatro malhas locais utilizadas naquela seção. Esta observação ilustra o fato de que as funções singulares são mais adequadas do que o refinamento $h$ convencional para representar a concentração do campo de tensões na vizinhança da frente de trinca. Um alternativa mais eficiente à divisão de malhas adotada seria realizar um refinamento geométrico ou mesmo um refinamento $h p$ adaptativo. Diferenças mais grosseiras que são observadas em alguns dos resultados desta e de outras seções são advindas de erros de discretização na solução do problema local e não da estratégia Global-Local ou da implementação apresentada neste trabalho.

\subsubsection{Consolidação dos Resultados do P1}

Pela análise dos resultados apresentados nas Seções 4.3.2 e 4.3.3. para os três tipos de solicitações, Tração em y, Cisalhamento em x e Cisalhamento em z, foi possível perceber que todos os resultados convergiam para a solução de referência à medida que se refinava a malha local a ser utilizada na técnica Global-Local. Além disso, via de regra, quanto mais nós são enriquecidos via técnica Global-Local melhores eram os resultados. 
Uma importante conclusão foi observada ao comparar-se as modelagens das Seções 4.3 .2 e 4.3 .3 submetidas a solicitações correlatas. Foi possível perceber que na situação de trinca coincidente com a face dos elementos globais e enriquecimento de 54 nós via técnica Global-Local gerou melhores resultados do que a situação de trinca no interior dos elementos globais e enriquecimento de 72 nós via técnica Global-Local, mesmo essa última possuindo mais nós enriquecidos. Considera-se que essa diferença se deve ao fato dos problemas inerentes a própria descrição de uma trinca no interior de um elemento.

Outra análise que merece destaque se refere a solução de 6 nós enriquecidos abordada na Seção 4.3.2, para os três tipos de solicitações. É possível perceber que ao enriquecer apenas um nó, o suporte de suas funções de PU não contém toda a superfície de trinca, logo a abertura da trinca não pode, de fato, ser descrita no modelo global enriquecido.

Foram construídos gráficos com a descrição da variação da componente de tensão $\sigma_{y y}$ ao longo da coordenada $x$, nas coordenadas $y=5$ e $z=0$, para as três solicitações aqui discriminadas. Todos os gráficos foram realizados para o problema modelado com a ML5, já que ela retornou melhores resultados, tanto no caso da trinca coincidindo com as faces dos elementos globais para 6 e 54 nós enriquecidos, quanto para os modelos da trinca no interior dos elementos globais para 24 e 72 nós enriquecidos.

Pela análise dos gráficos apresentados nas Figuras 4.18, 4.19 e 4.20 é possível perceber que todas as modelagens via técnica Global-Local têm a variação da componente de tensão $\sigma_{y y}$ ao longo de $x$ tendendo para a solução de referência. Nota-se que a solução com 54 nós enriquecidos atinge maiores valores de tensão próximo à frente de trinca, porém a solução com 72 nós enriquecidos descreve melhor a variação da componente de tensão ao longo de $x$. Isso indica que ainda que a modelagem com a trinca no interior do elemento global guarde dificuldades de representação da descontinuidade dentro do elemento, o fato do enriquecimento ocorrer em mais nós nesse modelo melhora a representação da variação da componente de tensão ao 


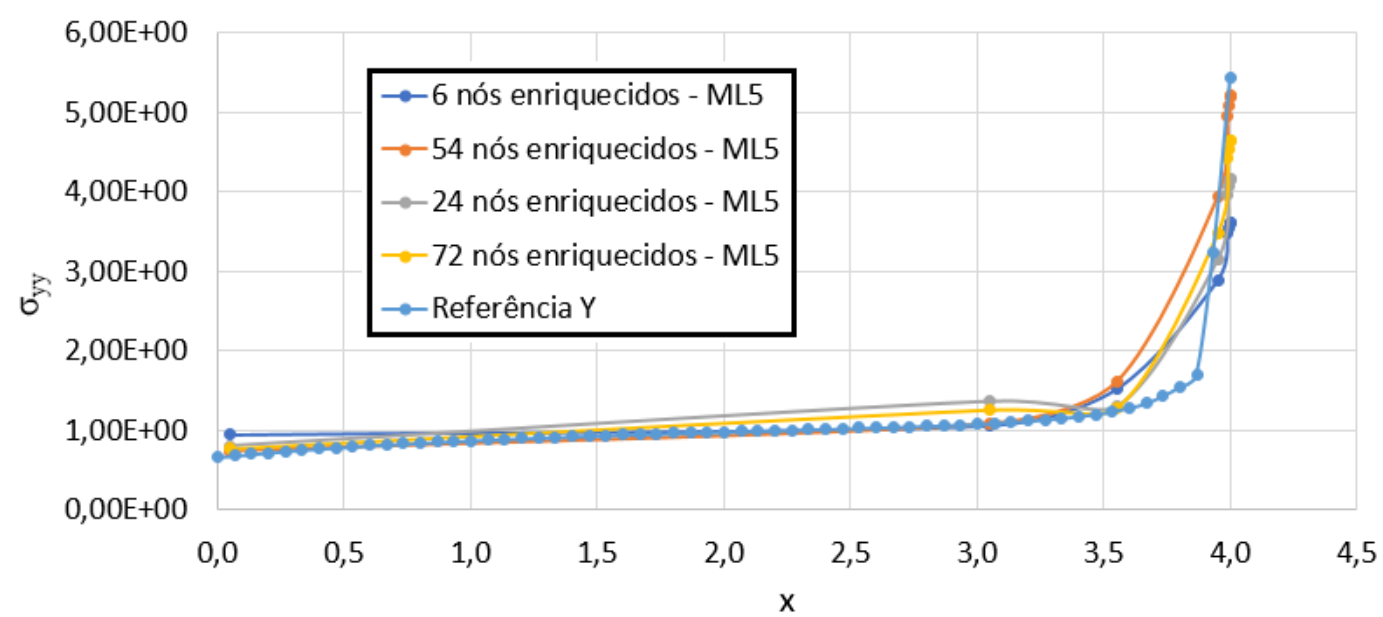

Figura 4.18: Variação de $\sigma_{y y}$ ao longo da coordenada $x$ em $y=5$ e $z=0$ - Tração em y.

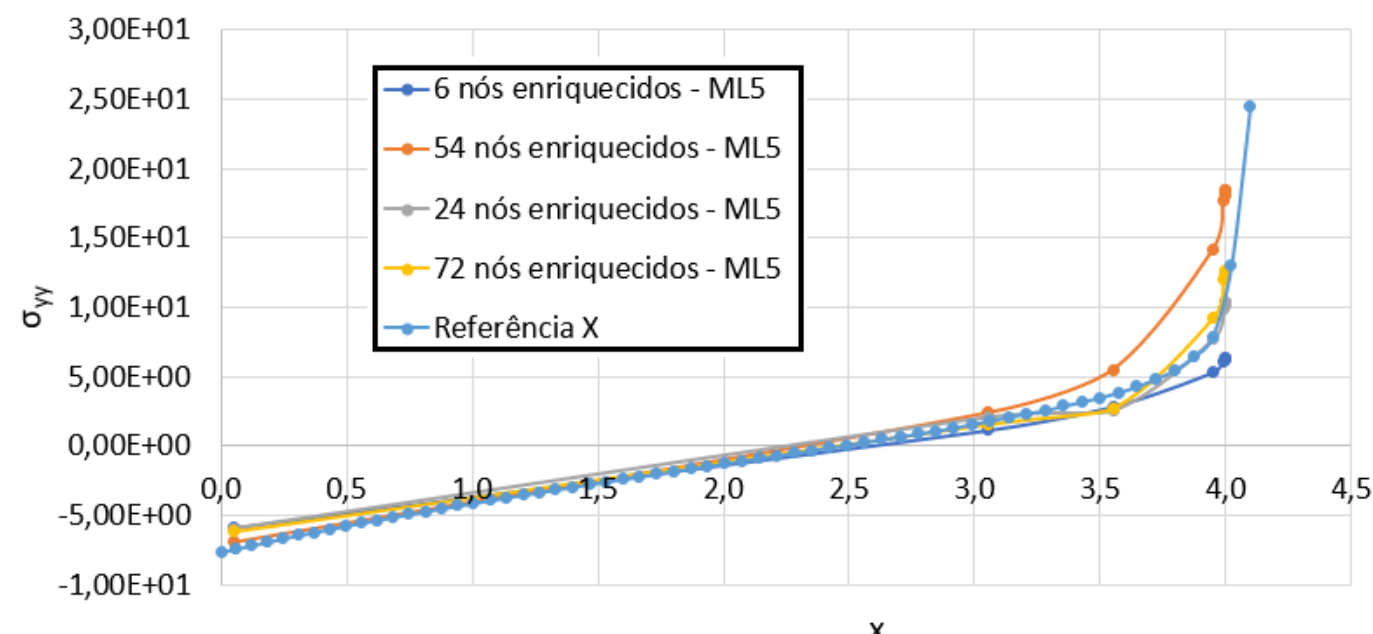

Figura 4.19: Variação de $\sigma_{y y}$ ao longo da coordenada $x$ em $y=5$ e $z=0$ Cisalhamento em $\mathrm{x}$.

longo de $x$ próximo à frente de trinca.

\subsection{Problema 2 - P2}

Conforme mencionado na Seção 4.2 , foi utilizado o software ANSYS ${ }^{\circledR}$ para criar o modelo de referência para o P2. Assim, utilizou-se uma malha de 130877 elementos finitos tetraédricos quadráticos (10 nós), concentrados na vizinhança da frente da superfície de trinca. A Figura 4.21 mostra a malha utilizada no $A N S Y S^{\circledR}$. Os 


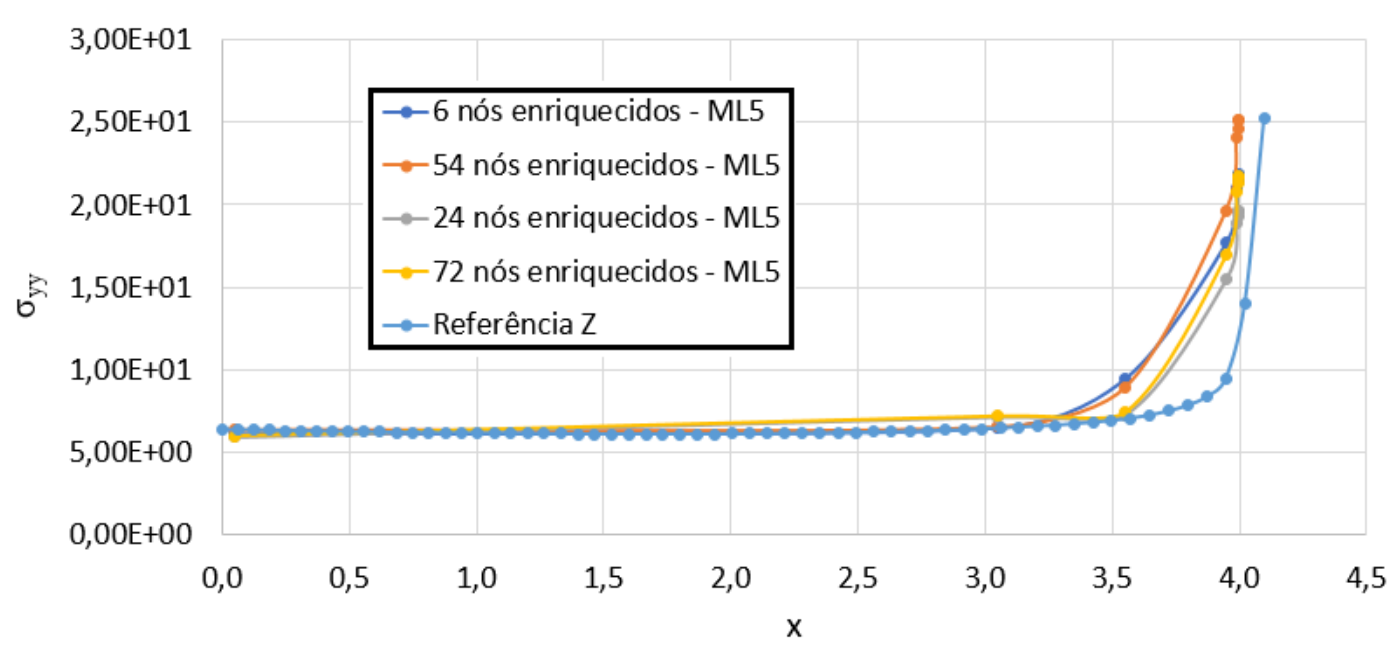

Figura 4.20: Variação de $\sigma_{y y}$ ao longo da coordenada $x$ em $y=5$ e $z=0$ Cisalhamento em z.

resultados encontrados serão apresentados nas seções que se seguem, de acordo com a solicitação aplicada no bloco.
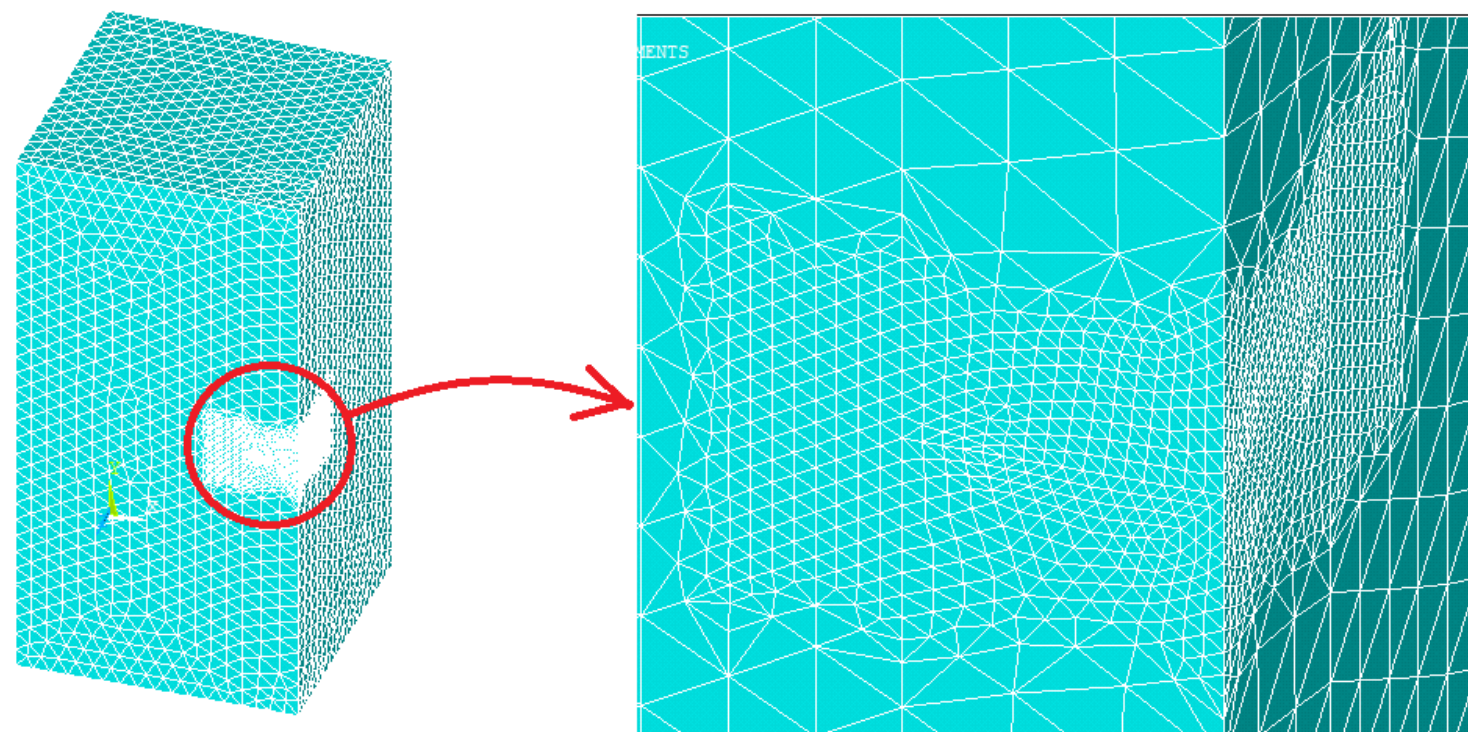

Figura 4.21: Malha do software $A N S Y S^{\circledR}$ usada para construir a solução de referência do $\mathrm{P} 2$. 


\subsubsection{Enriquecimento com Técnica Global-Local - Trinca Coincidente com as Faces dos Elementos Globais}

Nessa seção foi utilizada a malha Global MG2, ilustrada na Figura 4.4. Trata-se de uma modelagem analisada via MEFG com técnica Global-Local, sem a utilização de enriquecimento com funções que contêm derivadas singulares. Para tanto foram variadas as malhas locais de maneira a observar a influência do refinamento da malha local no resultado do modelo. Além disso, duas quantidades de nós enriquecidos via Global-Local foram estudados, a Figura 4.22 mostra o posicionamento e a quantidade desses nós, a saber, 4 e 27 nós, próximos à frente de trinca. A configuração de 4 nós enriquecidos, diz respeito àqueles que estão no contorno da superfície de trinca, já a de 27 nós, são todos os nós, compreendidos uma camada a mais em cada direção do contorno da trinca, ou seja, são os nós que envolvem toda a trinca no domínio local.
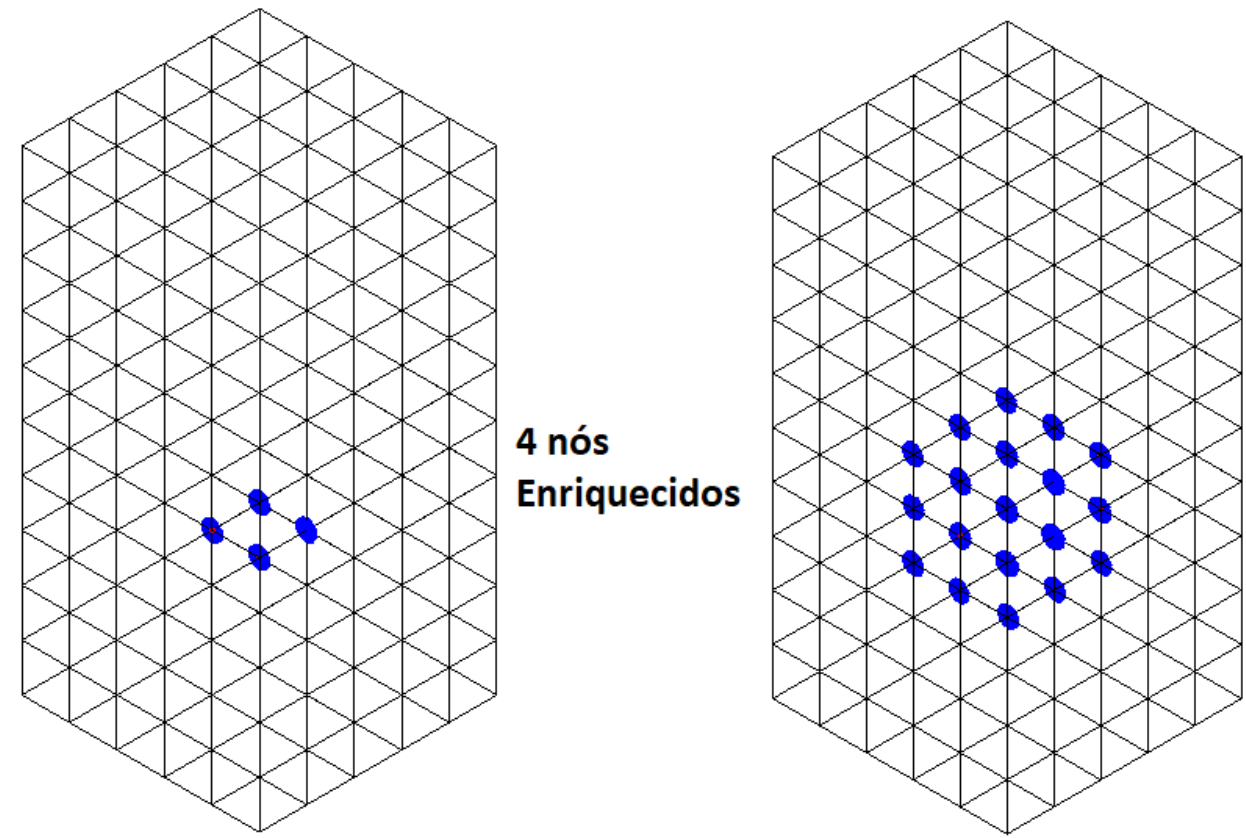

27 nós Enriquecidos

Figura 4.22: Desenho esquemático dos nós a serem enriquecidos do modelo.

Os modelos foram analisados com as malhas locais, ML1, ML2, ML3 e ML4, apresentadas nas Figuras 4.9, 4.10, 4.11 e 4.12, respectivamente. Não foi, contudo, possível modelar o problema local com a malha ML5 por problemas, provavelmente, 
inerentes a perturbações de ordem numérica e técnicas de solução de sistema de equações.

\subsubsection{Bloco Tracionado em y}

Nesta etapa é considerada a modelagem com a carga de tração de 1 em " $y$ ".

O resultado de referência encontrado no software $A N S Y S{ }^{\circledR}$ para a energia de deformação foi de 0.124143513. A componente de tensão de referência $\sigma_{y y}$ encontrada próxima à superfície de trinca, na coordenada $(3.9995,5.0000,5.0000)$ foi de 4.878. Já a abertura da trinca, em $x=5$ e $z=5$ entre $y=4.999$ e $y=5.001$, no modelo de referência foi de 3.95E-03.

Os valores de energia de deformação, tensão $\sigma_{y y}$ e abertura de trinca para cada uma das análises descritas nessa seção foram reunidos nas Tabelas 4.32, 4.33 e 4.34 , respectivamente.

Tabela 4.32: P2 contendo nós enriquecidos via técnica Global-Local em modelos de trinca coincidente com as faces dos elementos Globais: Energia de deformação Tração y-

\begin{tabular}{cccc}
\hline Tipo de Modelagem & NGL & Energia & Diferença Energia (\%) \\
\hline Referência & 546684 & 0.124144 & \\
S/ enriquecimento & 1083 & 0.123112 & 0.83 \\
4 nós enriquecidos - ML1 & 1092 & 0.123108 & 0.83 \\
27 nós enriquecidos - ML1 & 1161 & 0.123192 & 0.77 \\
4 nós enriquecidos - ML2 & 1092 & 0.123227 & 0.74 \\
27 nós enriquecidos - ML2 & 1161 & 0.123323 & 0.66 \\
4 nós enriquecidos - ML3 & 1092 & 0.123254 & 0.72 \\
27 nós enriquecidos - ML3 & 1161 & 0.123352 & 0.64 \\
4 nós enriquecidos - ML4 & 1092 & 0.123268 & 0.71 \\
27 nós enriquecidos - ML4 & 1161 & 0.123369 & 0.62 \\
\hline
\end{tabular}

Nas Tabelas 4.32 e 4.34 os resultados mostram que, ao enriquecer mais nós, menor é a diferença na energia e na abertura da trinca, calculados, quando comparados à referência. Na Tabela 4.33, os resultados mostram que ao enriquecer mais nós maior é a diferença em $\sigma_{y y}$, contrariando as expectativas. Esse fenômeno é observado apenas e excepcionalmente nesta seção e na Seção 4.4.1.3 e exclusivamente para o caso da tensão. Ainda que inesperado. Mesmo assim, deve ser destacado 
Tabela 4.33: P2 contendo nós enriquecidos via técnica Global-Local em modelos de trinca coincidente com as faces dos elementos Globais: $\sigma_{y y}$ - Tração y-

\begin{tabular}{cccc}
\hline Tipo de Modelagem & NGL & $\sigma_{y y}$ & Diferença $\sigma_{y y}(\%)$ \\
\hline Referência & 546684 & 4.878 & \\
4 nós enriquecidos - ML1 & 1092 & 2.310 & 52.64 \\
27 nós enriquecidos - ML1 & 1161 & 2.145 & 56.03 \\
4 nós enriquecidos - ML2 & 1092 & 2.880 & 40.96 \\
27 nós enriquecidos - ML2 & 1161 & 2.735 & 43.93 \\
4 nós enriquecidos - ML3 & 1092 & 3.090 & 36.65 \\
27 nós enriquecidos - ML3 & 1161 & 2.960 & 39.32 \\
4 nós enriquecidos - ML4 & 1092 & 3.685 & 24.46 \\
27 nós enriquecidos - ML4 & 1161 & 3.645 & 25.28 \\
\hline
\end{tabular}

Tabela 4.34: P2 contendo nós enriquecidos via técnica Global-Local em modelos de trinca coincidente com as faces dos elementos Globais: Abertura de Trinca -

Tração y-

\begin{tabular}{cccc}
\hline Tipo de Modelagem & NGL & Abertura & Diferença Abertura (\%) \\
\hline Referência & 546684 & $3.95 \mathrm{E}-03$ & \\
4 nós enriquecidos - ML1 & 1092 & $3.07 \mathrm{E}-03$ & 22.20 \\
27 nós enriquecidos - ML1 & 1161 & $3.04 \mathrm{E}-03$ & 22.96 \\
4 nós enriquecidos - ML2 & 1092 & $3.41 \mathrm{E}-03$ & 13.58 \\
27 nós enriquecidos - ML2 & 1161 & $3.44 \mathrm{E}-03$ & 12.82 \\
4 nós enriquecidos - ML3 & 1092 & $3.45 \mathrm{E}-03$ & 12.57 \\
27 nós enriquecidos - ML3 & 1161 & $3.49 \mathrm{E}-03$ & 11.56 \\
4 nós enriquecidos - ML4 & 1092 & $3.47 \mathrm{E}-03$ & 12.06 \\
27 nós enriquecidos - ML4 & 1161 & $3.52 \mathrm{E}-03$ & 10.80 \\
\hline
\end{tabular}

que a diferença entre as soluções com 4 e 27 nós enriquecidos tende a se reduzir à medida que a malha local é refinada. Isso é um indicativo da tendência de que para refinamentos complexos seria possível recuperar a superioridade do modelo com 27 nós enriquecidos.

\subsubsection{Bloco submetido a cisalhamento em $\mathrm{x}$}

Nesta etapa é considerada a modelagem com a carga de tração de -1 em " $x$ ".

O resultado de referência encontrado no software $A N S Y S^{\circledR}$ para a energia de deformação foi de 2.34627428. A componente de tensão de referência $\sigma_{y y}$ encontrada próxima à superfície de trinca, na coordenada (3.9995, 5.0000, 5.0000) foi de 21.032. Já a abertura da trinca, em $x=5$ e $z=5$ entre $y=4.999$ e $y=5.001$, no modelo de 
referência foi de 2.23E-02.

Os valores de energia de deformação, tensão $\sigma_{y y}$ e abertura de trinca para cada uma das análises descritas nessa seção foram reunidos nas Tabelas 4.35, 4.36 e 4.37. respectivamente.

Tabela 4.35: P2 contendo nós enriquecidos via técnica Global-Local em modelos de trinca coincidente com as faces dos elementos Globais: Energia de deformação -

Cisalhamento $\mathrm{x}$ -

\begin{tabular}{cccc}
\hline Tipo de Modelagem & NGL & Energia & Diferença Energia (\%) \\
\hline Referência & 546684 & 2.346274 & \\
S/ enriquecimento & 1083 & 2.249427 & 4.13 \\
4 nós enriquecidos - ML1 & 1092 & 2.246108 & 4.27 \\
27 nós enriquecidos - ML1 & 1161 & 2.248228 & 4.18 \\
4 nós enriquecidos - ML2 & 1092 & 2.248137 & 4.18 \\
27 nós enriquecidos - ML2 & 1161 & 2.250634 & 4.08 \\
4 nós enriquecidos - ML3 & 1092 & 2.248576 & 4.16 \\
27 nós enriquecidos - ML3 & 1161 & 2.251154 & 4.05 \\
4 nós enriquecidos - ML4 & 1092 & 2.248749 & 4.16 \\
27 nós enriquecidos - ML4 & 1161 & 2.251361 & 4.05 \\
\hline
\end{tabular}

Tabela 4.36: P2 contendo nós enriquecidos via técnica Global-Local em modelos de trinca coincidente com as faces dos elementos Globais: $\sigma_{y y}$ - Cisalhamento x-

\begin{tabular}{cccc}
\hline Tipo de Modelagem & NGL & $\sigma_{y y}$ & Diferença $\sigma_{y y}(\%)$ \\
\hline Referência & 546684 & 21.032 & \\
4 nós enriquecidos - ML1 & 1092 & 7.535 & 64.17 \\
27 nós enriquecidos - ML1 & 1161 & 8.645 & 58.90 \\
4 nós enriquecidos - ML2 & 1092 & 8.900 & 57.68 \\
27 nós enriquecidos - ML2 & 1161 & 10.415 & 50.48 \\
4 nós enriquecidos - ML3 & 1092 & 9.420 & 55.21 \\
27 nós enriquecidos - ML3 & 1161 & 11.070 & 47.37 \\
4 nós enriquecidos - ML4 & 1092 & 10.760 & 48.84 \\
27 nós enriquecidos - ML4 & 1161 & 12.900 & 38.66 \\
\hline
\end{tabular}

Nas Tabelas 4.35, 4.36 e 4.37 os resultados mostram que, ao enriquecer mais nós, menor é a diferença na energia, em $\sigma_{y y}$ e na abertura da trinca, calculados, quando comparados à referência. Percebe-se que a solução melhora com o refinamento da malha local, apresentando uma convergência maior para o caso de 27 nós enriquecidos, ainda que a diferença em $\sigma_{y y}$, em relação a solução de referência, ainda esteja alta. 
Tabela 4.37: P2 contendo nós enriquecidos via técnica Global-Local em modelos de trinca coincidente com as faces dos elementos Globais: Abertura de Trinca -

Cisalhamento $\mathrm{x}$ -

\begin{tabular}{cccc}
\hline Tipo de Modelagem & NGL & Abertura & Diferença Abertura (\%) \\
\hline Referência & 546684 & $2.23 \mathrm{E}-02$ & \\
4 nós enriquecidos - ML1 & 1092 & $1.32 \mathrm{E}-02$ & 40.75 \\
27 nós enriquecidos - ML1 & 1161 & $1.46 \mathrm{E}-02$ & 34.47 \\
4 nós enriquecidos - ML2 & 1092 & $1.44 \mathrm{E}-02$ & 35.37 \\
27 nós enriquecidos - ML2 & 1161 & $1.59 \mathrm{E}-02$ & 28.64 \\
4 nós enriquecidos - ML3 & 1092 & $1.47 \mathrm{E}-02$ & 34.02 \\
27 nós enriquecidos - ML3 & 1161 & $1.60 \mathrm{E}-02$ & 28.19 \\
4 nós enriquecidos - ML4 & 1092 & $1.48 \mathrm{E}-02$ & 33.57 \\
27 nós enriquecidos - ML4 & 1161 & $1.62 \mathrm{E}-02$ & 27.29 \\
\hline
\end{tabular}

\subsubsection{Bloco submetido a cisalhamento em $\mathrm{z}$}

Nesta etapa é considerada a modelagem com a carga de tração de -1 em " $z$ ".

O resultado de referência encontrado no software $A N S Y S^{\circledR}$ para a energia de deformação foi de 2.3462719. A componente de tensão de referência $\sigma_{y y}$ encontrada próxima à superfície de trinca, na coordenada $(3.9995,5.0000,5.0000)$ foi de 21.032. Já a abertura da trinca, em $x=5$ e $z=5$ entre $y=4.999$ e $y=5.001$, no modelo de referência foi de $2.22 \mathrm{E}-02$.

Os valores de energia de deformação, tensão $\sigma_{y y}$ e abertura de trinca para cada uma das análises descritas nessa seção foram reunidos nas Tabelas 4.38, 4.39 e 4.40. respectivamente.

Pela análise das Tabelas 4.38, 4.39 e 4.40, percebe-se que as mesmas conclusões encontradas na Seção 4.4.1.1 aplicam-se ao modelo avaliado nessa seção. Adicionalmente, observa-se na Tabela 4.39, que para a malha local ML4, mais refinada, o problema de se encontrar valores piores de $\sigma_{y y}$ para 27 nós enriquecidos, se comparado ao modelo de 4 nós enriquecidos, não mais ocorre alinhando-se com a tendência observada na Seção 4.4.1.1. 
Tabela 4.38: P2 contendo nós enriquecidos via técnica Global-Local em modelos de trinca coincidente com as faces dos elementos Globais: Energia de deformação -

Cisalhamento Z-

\begin{tabular}{cccc}
\hline Tipo de Modelagem & NGL & Energia & Diferença Energia (\%) \\
\hline Referência & 546684 & 2.346272 & \\
S/ enriquecimento & 1083 & 2.249427 & 4.13 \\
4 nós enriquecidos - ML1 & 1092 & 2.246107 & 4.27 \\
27 nós enriquecidos - ML1 & 1161 & 2.248220 & 4.18 \\
4 nós enriquecidos - ML2 & 1092 & 2.248136 & 4.18 \\
27 nós enriquecidos - ML2 & 1161 & 2.250626 & 4.08 \\
4 nós enriquecidos - ML3 & 1092 & 2.248575 & 4.16 \\
27 nós enriquecidos - ML3 & 1161 & 2.251145 & 4.05 \\
4 nós enriquecidos - ML4 & 1092 & 2.248919 & 4.15 \\
27 nós enriquecidos - ML4 & 1161 & 2.251539 & 4.04 \\
\hline
\end{tabular}

Tabela 4.39: P2 contendo nós enriquecidos via técnica Global-Local em modelos de trinca coincidente com as faces dos elementos Globais: $\sigma_{y y}$ - Cisalhamento z-

\begin{tabular}{cccc}
\hline Tipo de Modelagem & NGL & $\sigma_{y y}$ & Diferença $\sigma_{y y}(\%)$ \\
\hline Referência & 546684 & 21.032 & \\
4 nós enriquecidos - ML1 & 1092 & 10.335 & 50.86 \\
27 nós enriquecidos - ML1 & 1161 & 9.955 & 52.67 \\
4 nós enriquecidos - ML2 & 1092 & 12.650 & 39.85 \\
27 nós enriquecidos - ML2 & 1161 & 12.500 & 40.57 \\
4 nós enriquecidos - ML3 & 1092 & 13.500 & 35.81 \\
27 nós enriquecidos - ML3 & 1161 & 13.450 & 36.05 \\
4 nós enriquecidos - ML4 & 1092 & 15.550 & 26.07 \\
27 nós enriquecidos - ML4 & 1161 & 15.800 & 24.88 \\
\hline
\end{tabular}

Tabela 4.40: P2 contendo nós enriquecidos via técnica Global-Local em modelos de trinca coincidente com as faces dos elementos Globais: Abertura de Trinca -

Cisalhamento z-

\begin{tabular}{cccc}
\hline Tipo de Modelagem & NGL & Abertura & Diferença Abertura (\%) \\
\hline Referência & 546684 & $2.22 \mathrm{E}-02$ & \\
4 nós enriquecidos - ML1 & 1092 & $1.32 \mathrm{E}-02$ & 40.65 \\
27 nós enriquecidos - ML1 & 1161 & $1.46 \mathrm{E}-02$ & 34.35 \\
4 nós enriquecidos - ML2 & 1092 & $1.44 \mathrm{E}-02$ & 35.25 \\
27 nós enriquecidos - ML2 & 1161 & $1.59 \mathrm{E}-02$ & 28.51 \\
4 nós enriquecidos - ML3 & 1092 & $1.47 \mathrm{E}-02$ & 33.90 \\
27 nós enriquecidos - ML3 & 1161 & $1.60 \mathrm{E}-02$ & 28.06 \\
4 nós enriquecidos - ML4 & 1092 & $1.47 \mathrm{E}-02$ & 33.90 \\
27 nós enriquecidos - ML4 & 1161 & $1.61 \mathrm{E}-02$ & 27.61 \\
\hline
\end{tabular}




\subsubsection{Enriquecimento com Técnica Global-Local - Trinca no Interior dos Elementos Globais}

Nessa seção foi utilizada a malha Global MG3, ilustrada na Figura 4.5. Trata-se de uma modelagem analisada via MEFG com técnica Global-Local, sem a utilização de enriquecimento com funções que contêm derivadas singulares. Para tanto foram variadas as malhas locais de maneira a observar a influência do refinamento da malha local no resultado do modelo. Além disso, duas quantidades de nós enriquecidos via Global-Local foram estudados, a Figura 4.23 mostra o posicionamento e a quantidade desses nós, a saber, 8 e 36 nós, próximos à frente de trinca. A configuração de 8 nós enriquecidos diz respeito àqueles nós que compõem o elemento cortado pela trinca, já a de 36 nós, são todos os nós, compreendidos uma camada a mais em cada direção a partir do elemento que contém a trinca.
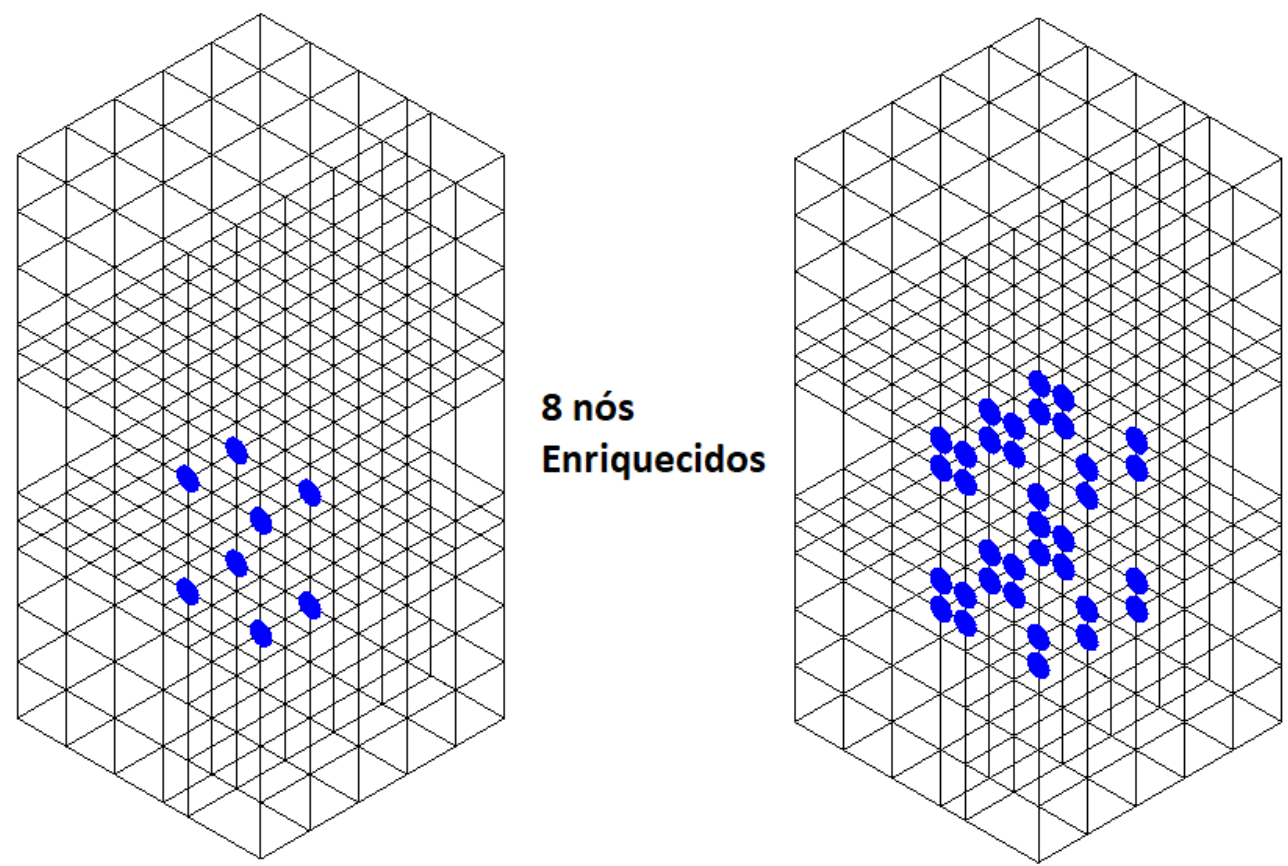

36 nós Enriquecidos

Figura 4.23: Desenho esquemático dos nós a serem enriquecidos do modelo.

Os modelos foram analisados com as malhas locais, ML1, ML2 e ML4, apresentadas nas Figuras 4.9, 4.10 e 4.12, respectivamente. A malha ML3 foi descartada nessa análise, pois seus elementos não se encontram completamente aninhados na 
malha do domínio global. Não foi, contudo, possível modelar o problema local com a malha ML5 pelo mesmo motivo apresentado na Seção 4.4.1.

\subsubsection{Bloco Tracionado em y}

Nesta etapa é considerada a modelagem com a carga de tração de 1. em " $y$ ".

O resultado de referência encontrado no software $A N S Y S^{\circledR}$ para a energia de deformação foi de 0.124143513. A componente de tensão de referência $\sigma_{y y}$ encontrada próxima à superfície de trinca, na coordenada $(3.9995,5.0000,5.0000)$ foi de 4.878. Já a abertura da trinca, em $x=5$ e $z=5$ entre $y=4.999$ e $y=5.001$, no modelo de referência foi de 3.95E-03. Conforme já apresentado na Seção 4.4.1.1.

Os valores de energia de deformação, tensão $\sigma_{y y}$ e abertura de trinca para cada uma das análises descritas nessa seção foram reunidos nas Tabelas 4.41 , 4.42 e 4.43 , respectivamente.

Tabela 4.41: P2 contendo nós enriquecidos via técnica Global-Local em modelos de trinca no interior dos elementos Globais: Energia de deformação - Tração y-

\begin{tabular}{cccc}
\hline Tipo de Modelagem & NGL & Energia & Diferença Energia (\%) \\
\hline Referência & 546684 & 0.124144 & \\
S/ enriquecimento & 1083 & 0.123112 & 0.83 \\
8 nós enriquecidos - ML1 & 1212 & 0.123100 & 0.84 \\
36 nós enriquecidos - ML1 & 1296 & 0.123172 & 0.78 \\
8 nós enriquecidos - ML2 & 1212 & 0.123234 & 0.73 \\
36 nós enriquecidos - ML2 & 1296 & 0.123315 & 0.67 \\
8 nós enriquecidos - ML4 & 1212 & 0.123280 & 0.70 \\
36 nós enriquecidos - ML4 & 1296 & 0.123366 & 0.63 \\
\hline
\end{tabular}

Tabela 4.42: P2 contendo nós enriquecidos via técnica Global-Local em modelos de trinca no interior dos elementos Globais: $\sigma_{y y}$ - Tração y-

\begin{tabular}{cccc}
\hline Tipo de Modelagem & NGL & $\sigma_{y y}$ & Diferença $\sigma_{y y}(\%)$ \\
\hline Referência & 546684 & 4.878 & \\
8 nós enriquecidos - ML1 & 1212 & 1.460 & 70.07 \\
36 nós enriquecidos - ML1 & 1296 & 1.550 & 68.22 \\
8 nós enriquecidos - ML2 & 1212 & 1.950 & 60.02 \\
36 nós enriquecidos - ML2 & 1296 & 2.100 & 56.95 \\
8 nós enriquecidos - ML4 & 1212 & 2.720 & 44.24 \\
36 nós enriquecidos - ML4 & 1296 & 2.980 & 38.91 \\
\hline
\end{tabular}


Tabela 4.43: P2 contendo nós enriquecidos via técnica Global-Local em modelos de trinca no interior dos elementos Globais: Abertura de Trinca - Tração y-

\begin{tabular}{cccc}
\hline Tipo de Modelagem & NGL & Abertura & Diferença Abertura (\%) \\
\hline Referência & 546684 & $3.95 \mathrm{E}-03$ & \\
8 nós enriquecidos - ML1 & 1212 & $2.62 \mathrm{E}-03$ & 33.60 \\
36 nós enriquecidos - ML1 & 1296 & $2.71 \mathrm{E}-03$ & 31.32 \\
8 nós enriquecidos - ML2 & 1212 & $3.08 \mathrm{E}-03$ & 21.95 \\
36 nós enriquecidos - ML2 & 1296 & $3.22 \mathrm{E}-03$ & 18.40 \\
8 nós enriquecidos - ML4 & 1212 & $3.18 \mathrm{E}-03$ & 19.41 \\
36 nós enriquecidos - ML4 & 1296 & $3.33 \mathrm{E}-03$ & 15.61 \\
\hline
\end{tabular}

Nas Tabelas 4.41, 4.42 e 4.43 os resultados mostram que, ao enriquecer mais nós menor é a diferença na energia, em $\sigma_{y y}$ e na abertura da trinca, calculados, quando comparados à referência. Percebe-se que a solução melhora com o refinamento da malha local, apresentando uma convergência maior para o caso de 36 nós enriquecidos. Comparando-se com a Seção 4.4.1.1, o modelo de 36 nós, aqui apresentado, mostra-se menos eficiente para gerar melhores resultados do que o modelo daquela seção de 24 nós. Ainda que não haja erros oriundos da integração numérica, uma vez que essa ocorre nos pontos de Gauss dos elementos locais, há uma dificuldade inerente ao fato de se descrever uma trinca no interior de um elemento, já discutida naquela seção.

\subsubsection{Bloco submetido a cisalhamento em $\mathrm{x}$}

Nesta etapa é considerada a modelagem com a carga de tração de -1 em " $x$ ".

O resultado de referência encontrado no software $A N S Y S^{\circledR}$ para a energia de deformação foi de 2.34627428. A componente de tensão de referência $\sigma_{y y}$ encontrada próxima à superfície de trinca, na coordenada $(3.9995,5.0000,5.0000)$ foi de 21.032. Já a abertura da trinca, em $x=5$ e $z=5$ entre $y=4.999$ e $y=5.001$, no modelo de referência foi de 2.23E-02. Conforme já apresentado na Seção 4.4.1.2.

Os valores de energia de deformação, tensão $\sigma_{y y}$ e abertura de trinca para cada uma das análises descritas nessa seção foram reunidos nas Tabelas $4.44,4.45$ e 4.46, respectivamente. 
Tabela 4.44: P2 contendo nós enriquecidos via técnica Global-Local em modelos de trinca no interior dos elementos Globais: Energia de deformação - Cisalhamento x-

\begin{tabular}{cccc}
\hline Tipo de Modelagem & NGL & Energia & Diferença Energia (\%) \\
\hline Referência & 546684 & 2.346274 & \\
S/ enriquecimento & 1083 & 2.249427 & 4.13 \\
8 nós enriquecidos - ML1 & 1212 & 2.224659 & 5.18 \\
36 nós enriquecidos - ML1 & 1296 & 2.229721 & 4.97 \\
8 nós enriquecidos - ML2 & 1212 & 2.226287 & 5.11 \\
36 nós enriquecidos - ML2 & 1296 & 2.231718 & 4.88 \\
8 nós enriquecidos - ML4 & 1212 & 2.226823 & 5.09 \\
36 nós enriquecidos - ML4 & 1296 & 2.232366 & 4.85 \\
\hline
\end{tabular}

Tabela 4.45: P2 contendo nós enriquecidos via técnica Global-Local em modelos de trinca no interior dos elementos Globais: $\sigma_{y y}$ - Cisalhamento x-

\begin{tabular}{cccc}
\hline Tipo de Modelagem & NGL & $\sigma_{y y}$ & Diferença $\sigma_{y y}(\%)$ \\
\hline Referência & 546684 & 21.032 & \\
8 nós enriquecidos - ML1 & 1212 & 4.615 & 78.06 \\
36 nós enriquecidos - ML1 & 1296 & 4.905 & 76.68 \\
8 nós enriquecidos - ML2 & 1212 & 5.695 & 72.92 \\
36 nós enriquecidos - ML2 & 1296 & 6.230 & 70.38 \\
8 nós enriquecidos - ML4 & 1212 & 7.405 & 64.79 \\
36 nós enriquecidos - ML4 & 1296 & 8.325 & 60.42 \\
\hline
\end{tabular}

Tabela 4.46: P2 contendo nós enriquecidos via técnica Global-Local em modelos de trinca no interior dos elementos Globais: Abertura de Trinca - Cisalhamento x-

\begin{tabular}{cccc}
\hline Tipo de Modelagem & NGL & Abertura & Diferença Abertura (\%) \\
\hline Referência & 546684 & $2.23 \mathrm{E}-02$ & \\
8 nós enriquecidos - ML1 & 1212 & $8.80 \mathrm{E}-03$ & 60.50 \\
36 nós enriquecidos - ML1 & 1296 & $1.03 \mathrm{E}-02$ & 53.77 \\
8 nós enriquecidos - ML2 & 1212 & $9.80 \mathrm{E}-03$ & 56.01 \\
36 nós enriquecidos - ML2 & 1296 & $1.13 \mathrm{E}-02$ & 49.28 \\
8 nós enriquecidos - ML4 & 1212 & $1.00 \mathrm{E}-02$ & 55.12 \\
36 nós enriquecidos - ML4 & 1296 & $1.16 \mathrm{E}-02$ & 47.94 \\
\hline
\end{tabular}

Pela análise das Tabelas 4.44, 4.45 e 4.46, percebe-se que as mesmas conclusões encontradas na Seção 4.4.2.1 aplicam-se ao modelo avaliado nessa seção, comparando essa seção com a Seção 4.4.1.2.

\subsubsection{Bloco submetido a cisalhamento em $\mathrm{z}$}

Nesta etapa é considerada a modelagem com a carga de tração de -1 em " $z$ ".

O resultado de referência encontrado no software $A N S Y S{ }^{\circledR}$ para a energia de 
deformação foi de 2.3462719. A componente de tensão de referência $\sigma_{y y}$ encontrada próxima à superfície de trinca, na coordenada (3.9995, 5.0000, 5.0000) foi de 21.032. Já a abertura da trinca, em $x=5$ e $z=5$ entre $y=4.999$ e $y=5.001$, no modelo de referência foi de 2.22E-02. Conforme já apresentado na Seção 4.4.1.3.

Os valores de energia de deformação, tensão $\sigma_{y y}$ e abertura de trinca para cada uma das análises descritas nessa seção foram reunidos nas Tabelas 4.47, 4.48 e 4.49 . respectivamente.

Tabela 4.47: P2 contendo nós enriquecidos via técnica Global-Local em modelos de trinca no interior dos elementos Globais: Energia de deformação - Cisalhamento z-

\begin{tabular}{cccc}
\hline Tipo de Modelagem & NGL & Energia & Diferença Energia (\%) \\
\hline Referência & 546684 & 2.346272 & \\
S/ enriquecimento & 1083 & 2.249427 & 4.13 \\
8 nós enriquecidos - ML1 & 1212 & 2.231383 & 4.90 \\
36 nós enriquecidos - ML1 & 1296 & 2.236088 & 4.70 \\
8 nós enriquecidos - ML2 & 1212 & 2.232625 & 4.84 \\
36 nós enriquecidos - ML2 & 1296 & 2.237807 & 4.62 \\
8 nós enriquecidos - ML4 & 1212 & 2.233109 & 4.82 \\
36 nós enriquecidos - ML4 & 1296 & 2.238465 & 4.59 \\
\hline
\end{tabular}

Tabela 4.48: P2 contendo nós enriquecidos via técnica Global-Local em modelos de trinca no interior dos elementos Globais: $\sigma_{y y}$ - Cisalhamento z-

\begin{tabular}{cccc}
\hline Tipo de Modelagem & NGL & $\sigma_{y y}$ & Diferença $\sigma_{y y}(\%)$ \\
\hline Referência & 546684 & 21.032 & \\
8 nós enriquecidos - ML1 & 1212 & 6.670 & 68.29 \\
36 nós enriquecidos - ML1 & 1296 & 7.150 & 66.00 \\
8 nós enriquecidos - ML2 & 1212 & 7.650 & 63.63 \\
36 nós enriquecidos - ML2 & 1296 & 8.440 & 59.87 \\
8 nós enriquecidos - ML4 & 1212 & 9.125 & 56.61 \\
36 nós enriquecidos - ML4 & 1296 & 10.400 & 50.55 \\
\hline
\end{tabular}

Pela análise das Tabelas 4.47, 4.48 e 4.49, as mesmas conclusões observadas na Seção 4.4.2.1 aplicam-se ao modelo avaliado nessa seção, comparando essa seção com a Seção 4.4.1.3. 
Tabela 4.49: P2 contendo nós enriquecidos via técnica Global-Local em modelos de trinca no interior dos elementos Globais: Abertura de Trinca - Cisalhamento z-

\begin{tabular}{cccc}
\hline Tipo de Modelagem & NGL & Abertura & Diferença Abertura (\%) \\
\hline Referência & 546684 & $2.22 \mathrm{E}-02$ & \\
8 nós enriquecidos - ML1 & 1212 & $7.50 \mathrm{E}-03$ & 66.28 \\
36 nós enriquecidos - ML1 & 1296 & $9.60 \mathrm{E}-03$ & 56.83 \\
8 nós enriquecidos - ML2 & 1212 & $8.40 \mathrm{E}-03$ & 62.23 \\
36 nós enriquecidos - ML2 & 1296 & $1.08 \mathrm{E}-02$ & 51.44 \\
8 nós enriquecidos - ML4 & 1212 & $8.70 \mathrm{E}-03$ & 60.88 \\
36 nós enriquecidos - ML4 & 1296 & $1.11 \mathrm{E}-02$ & 50.09 \\
\hline
\end{tabular}

\subsubsection{Consolidação dos Resultados do P2}

Pela análise dos resultados apresentados nas Seções 4.4.1 e 4.4.2, para os três tipos de solicitações, Tração em y, Cisalhamento em x e Cisalhamento em z, foi possível perceber que todos os resultados convergiam para a solução de referência à medida que se refinava a malha local a ser utilizada na técnica Global-Local. Além disso, via de regra, quanto mais nós são enriquecidos via técnica Global-Local melhores eram os resultados. De forma semelhante ao observado para o problema P1, conforme apresentado na Seção 4.3.4.

Também de maneira análoga ao problema P1, comparou-se as modelagens das Seções 4.4.1 e 4.4 .2 submetidas a solicitações correlatas. Foi possível perceber que na situação de trinca coincidente com a face dos elementos globais e enriquecimento de 24 nós via técnica Global-Local gerou melhores resultados do que a situação de trinca no interior dos elementos globais e enriquecimento de 36 nós via técnica Global-Local, mesmo essa última possuindo mais nós enriquecidos. Considera-se que essa diferença deve-se ao fato dos problemas inerentes a própria descrição de uma trinca no interior de um elemento, assim como o concluído na Seção 4.3.4, referente ao P1.

Foram traçados gráficos com a descrição da variação da componente de tensão $\sigma_{y y}$ ao longo da coordenada $x$, nas coordenadas $y=5$ e $z=5$, para as três solicitações aqui discriminadas. Todos os gráficos foram realizados para o problema modelado com a 
ML4, já que ela retornou melhores resultados, tanto no caso da trinca coincidindo com as faces dos elementos globais para 4 e 27 nós enriquecidos, quanto para os modelos da trinca no interior dos elementos globais para 8 e 36 nós enriquecidos.

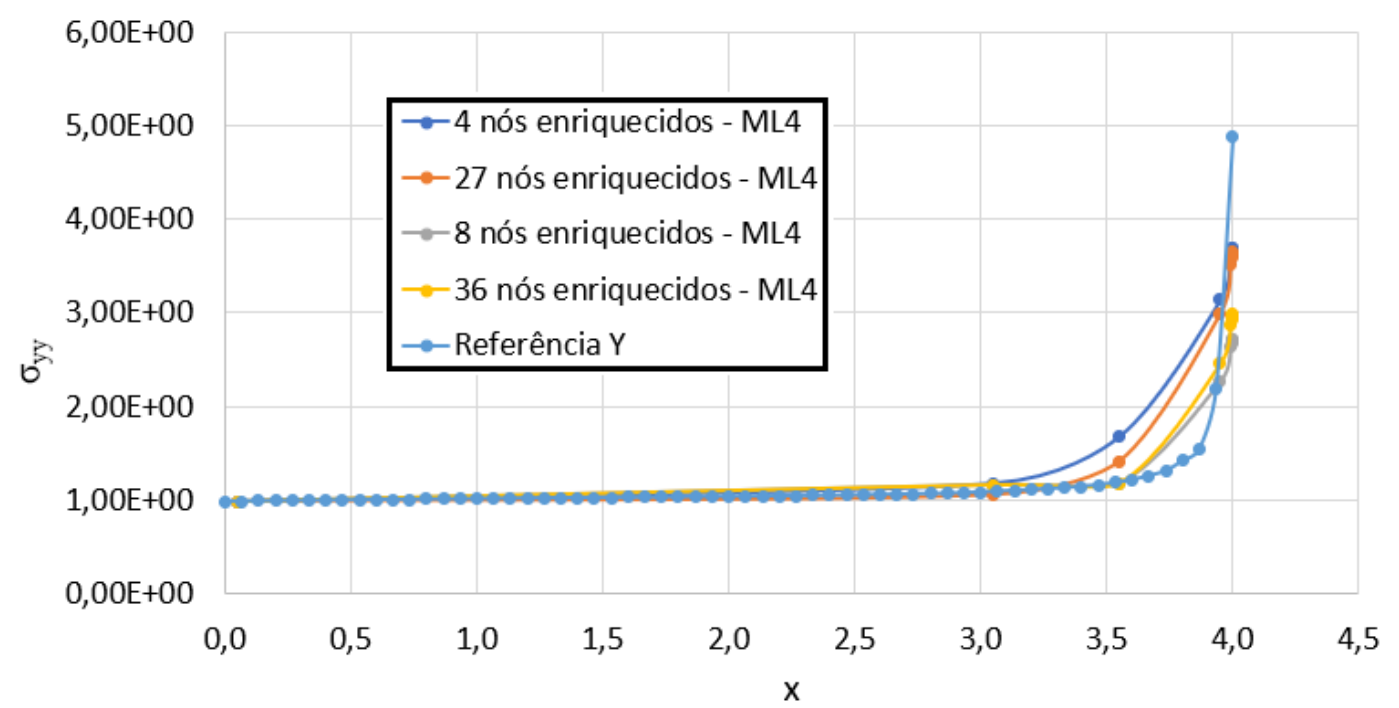

Figura 4.24: Variação de $\sigma_{y y}$ ao longo da coordenada $x$ em $y=5$ e $z=5$ - Tração em $\mathrm{y}$.

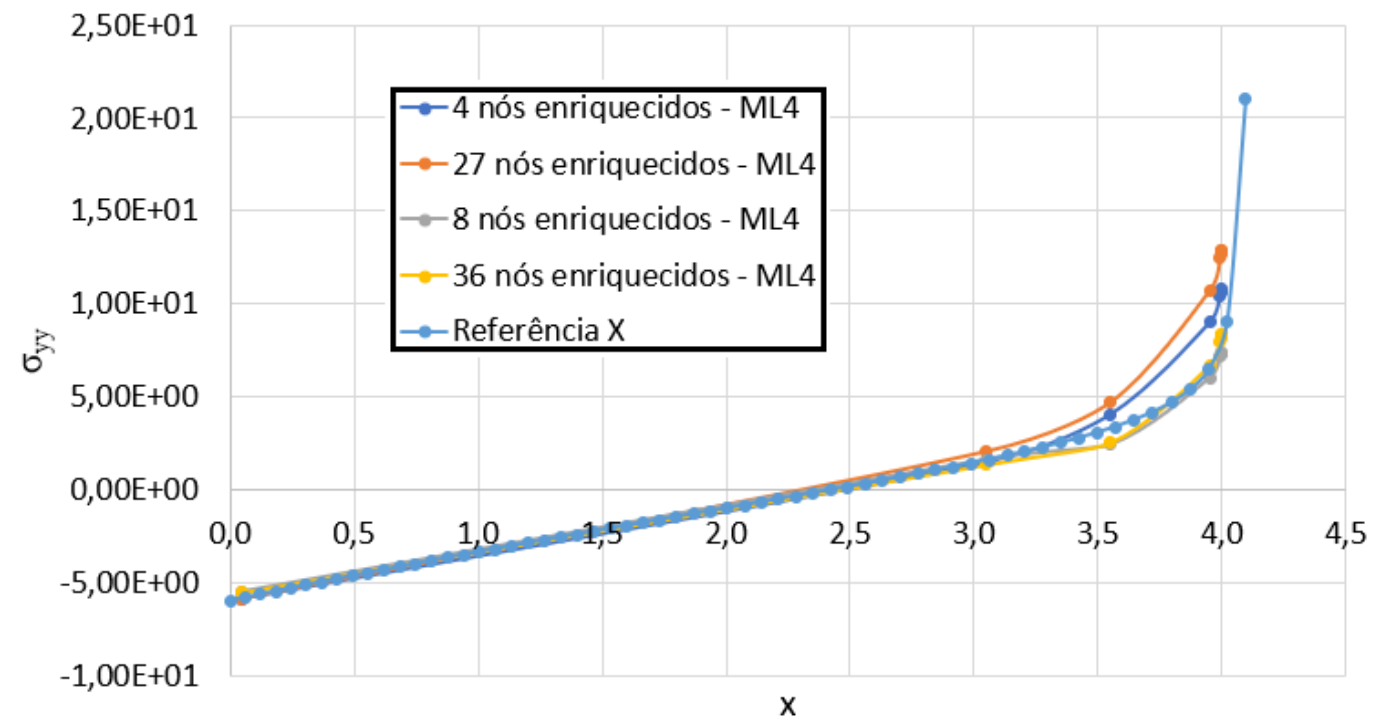

Figura 4.25: Variação de $\sigma_{y y}$ ao longo da coordenada $x$ em $y=5$ e $z=5$ -

Cisalhamento em $\mathrm{x}$.

Pela análise dos gráficos apresentados nas Figuras 4.24, 4.25 e 4.26 é possível perceber que todas as modelagens analisadas via técnica Global-Local têm a variação 


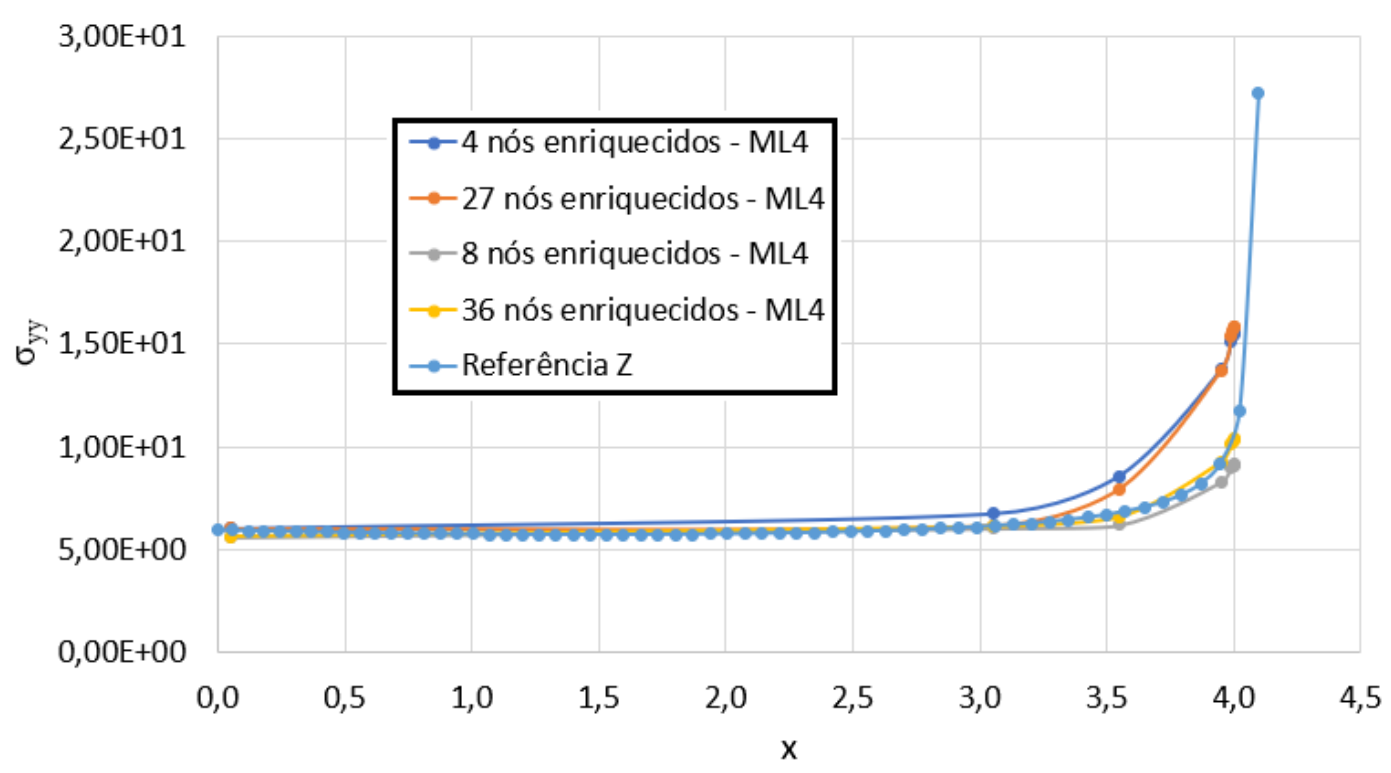

Figura 4.26: Variação de $\sigma_{y y}$ ao longo da coordenada $x$ em $y=5$ e $z=5$ Cisalhamento em z.

da componente de tensão $\sigma_{y y}$ ao longo de $x$ tendendo para a solução de referência. Nota-se que a solução com 27 nós enriquecidos atinge maiores valores de tensão próximo à frente de trinca, porém a solução com 36 nós enriquecidos descreve melhor a variação da componente de tensão ao longo de $x$. Este fato já havia sido identificado para o problema $\mathrm{P} 1$. 


\section{Capítulo 5}

\section{Conclusões}

\subsection{Breve Resumo do que Foi Exposto}

O Capítulo 1 apresentou um contexto geral sobre o trabalho exposto nesse texto, seus objetivos e metodologia. O Capítulo 2 mostrou os principais conceitos acerca do MEFG e da técnica Global-Local. O Capítulo 3 apresentou os principais aspectos do sistema INSANE e a implementação necessária ao funcionamento do enriquecimento via MEFG com funções que descrevem os três modos de abertura de trinca e também utilizando a técnica Global-Local.

Já o Capítulo 4, exibiu os exemplos realizados para testar e também mostrar o funcionamento da nova implementação realizada no sistema INSANE. Foram analisados dois grandes problemas, P1 e P2, analisados sob carregamento em " $x$ ", " $y$ " e "z".

\subsection{Conclusões do Trabalho e Sugestões de Tra- balhos Futuros}

Considera-se que os objetivos propostos neste trabalho foram satisfatoriamente atingidos. Os estudos sobre o MEFG, funções que contêm singularidade e técnica Global-Local foram fundamentais para a implementação desses conceitos no sistema INSANE. O núcleo numérico do sistema INSANE foi adequadamente expandido de modo a compreender, agora, análises tridimensionais, utilizando o MEFG enriquecido com funções que contêm singularidade e descrevem os três modos de abertura 
de trinca e também por meio da técnica Global-Local.

O MEFG vem se mostrando uma ferramenta poderosa para a modelagem de problemas estruturais com a presença de concentração de tensões e de descontinuidades no campo de deslocamentos, como é o caso da análise de meios com a presença de trincas. Simulações via MEFG, graças à técnica de enriquecimento da aproximação, são capazes de reproduzir os fenômenos inerentes a estes problemas, de forma mais adequada do que o MEF para uma mesma malha de elementos. Torna-se possível descrever a concentração de tensões na vizinhança da frente de trinca e a descontinuidade no campo de deslocamentos, em malhas grosseiras e sem a necessidade de se fazer a duplicação dos nós ao longo da superfície de trinca.

De fato, o enriquecimento das funções de partição da unidade associadas aos nós, via MEFG, com funções que contêm derivadas singulares, como as mostradas nesse trabalho mostraram-se funcionais e capazes de melhorar os resultados a partir de sua aplicação nos modelos apresentados.

Nos exemplos analisados na Seção 4.3 .1 fica claro que a utilização das funções apresentadas na Seção 2.3.2, que descrevem os três modos de abertura de trinca, reduz significativamente o erro da aproximação, sem a necessidade de alteração da malha de elementos finitos. Além disso, quanto maior o número de nós com enriquecimentos associados às correspondentes PUs, mais a solução se aproxima da solução de referência, que foi construída via MEF com uma malha bastante refinada. Desta maneira, há uma economia no custo computacional sem penalizar a qualidade do resultado. Cabe registrar que a questão do custo computacional torna-se ainda mais relevante em se tratando de modelos tridimensionais.

Para se alcançar resultados ainda melhores, torna-se necessário aumentar a quantidade de nós na proximidade da trinca e, para isso, a malha precisaria ser refinada, o que implicaria em elevação do custo computacional do problema. Outra possibilidade seria aumentar a região enriquecida com as funções singulares. Esta, contudo, não seria uma boa estratégia, pois poderia trazer perturbação de ordem numérica 
à solução do problema. Isso ocorre, pois, as funções singulares são funções representativas da solução em uma região muito pequena ao redor da frente de trinca. Aplicá-las sobre PUs associadas a nós cobrindo uma extensa região do domínio pode acrescentar à aproximação informações redundantes, quando distantes da frente da trinca, produzindo problemas de condicionamento do sistema de equações. Esta questão, relevante em qualquer análise, torna-se ainda mais importante no contexto das análises tridimensionais. A estratégia Global-Local surge então para apresentar uma alternativa mais eficiente.

A técnica Global-Local, utilizada para a obtenção de uma função de aproximação personalizada para o modelo, dentro da abordagem do MEFG, mostrou-se, de fato, uma estratégia muito interessante para modelos tridimensionais. Nas análises realizadas nas Seções 4.3.2, 4.3.3, 4.4.1 e 4.4.2 foram registrados bons resultados em termos de convergência para a solução de referência, tanto em termos de energia de deformação quanto de tensão $\sigma_{y y}$ e abertura de trinca.

Foi observado, de uma maneira geral, que quanto maior a região enriquecida com a solução local, mais a solução de energia de deformação, tensão $\sigma_{y y}$ e abertura de trinca convergem para a solução de referência à medida que se refina a malha local. É importante, contudo, selecionar adequadamente quais os nós cujas funções de PU serão enriquecidas, para que não sejam introduzidos erros numéricos ao sistema, assim como também observado quando do uso das funções com singularidade.

O refinamento da malha local não onera computacionalmente a solução do modelo global, pois é independente deste não demandando a compatibilização entre elementos de tamanhos diferentes. Para melhor capturar o gradiente elevado do campo de deslocamentos na região da frente de trinca, estas malhas devem acompanhar o gradiente com a redução drástica no tamanho dos elementos. Torna-se, portanto, necessário o emprego de um gerador de malhas não uniformes para domínios tridimensionais. 
Na Seção 4.3.3.6 a estratégia Global-Local foi combinada ao uso do enriquecimento com funções com derivadas singulares. Mostrou-se, com base nos resultados encontrados, que é significativo o impacto da melhoria da qualidade da solução local sobre a solução final do problema global. Esta conclusão corrobora a expectativa do parágrafo anterior de que um refinamento mais adequado do modelo local deverá melhorar significativamente o resultado do problema global. A combinação das duas estratégias de enriquecimento surge, também, como uma interessante alternativa para a análise de problemas tridimensionais. Quando inseridas no modelo local, estas funções podem ser usadas para enriquecer uma pequena vizinhança da trinca, pois a malha utilizada é bem mais refinada neste modelo. Não se prejudica, então, a simplicidade com que a malha grosseira do modelo global é construída. Por esse motivo, para trabalhos futuros, sugere-se maior investigação sobre esta possibilidade de combinação de enriquecimentos, comparando-a com a utilização de diversos níveis de refinamentos não uniformes da malha local.

No caso de problemas do tipo P1, observou-se ainda, ao se comparar as modelagens de trinca coincidente com as faces dos elementos globais e de trinca no interior dos elementos globais, Seções 4.3.2 e 4.3.3, que no segundo tipo de modelagem não são alcançados os bons resultados da primeira, mesmo com um número superior de nós com funções enriquecidas associadas a eles. Justificou-se este comportamento pela diferença do posicionamento da trinca com relação aos dois tipos de malha. Em ambos os casos, o modelo local enriquece o global descrevendo uma descontinuidade. Na malha em que a trinca coincide com a aresta dos elementos globais, esta descontinuidade é descrita em uma região em que é possível se ter descontinuidades na primeira derivada da parcela da aproximação construída pela malha global. Já no segundo modelo, em que a descontinuidade é descrita no interior do elemento global, a primeira derivada da parcela da aproximação construída pela malha global é também contínua, criando mais restrições, provavelmente, à correção da solução advinda do enriquecimento com a reposta do modelo local. 
No problema do tipo P2, Seções 4.4.1.1 4.4.1.3, observa-se que os resultados da componente de tensão $\sigma_{y y}$ pioram com o aumento do número de nós com funções de enriquecimentos associados a eles construídas via técnica Global-Local. Não era um cenário esperado. Devido à geometria mais complexa da trinca estudada em P2, a malha local possivelmente demande um refinamento mais rigoroso do que aquele empregado nos problemas P1 e repetidos para P2. O enriquecimento da malha global com uma solução local de baixa qualidade pode estar introduzindo uma perturbação numérica na solução do problema. À medida que se refina o problema local, este cenário tende a mudar, fato este ratificado com os resultados encontrados na Seção 4.4 .1 .3 ,

Concluindo, sugere-se também para trabalhos futuros a implementação de geradores de superfícies de trinca para automatizar sua inclusão no modelo local. A definição do problema local e sua discretização também precisam ser estabelecidos independentemente do usuário para possibilitar análises mais complexas. Feito isso, sugere-se que o solucionador, no INSANE, da propagação de trincas, seja generalizado para descrever a propagação de uma superfície de trinca em um domínio tridimensional. Por último, o INSANE deve ser adaptado para ser capaz de usar o processamento paralelo para viabilizar sem onerar o tempo final de execução, especialmente no caso de modelos tridimensionais, a solução de vários modelos locais independentes. 


\section{Apêndice A}

\section{Entrada de dados no Sistema INSANE para um modelo tridimensional utilizando MEFG com técnica Global-Local}

\section{A.1 Entrada de Dados do Modelo Global}

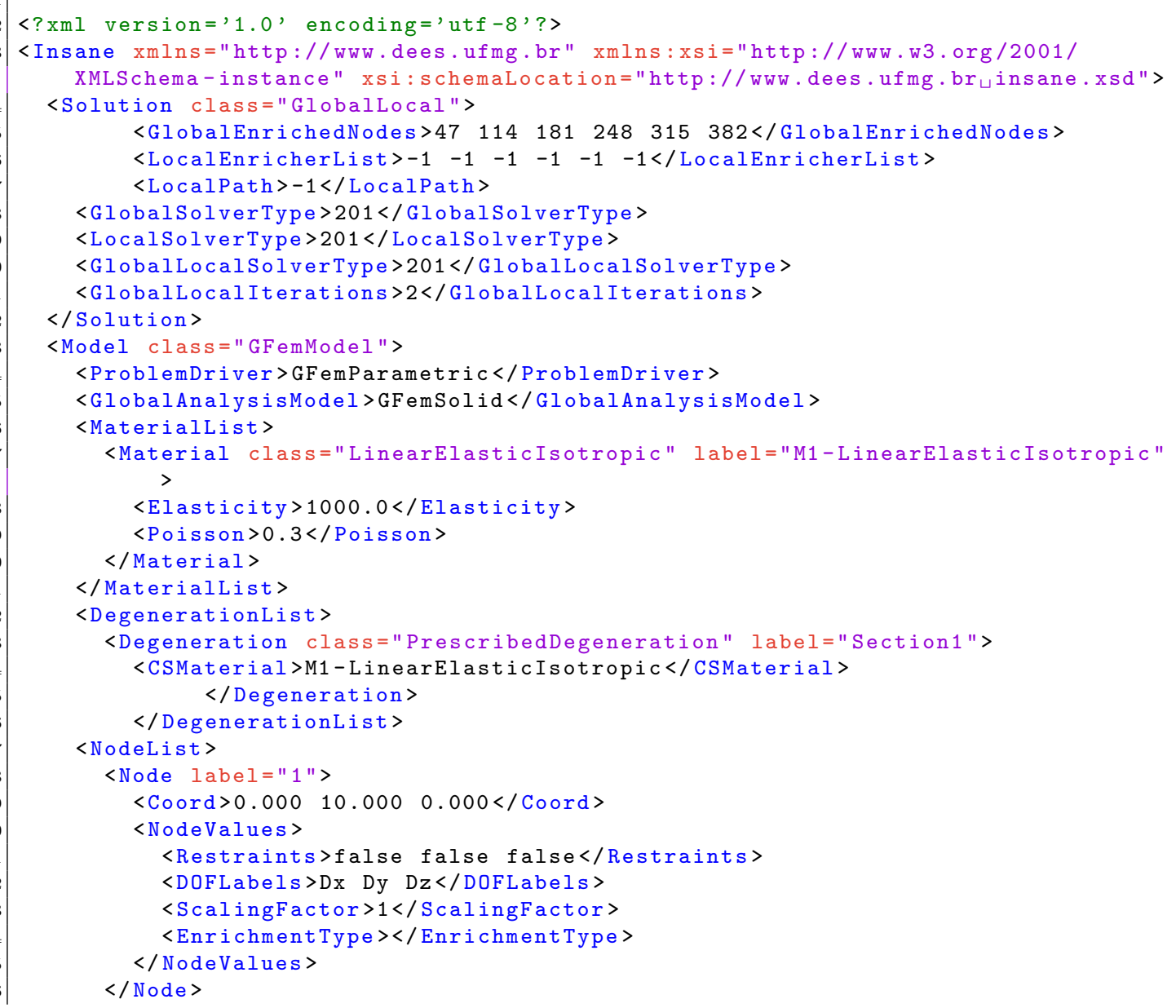




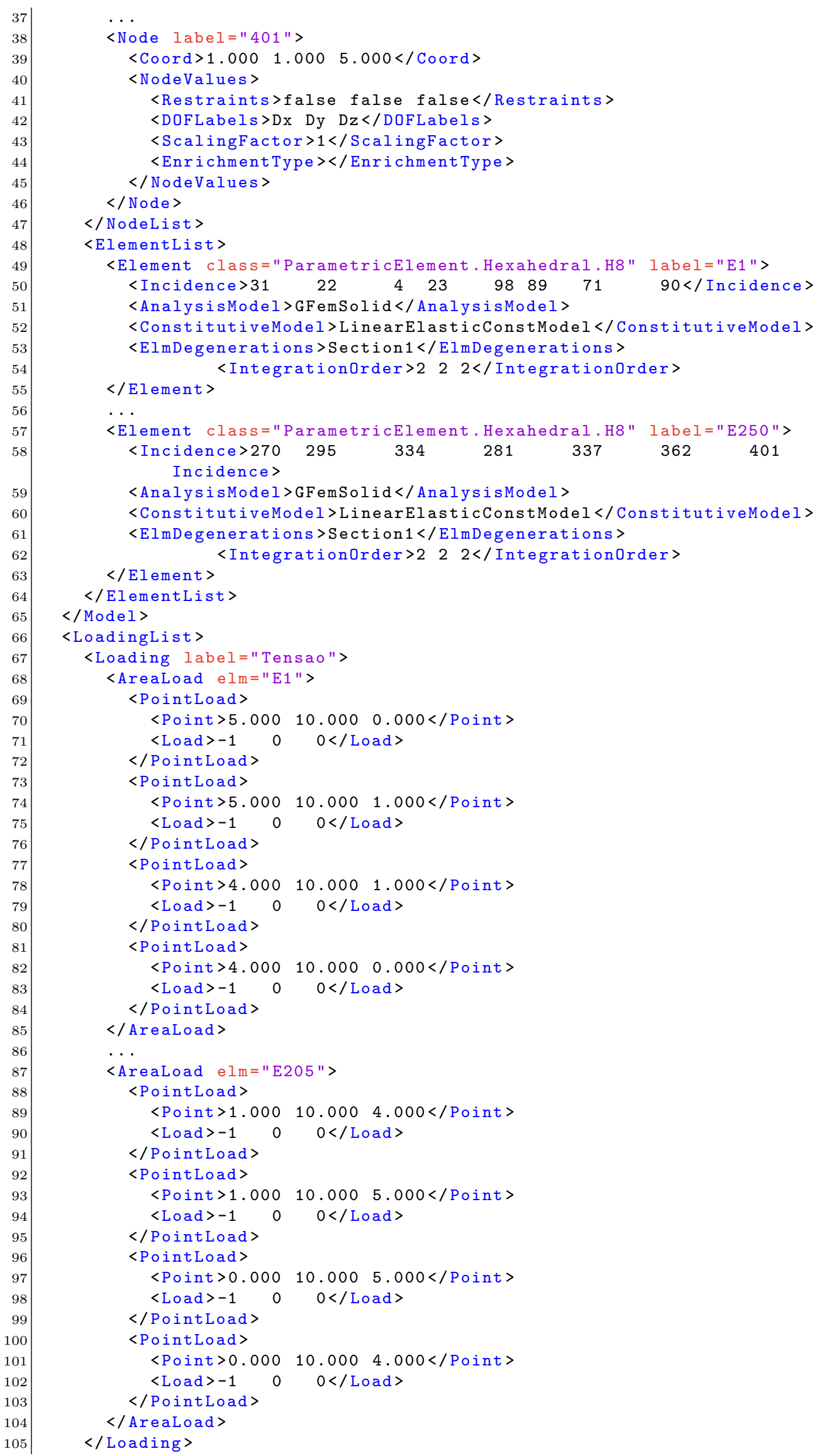




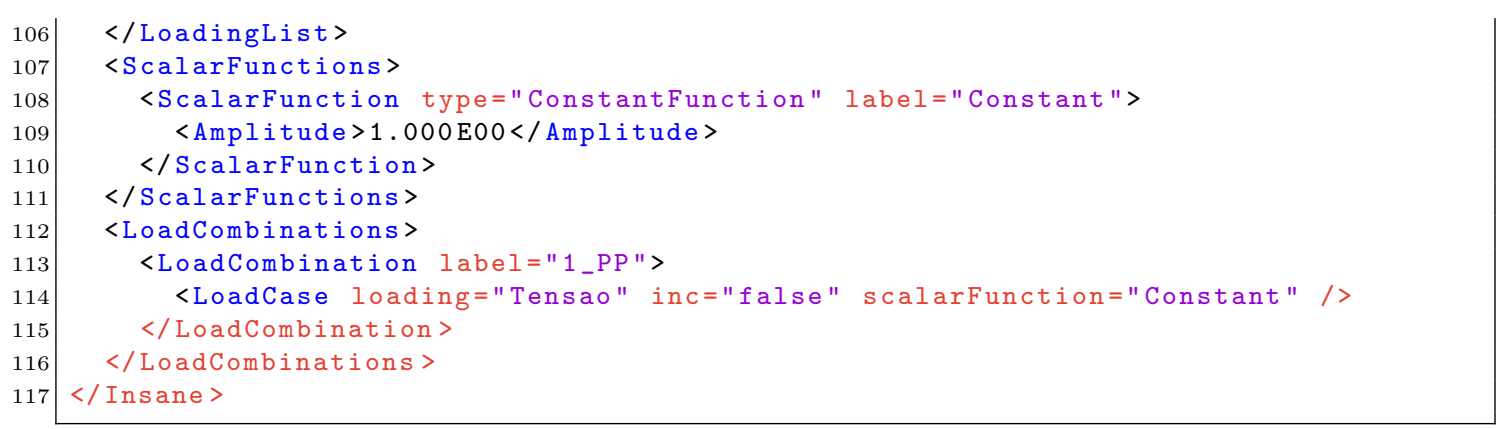

\section{A.2 Entrada de Dados do Modelo Local}

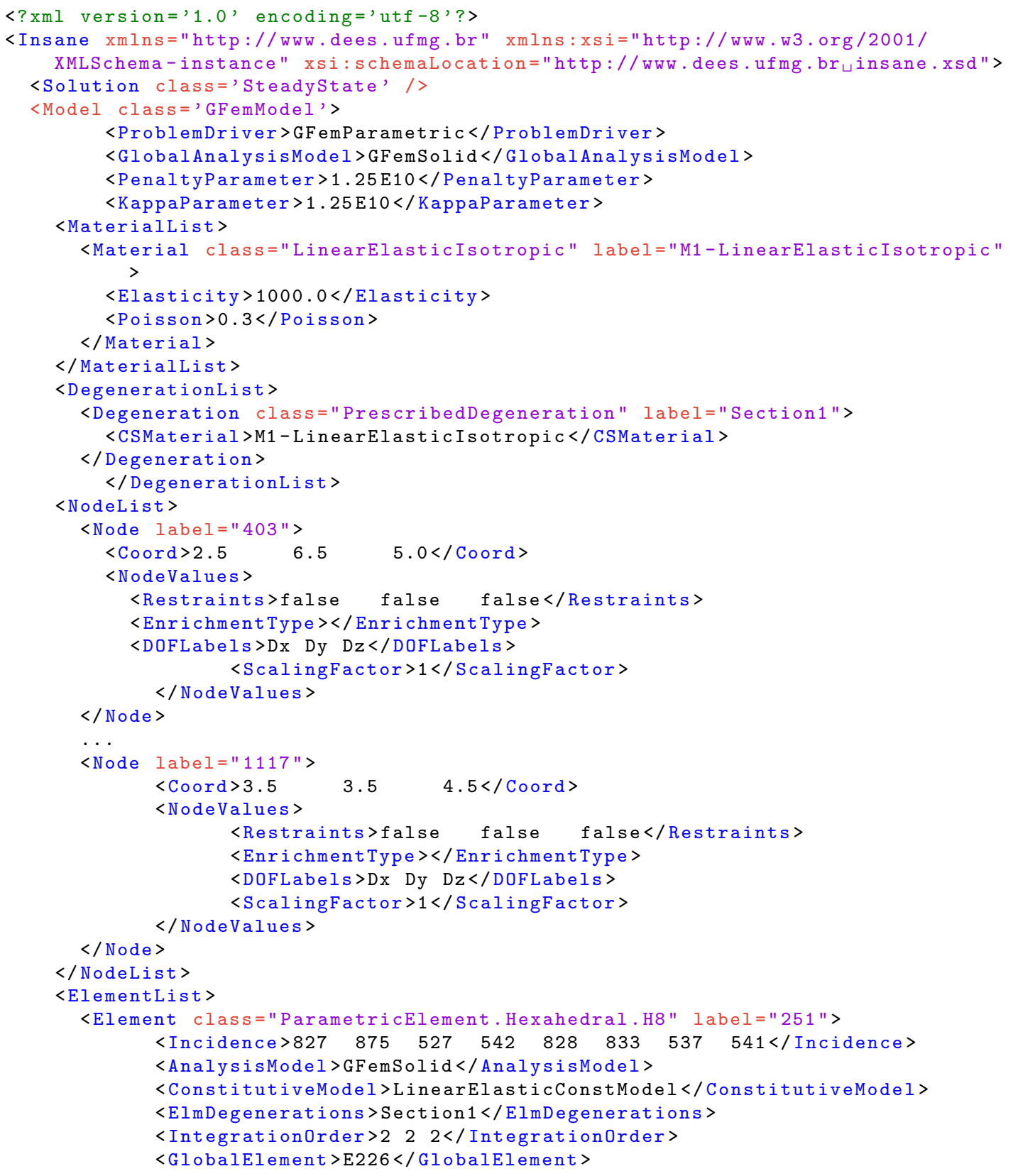




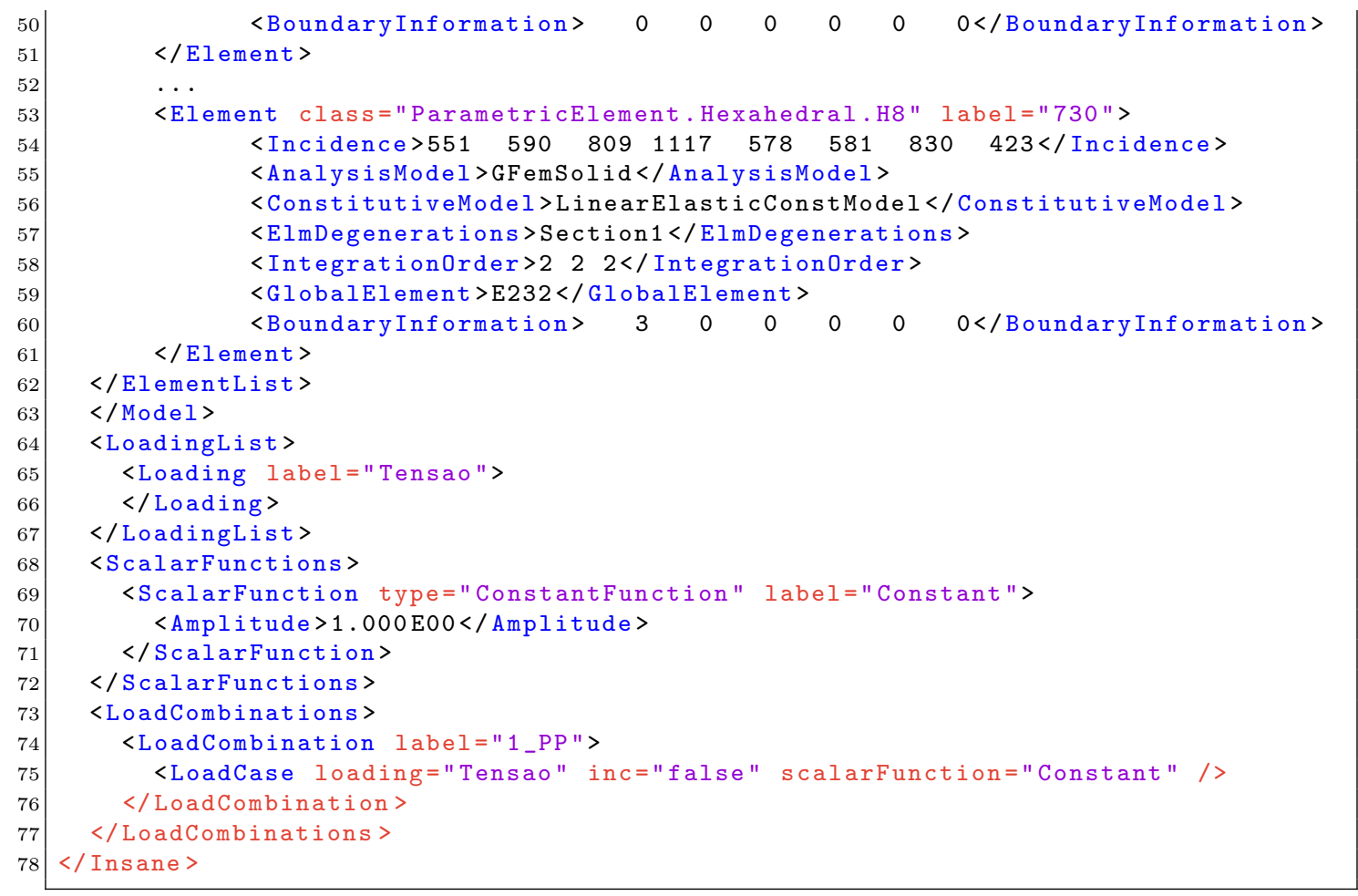




\section{Apêndice B}

\section{Programa Responsável por converter Dados da Malha do Software $A N S Y S^{\circledR}$ para o Sistema INSANE}

As malhas locais, dentro da técnica Global-Local abordada nesse trabalho, foram geradas a partir de um sistema desenvolvido utilizando o paradigma da POO, em linguagem de programação JAVA. Sua função é converter uma malha tridimensional desenvolvida no software $A N S Y S^{\circledR}$ para um arquivo de leitura capaz de ser solucionado no sistema INSANE. O funcionamento do mesmo é bastante simples e segue o fluxo apresentado na Figura B.1.

Na Figura B.1, o fluxo de funcionamento do sistema começa a partir da seleção do arquivo de entrada. Esse arquivo deve conter a saída de dados do software $A N S Y S^{\circledR}$ abrangendo os nós e os elementos da malha criada, além disso, é preciso que se preencha informações adicionais do modelo global, como o último identificador de nó e elemento, condições de contorno, quantidade de elementos globais e quais são eles. Em seguida, o programa lê o arquivo e armazena as informações, na ordem do fluxo, de todos os dados mencionados, nas classes do programa. Essas classes serão, posteriormente, detalhadas, bem como os principais atributos e métodos que as compõem. O programa, então, acrescenta variáveis dos elementos locais utilizadas somente pelo sistema INSANE, na técnica Global-Local. Por fim, ele preenche um 


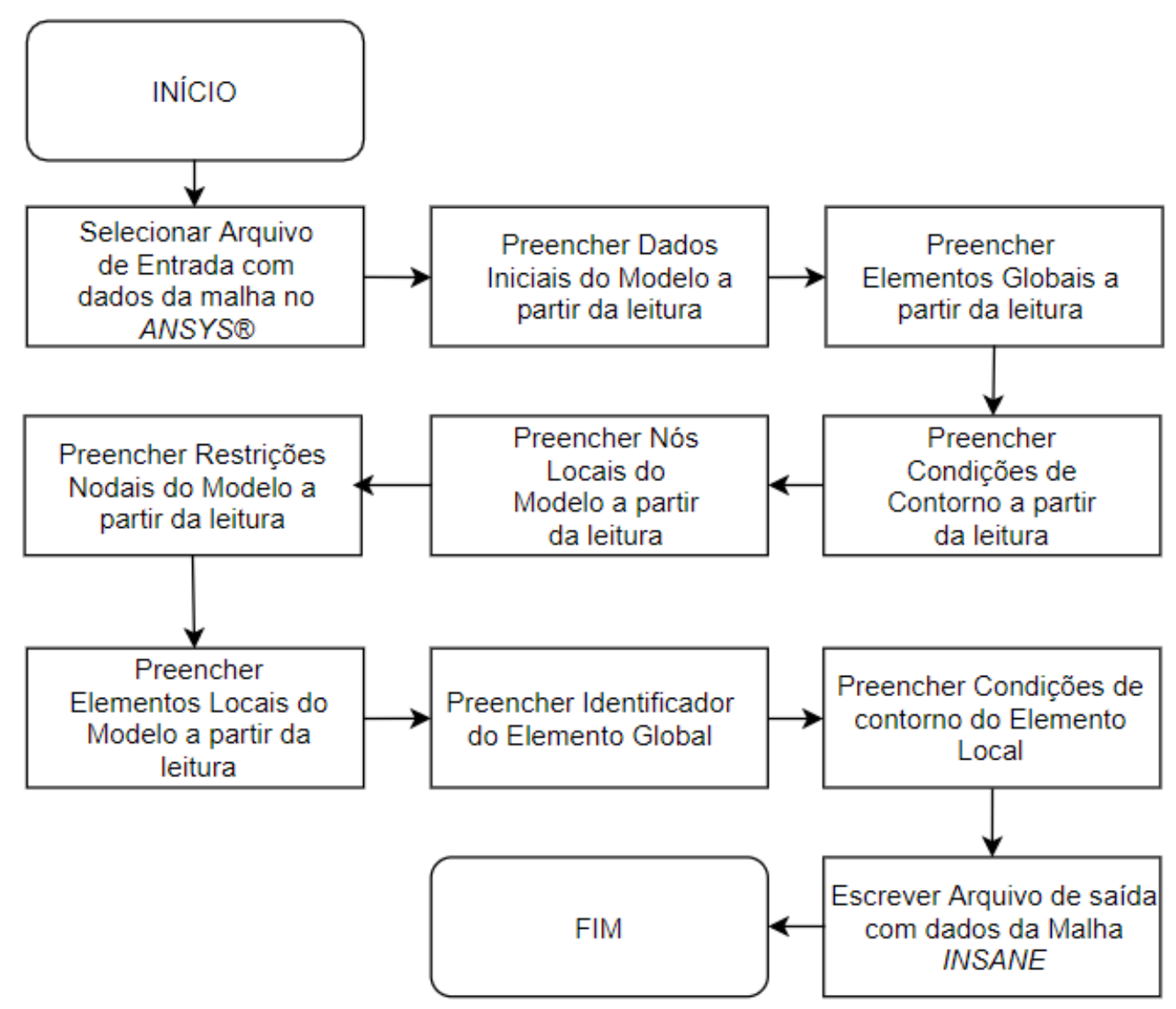

Figura B.1: Fluxo de funcionamento do programa de conversão de malhas: ANSYS ${ }^{\circledR}$ para INSANE.

arquivo de saída já no formato do arquivo de leitura INSANE, contendo os nós e elementos que compõem a malha local desejada.

O sistema é composto por nove classes, sendo que a classe que guarda o método main, responsável por disparar o processo de execução dos processos é a Aplicacao. A Figura B.2 mostra todas as classes do sistema bem como seus principais atributos e métodos.

A Classe Aplicacao, além de possuir o método main, é responsável por mapear qual é o elemento global, pai, de cada um dos elementos locais, filhos, criados através do método "idElmGlobal" e também por preencher as condições de contorno de cada elemento local de acordo com as condições de contorno globais atribuídas no arquivo de entrada, através do método "preencherCCElemento". A convenção sobre 


\begin{tabular}{|l|}
\hline \multicolumn{1}{|c|}{ Aplicacao } \\
\hline+ main(String] args): void \\
+ idElmGlobal(ArrayList<ElmGlobal> elmGlobal, ArrayList<Elemento> elmLocal): void \\
+ preencherCCElemento(ArrayList<Elemento> elmLocal,ArrayList<CondicaoContorno> cc): void
\end{tabular}

\begin{tabular}{|l|}
\hline \multicolumn{1}{|c|}{ Ler } \\
\hline \\
\hline $\begin{array}{l}\text { + preencherDadosIniciaisArquivo (FileReader fi, Modelo modelo): void } \\
\text { + preencherElmGlobal (FileReader fi, Modelo modelo): void } \\
\text { + preencherCondicaoContorno (FileReader fi, Modelo modelo): void } \\
\text { + preencherNosArquivo (FileReader fi, Modelo modelo): void } \\
\text { + preencherRestricoesArquivo (FileReader fi, Modelo modelo): void } \\
\text { + preencherElementosArquivo (FileReader fi, Modelo modelo): void }\end{array}$ \\
\hline
\end{tabular}

\begin{tabular}{|l|}
\hline \multicolumn{1}{|c|}{ Modelo } \\
\hline + noinicial: int \\
+ elmInicial: int \\
+ numElmGlobal: int \\
+ elementosGlobais: ArrayList<ElmGlobal> \\
+ condicaoContorno: ArrayList<CondicaoContorno> \\
+ nodes: ArrayList <Node> \\
+ elementos: ArrayList <Elemento> \\
\hline
\end{tabular}
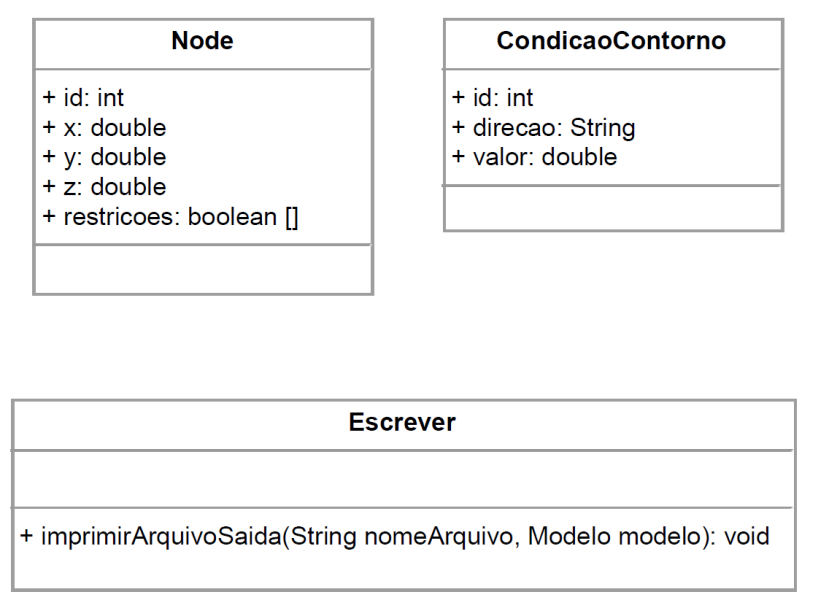

\begin{tabular}{|l|}
\hline \multicolumn{1}{|c|}{ H8 } \\
\hline+ id: int \\
+ n1: Node \\
+ n2: Node \\
+ n3: Node \\
+ n4: Node \\
+ n5: Node \\
+ n6: Node \\
+ n7: Node \\
+ n8: Node \\
+ idElmGlobal: int \\
+ cC: int[] \\
\hline
\end{tabular}

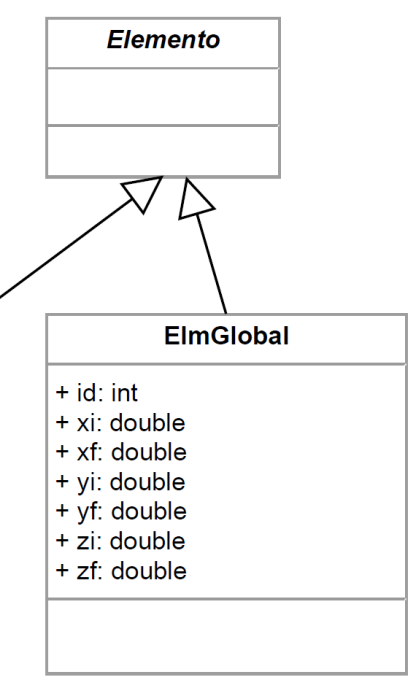

Figura B.2: Diagrama de Classes do Sistema de conversão de Malhas: ANSYS ${ }^{\circledR}$ para INSANE.

a atribuição das condições de contorno para elementos locais foi explicada na Seção

\section{2 .4}

A Classe Ler é responsável por ler o arquivo de entrada e armazenar as informações, nele contidas, no sistema. Os seus métodos têm as seguintes funcionalidades específicas:

- "preencherDadosIniciaisArquivo": lê e guarda as informações do último identificador do nó e elemento utilizado na malha global, bem como a quantidade de elementos globais existente. 
- "preencherElmGlobal": identifica e guarda as informações de todos os elementos globais formadores da malha local.

- "preencherCondicaoContorno": identifica e guarda as informações das condições de contorno do modelo global.

- "preencherNosArquivo": identifica e guarda as informações dos nós da malha local.

- "preencherRestricoesArquivo": identifica e guarda as informações das restrições nodais.

- "preencherElementosArquivo": identifica e guarda as informações dos elementos da malha local.

A Classe Modelo guarda as informações gerais sobre a malha que está sendo construída. Além das listas dos nós e dos elementos. A Classe Node armazena das informações dos nós da malha, tais como suas coordenadas. A Classe CondicaoContorno guarda as informações sobre as condições de contorno globais, tais como sua direção e coordenada cartesiana. É importante mencionar que esse sistema somente compreende a possibilidade da imposição de condições de contorno com direção coincidente com as dos eixos cartesianos.

A Classe Abstrata Elemento armazena das informações dos elementos. Já a Classe H8, que estende da Classe Elemento, armazena as informações específicas dos elementos hexaédricos de 8 nós, utilizados nesse trabalho, tais como nós que compõem sua incidência, elemento global pai e lista de condições de contorno. A Classe ElmGlobal que também estende de Elemento guarda as informações dos elementos globais que dão origem os elementos da malha local.

Por fim, a Classe Escrever, monta o arquivo de saída a partir do método " imprimirArquivoSaida". Essa saída contém os nós e elementos da malha local já no formato do arquivo de entrada do sistema INSANE. 


\section{Referências Bibliográficas}

Alves, P. D., 2012. Estratégia global-local aplicada ao método dos elementos finitos generalizados. Dissertação de Mestrado, Universidade Federal de Minas Gerais, Belo Horizonte, MG, Brasil.

Alves, P. D., Barros, F. B. e Pitangueira, R. L. S., 2013. 'An object-oriented approach to the generalized finite element method'. Advances in Engineering Software, vol. 59, pp. 1-18.

Babuška, I., Caloz, G. e Osborn, J. E., 1994. 'Special finite element methods for a class of second order elliptic problems with rough coefficients'. SIAM Journal on Numerical Analysis, vol. 31, pp. 945-981.

Babuška, I. e Melenk, J. M., 1997. 'The partition of unity finite element method'. International journal for numerical methods in engineering, vol. 40, pp. 727-58.

Barros, F. B., 2002. Métodos Sem Malha e Métodos dos Elementos Finitos Generalizados em Análise Não-Linear de Estruturas. Tese de Doutorado, EESC - USP, São Carlos, SP, Brasil.

Belytschko, T. e Black, T., 1999. 'Elastic crack growth in finite elements with minimal remeshing'. International journal for numerical methods in engineering, vol. 45 , pp. 601-620.

Dolbow, J., Moës, N. e Belytschko, T., 2000. 'Discontinuous enrichment in finite elements with partition of unity method'. Finite Elements in Analysis and Design, vol. 36, pp. 235-260. 
Duarte, C. A., 1996. The hp cloud method. Tese de Doutorado, University of Texas at Austin, Austin, TX, USA.

Duarte, C. A., Babuska, I. e Oden, J. T., 2000. 'Generalized finite element methods for three-dimensional structural mechanics problems'. Computers and Structures, vol. 77 , pp. $215-232$.

Duarte, C. A. e Kim, D.-J., 2008. 'Analysis and applications of a generalized finite element method with global-local enrichment functions'. Computer methods in applied mechanics and engineering, vol. 197, pp. 487-504.

Fish, J. e Belytschko, T., 2007. A First Course in Finite Elements. John Wiley \& Sons, Inc., West Sussex, England.

Fonseca, F. T., 2008. Sistema computacional para análise dinâmica geometricamente não-linear através do método dos elementos finitos. Dissertação de Mestrado, Universidade Federal de Minas Gerais, Belo Horizonte, MG, Brasil.

Fries, T. P. e Belytschko, T., 2010. 'The extended/generalized finite element method: An overview of the method and its applications'. International journal for numerical methods in engineering, vol. 84, pp. 253-304.

Gupta, V., Kim, D.-J. e Duarte, C. A., 2012. 'Analysis and improvements of globallocal enrichments for the generalized finite element method'. Computer methods in applied mechanics and engineering, vol. 245-246, pp. 47-62.

Kim, D.-J. e Duarte, C. A., 2015. 'A new generalized finite element method for twoscale simulations of propagating cohesive fractures in 3-d'. International journal for numerical methods in engineering, vol. 104, pp. 1139-1172.

Kim, D.-J., Pereira, J. P. e Duarte, C. A., 2010. 'Analysis of three-dimensional fracture mechanics problemns: A two-scale approach using coarse-generalized fem meshes'. International journal for numerical methods in engineering, vol. 81, pp. $335-365$. 
Li, H. e Duarte, C. A., 2018. 'A two-scale generalized finite element method for parallel simulations of spot welds in large structures'. Computer Methods in Applied Mechanics and Engineering, .

Malekan, M., Barros, F. B., Pitangueira, R. L. S., Alves, P. D. e Penna, S. S., 2016. 'A computational framework for a two-scale generalized/extended finite element method: generic imposition of boundary conditions'. Engineering Computations, vol. 34 .

Malekan, M., Silva, L. L., Barros, F. B., Pitangueira, R. L. S., Alves, P. D. e Penna, S. S., 2018. 'Two-dimensional fracture modeling with the generalized/extended finite element method: An object-oriented programming approach'. Advances in Engineering Software, vol. 115, pp. 168-193.

Moës, N., Dolbow, J. e Belytschko, T., 1999. 'A finite element method for crack growth without remeshing'. International journal for numerical methods in engineering, vol. 46, pp. 131-150.

Oden, J. T. e Reddy, J. N., 2011. An Introduction to the Mathematical Theory of the Finite Element Method. Dover.

O'Hara, P., Duarte, C. A. e Eason, T., 2016. 'A two-scale generalized finite element method for interaction and coalescence of multiple crack surfaces'. Engineering Fracture Mechanics, vol. 163.

Pitangueira, R. L. S., 2016. Notas de Aula. Método dos Elementos Finitos.

Stazi, F. L., Budyn, E., Chessa, J. e Belytschko, T., 2003. 'An extended finite element method with higher-order elements for curved cracks'. Computational Mechanics, vol. 31, pp. 38-48.

Strouboulis, T., Babuska, I. e Copps, K., 2000. 'The design and analysis of the generalized finite element method'. Computer methods in applied mechanics and engineering, vol. 181, pp. 43-69. 
Szabo, B. A. e Babuška, I., 1988. Computation of the amplitude of stress singular terms for cracks and reentrant corners. Cruse TA (ed) Fracture mechanics: nineteenth symposium. 